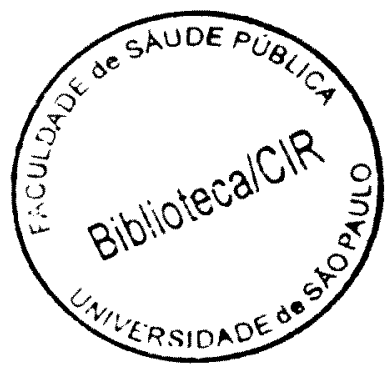

O USO DA MÉDIA DE ESTIMADORES CUSUM POR CATEGORIA DE EXPOSIÇÃO COMO MEDIDA DE INCIDENCIA DE AIDS EM UM ESTUDO ESPAÇOTEMPORAL. BRASIL, 1990 A 1998.

Antonio Luiz Rodrigues Júnior 


\section{O USO DA MÉDIA DE ESTIMADORES CUSUM POR CATEGORIA DE EXPOSIÇÃO COMO MEDIDA DE INCIDÊNCIA DE AIDS EM UM ESTUDO ESPAÇO- TEMPORAL. BRASIL, 1990 A 1998.}

Antonio Luiz Rodrigues Júnior

Tese apresentada ao Departamento de Epidemiologia da Faculdade de Saúde Pública da Universidade de São Paulo para obtenção do Grau de Doutor.

Área de concentração: Epidemiologia

Orientador: Prof.Dr. Euclides Ayres de Castilho

São Paulo

2002 
Autorizo, exclusivamente para fins acadêmicos e científicos, a reprodução total ou parcial desta tese, por processos

fotocopiadores.

Assinatura

São Paulo, 1 de fevereiro de 2002 
Aos meus pais, Antonio e Santina, pela educação e pela vida.

Para a Mônica, minha esposa, que compartilha minha vida profissional e, sobretudo, amorosa. 


\section{Agradecimentos}

À Faculdade de Saúde Pública da USP, em especial ao Departamento de Epidemiologia, por ter possibilitado esta etapa importante em minha formação.

Ao meu Orientador, pela oportunidade impar e inovadora, pelo respeito humano e profissional.

À Faculdade de Odontologia de Araraquara da Universidade Estadual Paulista UNESP, em especial à Leonor pelo apoio.

À Fundação Coordenação de Aperfeiçoamento de Pessoal de Nível Superior CAPES.

À CN-DST/AIDS, pelo acesso ao banco de dados de notificação de casos de aids. 


\section{RESUMO}

Rodrigues Jr AL, Castilho EA. O Uso da Média de estimadores CuSum por categoria de exposição como medida de incidência de aids em um estudo espaçotemporal. Brasil, 1990 a 1998. São Paulo; 2001. [Tese de Doutorado - Faculdade de Saúde Pública da Universidade de São Paulo].

Objetivo. Estudar a epidemia de aids, incluindo dimensões socioeconômicas ao modelo da doença. Usar a média de estimadores CuSum por categorias de exposição, como um índice proposto, para quantificar a epidemia, para estudar a correlação com o Índice de Desenvolvimento Humano - IDH e para produzir conhecimento espacial. Métodos. Consideraram-se o número de casos de aids notificados entre 1990 e 1998 , por município de residência, por ano e por categoria de exposição, além do IDH, constituindo um modelo espaço-temporal baseado na teoria de localidade centrais. A média dos estimadores CuSum por categoria de exposição, em cada município, foi usada para quantificar a epidemia e para realizar um estudo de correlação com o IDH, pelo método de Pearson. Mapas temáticos foram empregados para produzir conhecimento espacial. Resultados. Todos os municipios com mais de $50 \mathrm{mil}$ habitantes apresentaram ao menos um caso até 1998. Houve diferenças entre os perfis epidemiológicos das regiões do Pais. As regiões Sul e Sudeste, além da quantidade de casos por transmissão sexual, destacaram-se pelas proporções de casos de UDI. O indice proposto identificou 152 municipios de alta incidência. Houve correlação significativa entre o indice proposto e o IDH, principalmente com os componentes "renda" e "educação". Os Estados de São Paulo, Pernambuco e Santa Catarina apresentaram padrões distintos da epidemia. Conclusões. Há diferenças entre o perfil epidemiológico das regiões do Pais, que são, provavelmente, resultantes das desigualdades sociais. $\mathrm{O}$ índice proposto apresentou distribuição espacial distinta do risco relativo.

Descritores: aids, estatisticas espaço-temporais, estimador cusum, epidemiologia 


\section{SUMMARY}

Rodrigues Jr AL, Castilho EA. O Uso da Média de estimadores CuSum por categoria de exposição como medida de incidência de aids num estudo espaçotemporal. Brasil, 1990 a 1998. [The use of CuSum estimators average by transmission categories as aids incidence measurement in a spatial-time study approach. Brazil 1990 to 1998]. São Paulo (BR); 2001. [Tese de Doutorado Faculdade de Saúde Pública da Universidade de São Paulo].

Objective. To study the epidemic of aids including socioeconomic dimensions to the disease model. The use of average of CuSum estimator by HIV transmission categories as a proposed measure, leading to epidemic quantifications and Human Development Index - HDI - correlation study. Methods. AIDS mandatory case reports were taken, from 1990 to 1998, by municipality of residence, by year and by categories of HIV transmission. In addition to HDI, it was setted up a spatial-time model based on central place theory. The average of CuSum estimators by HIV transmission categories and by municipality, which were used to quantify the epidemy and to study its Pearson's correlation to HDI. Thematic map charts were employed to produce spacial knowledge. Results. Every city greater than 50000 inhabitants have had already reported case(s) at least once until 1998. There were differences in the epidemiological patterns among Brazilian regions. The South and Southeast regions highlighted rates of cases among IDUs besides sexual transmition. The proposed measure highlighted 152 high incidence cities. There were significant correlation among the proposed measure and HDI, mainly with income and educational level components. Sao Paulo, Pernambuco and Santa Catarina States showed different epidemiological patterns. Conclusions. There were differences among the AIDS epidemiological patterns from different regions in Brazil which probably are results of social inequalities. The proposed measure showed a diferent spatial distribution from the relative risk.

Descriptors - AIDS, spatial-time study, cusum estimator, epidemiology 


\title{
ÍNDICE
}

\author{
RESUMO \\ SUMMARY \\ INDICE \\ LISTA DE TABELAS \\ LISTA DE FIGURAS \\ SIGLAS E ACRÔNIMOS

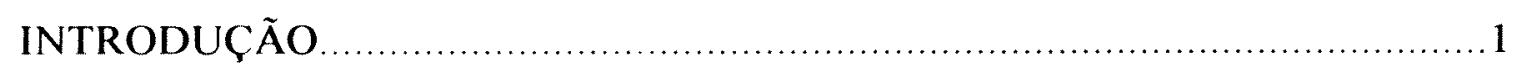

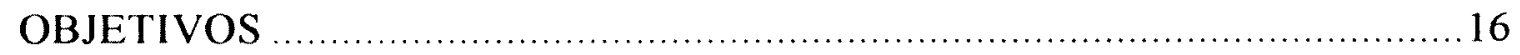

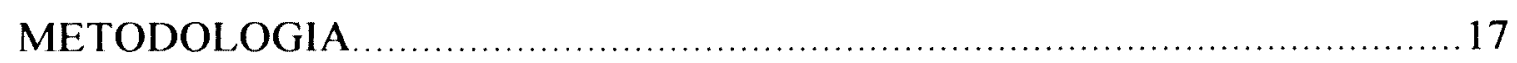

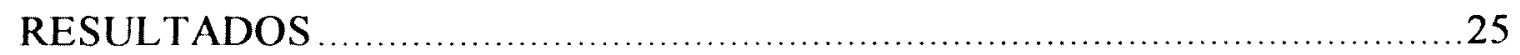

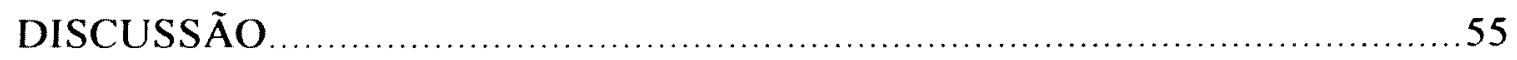

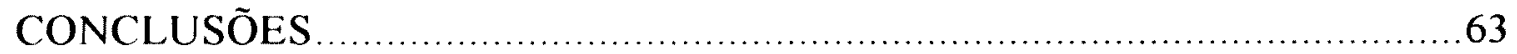

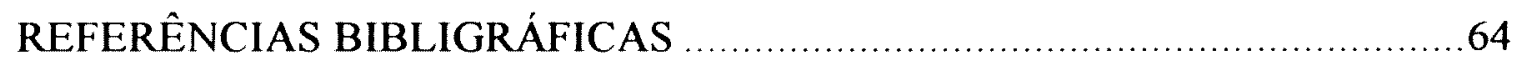 \\ ANEXO 1 - Critério de hierarquização das categorias de exposição ao HIV ...............67

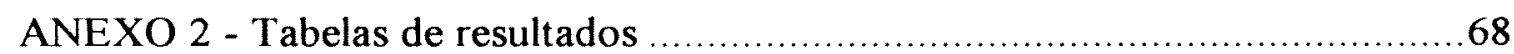 \\ ANEXO 3 - Lista dos municípios considerados de alta incidência de aids \\ pelo índice proposto $(\delta)$, dividido pelo tamanho da \\ população em 1996 .




\section{LISTA DE TABELAS}

Tabela 1 - Distribuição do número acumulado de municípios que notificaram ao menos 1 caso de aids, segundo região, ano de diagnóstico e tamanho populacional. Brasil. 1990-1998.

Tabela 2 - Distribuição de casos de aids, segundo sexo, estrato do IDH e ano de notificação. Brasil. 1990-1998.

Tabela 3 - Distribuição de casos de aids da categoria de exposição ignorada, segundo sexo, estrato do IDH e ano de diagnóstico. Brasil. 19901998

Tabela 4 - Coeficientes de correlação entre IDH e o índice proposto, segundo macro-região, e as correlações entre as categoria de exposição ao HIV e os componentes do IDH. Brasil. 1990-1998.

Tabela 5 - Distribuição de casos de aids segundo sexo e ano de notificação.

São Paulo. 1990-1998.

Tabela 6 - Distribuição de casos de aids segundo sexo e ano de notificação.

Pernambuco. 1990-1998.

Tabela 7 - Distribuição de casos de aids segundo sexo e ano de notificação. Santa Catarina. 1990-1998.

Tabela 8 - Distribuição de casos de aids, segundo IDH, região e ano de notificação de aids. Brasil. 1990-1998.

Tabela 9 - Distribuição da incidência de casos de aids, segundo ano de notificação, categoria de exposição e IDH. Brasil. 1990-1998.

Tabela 10 - Distribuição de casos de aids, segundo região, categoria de exposição e ano de notificação. Brasil. 1990-1998.

Tabela 11 - Distribuição de casos, segundo IDH, faixa etária e ano de notificação. Brasil. 1990-1998

Tabela 12 - Distribuição de casos de aids, segundo IDH, escolaridade e ano de notificação. Brasil. 1990-1998 
Tabela 13 - Distribuição de casos de aids, segundo sexo, região e ano de notificação de aids, para a categoria de exposição ignorada. Brasil. 1990-1998.

Tabela 14 - Distribuição de casos de aids, segundo sexo, escolaridade e ano de notificação, para a categoria de exposição ignorada. . Brasil. 19901998

Tabela 15 - Distribuição de casos de aids, segundo sexo, faixa etária e ano de notificação, para a categoria de exposição ignorada. Brasil. 19901998

Tabela 16 - Distribuição da incidência de casos de aids, segundo ano de notificação e categoria de exposição. São Paulo. 1990-1998.

Tabela 17 - Distribuição de casos, segundo faixa etária e ano de notificação.

São Paulo. 1990-1998.

Tabela 18 - Distribuição de casos de aids, segundo escolaridade e ano de notificação. São Paulo. 1990-1998.

Tabela 19 - Distribuição da incidência de casos de aids, segundo ano de notificação e categoria de exposição. Pernambuco. 1990-1998

Tabela 20 - Distribuição de casos, segundo faixa etária e ano de notificação.

Pernambuco. 1990-1998

Tabela 21 - Distribuição de casos de aids, segundo escolaridade e ano de notificação. Pernambuco. 1990-1998.

Tabela 22 - Distribuição da incidência de casos de aids, segundo ano de notificação e categoria de exposição. Santa Catarina. 1990-1998

Tabela 23 - Distribuição de casos, segundo faixa etária e ano de notificação. Santa Catarina. 1990-1998.

Tabela 24 - Distribuição de casos de aids, segundo escolaridade e ano de notificação. Santa Catarina. 1990-1998. 


\section{LISTA DE FIGURAS}

Figura 1 - Distribuição geográfica do Índice de Desenvolvimento Humano IDH, segundo informações do IPEA. Brasil, 1997.

Figura 2 - Distribuição proporcional dos casos de aids, segundo macro-região, estrato de IDH e ano de diagnóstico. Brasil. 1990-1998.

Figura 3 - Distribuição proporcional dos casos de aids, segundo categoriade exposição ao HIV, estratos de desenvolvimento humano e ano de diagnóstico. Brasil. 1990-1998.

Figura 4 - Distribuição proporcional de casos de aids, segundo macro-região, ano de diagnóstico e categoria de exposição. Brasil. 1990-1998.

Figura 5 - Distribuição proporcional de casos de aids, segundo faixa etária, estrato do IDH e ano de notificação. Brasil. 1990-1998.

Figura 6 - Distribuição proporcional de casos de aids, segundo escolaridade, estrato do IDH e ano de diagnóstico. Brasil. 1990-1998.

Figura 7 - Distribuição proporcional de casos de aids da categoria de exposição ignorada segundo sexo, macro-região e ano de diagnóstico. Brasil. 1990-1998.

Figura 8 - Distribuição proporcional de casos de aids da categoria de exposição ignorada, segundo sexo, escolaridade e ano de diagnóstico. Brasil. 1990-1998.

Figura 9 - Distribuição proporcional de casos de aids da categoria de exposição ignorada, segundo sexo, faixa etária e ano de diagnóstico. Brasil. 1990-1998.

Figura 10 - Distribuição percentual dos valores observados do índice proposto, em escala logaritmica. Brasil. 1990-1998.

Figura 11 - Distribuição dos pares coordenados do logarítmo do índice proposto e do $\mathrm{IDH}$, para a região norte. Brasil 1990-1998.....

Figura 12 - Distribuição dos pares coordenados do logarítmo do índice proposto e do IDH, para a região nordeste. Brasil 1990-1998. 
Figura 13 - Distribuição dos pares coordenados do logarítmo do índice proposto e do IDH, para a região sudeste. Brasil 1990-1998

Figura 14 - Distribuição dos pares coordenados do logarítmo do índice proposto e do IDH, para a região sul. Brasil 1990-1998 40

Figura 15 - Distribuição dos pares coordenados do logarítmo do índice proposto e do IDH, para a região centro-oeste. Brasil 1990-1998. 40

Figura 16 - Mapa temático da distribuição espacial do risco relativo da epidemia de aids. Brasil 1990-1998.

Figura 17 - Mapa temático da distribuição espacial da média dos estimadores CuSum da epidemia de aids. Brasil 1990-1998.

Figura 18 - Mapa temático da distribuição espacial da média dos estimadores ( 'uS Sum da epidemia de aids e dos estratos de IDH. Brasil 19901998

Figura 19 - Distribuição proporcional de casos de aids, segundo categoriade exposição e ano de diagnóstico. São Paulo. 1990-1998.

Figura 20 - Distribuição proporcional de casos de aids, segundo faixa etária e ano de diagnóstico. São Paulo. 1990-1998.

Figura 21 - Distribuição proporcional de casos de aids, segundo escolaridade e ano de diagnóstico. São Paulo. 1990-1998.

Figura 22 - Mapa temático da distribuição espacial da média dos estimadores CuSum da epidemia de aids e dos estratos de IDH. São Paulo 19901998

Figura 23 - Distribuição proporcional de casos de aids, segundo categoriade exposição e ano de diagnóstico. Pernambuco. 1990-1998

Figura 24 - Distribuição proporcional de casos de aids, segundo faixa etária e ano de diagnóstico. Pernambuco. 1990-1998.

Figura 25 - Distribuição proporcional de casos de aids, segundo escolaridade e ano de diagnóstico. Pernambuco. 1990-1998.

Figura 26 - Mapa temático da distribuição espacial da média dos estimadores ( 'uSum da epidemia de aids e dos estratos de IDH. Pernambuco 1990-1998.

Figura 27 - Distribuição proporcional de casos de aids, segundo categoriade exposição e ano de diagnóstico. Santa Catarina. 1990-1998. 
Figura 28 - Distribuição proporcional de casos de aids, segundo faixa etária e ano de diagnóstico. Santa Catarina. 1990-1998.

Figura 29 - Distribuição proporcional de casos de aids, segundo escolaridade e ano de diagnóstico. Santa Catarina. 1990-1998

Figura 30 - Mapa temático da distribuição espacial da média dos estimadores CuSum da epidemia de aids e dos estratos de IDH. Santa Catarina 1990-1998 


\section{SIGLAS* E ACRÔNIMOS}

$\begin{array}{ll}\text { ABIA } & \text { Associação Brasileira Interdisciplinar de Aids } \\ \text { AIDS } & \text { Sindrome de Imunodeficiência Adquirida } \\ \text { CN-DSTIAIDS } & \text { Coordenação Nacional de Doenças Sexualmente Transmissíveis e } \\ & \text { Aids do Ministério da Saúde do Brasil } \\ \text { HIV } & \text { Virus da Imunodeficiência Humana } \\ \text { IBGE } & \text { Fundação Instituto Brasileiro de Geografia e Estatística } \\ \text { FJP } & \text { Fundação João Pinheiro } \\ \text { GAPASP } & \text { Grupo de Apoio a Pacientes com Aids do Estado de São Paulo } \\ \text { GEMPAC } & \text { Grupo de Mulheres Prostitutas da Área Central } \\ \text { GIV } & \text { Grupo de Incentivo à Vida } \\ \text { IDH } & \text { Indice de Desenvolvimento Humano } \\ \text { INPE } & \text { Instituto Nacional de Pesquisas Espaciais } \\ \text { IPEA } & \text { Instituto de Pesquisa Econômica Aplicada } \\ \text { ISER } & \text { Instituto de Estudos da Religião } \\ \text { OMS } & \text { Organização Mundial da Saúde } \\ \text { ONG } & \text { Organização Não-Governamental } \\ \text { Pela VIDDA } & \text { Pela Valorização, Integração e Dignidade do Doente de Aids. } \\ \text { GPA } & \text { Programa Global de Aids } \\ \text { PNUD } & \text { Programa das Nações Unidas para o Desenvolvimento } \\ \text { SINAN } & \text { Sistema de Informações Nacional de Agravos de Notificação } \\ \text { SMR } & \text { Razão de Mortalidade/Morbidade Padronizada } \\ \text { TULIPA } & \text { Travestis Unidos Lutando Incansavelmente Prevenindo a Aids. } \\ \text { UDI } & \text { Usuário de Drogas Injetáveis } \\ \text { USAID } & \text { Agência dos Estados Unidos para o Desenvolvimento Internacional } \\ \end{array}$

* As siglas em lingua estrangeira foram traduzidas para o Português 


\section{INTRODUÇÃO}

\section{A Epidemia da Aids no Brasil: A Títulode Introdução.}

Os primeiros casos de aids no Brasil foram notificados em 1982, incidindo em homens que faziam sexo com outros homens, em hemofilicos ou receptores de sangue, que habitavam nas grandes metrópoles, São Paulo e Rio de Janeiro, e de alta escolaridade. Vinte anos após, o perfil epidemiológico mudou, abrangendo heterossexuais, mulheres, habitantes de pequenas cidades e individuos de estratos socioeconômicos mais baixos (PARKER 2000; PARKER e DE CAMARGO JR 2000; FONSECA et al. 2000; CASTILHO e CHEQUER 1997; SZWARCWALD et al. 1997, 2000; CNDST/AIDS 2000: BARCELLOS e BASTOS 1996; BASTOS e BARCELLOS 1995).

Enquanto o conhecimento científico era construído para sustentar o enfrentamento da epidemia, emergiu, em muitos cenários sociais, o discurso da moral, criando a ídéia de grupos de risco, dado que a doença incidia em indivíduos marginalizados. As conseqüências deste ideário podem ser percebidas pela difusão do medo e da opressão, ao invés de constituir uma barreira social e cultural em resposta à epidemia e não à população sob risco, contribuindo, assim, para o aumento da vulnerabilidade e para a diminuição do impacto das intervenções sociais baseadas em informação (PARKER 2000). No início, vários atores sociais tiveram papeis importantes e paradoxais, pois, enquanto alguns segmentos consideravam a aids como mais uma doença emergente, outros segmentos a encaravam como um castigo, um flagelo, pelas inversões de sexualidade e pelo consumo de drogas (GALVÃo 1997). O discurso moralista subsidiou a discriminação generalizada, que possibilitou a muitos médicos cederem aos pedidos dos seus pacientes, alegando que pouco, ou nada, tinham a perder com a notificação obrigatória, em contraste ao muito que perderiam com o estigma social, se o sigilo fosse quebrado, principalmente se o individuo participasse de uma camada socioeconômica mais alta, ou se tivesse uma atuação pública ou uma boa colocação profissional (PARKER 2000). 
Por outro lado, em 1983, um grupo de militantes pelos direitos dos homossexuais do Estado de São Paulo procurou a Secretaria Estadual de Saúde para exigir um posicionamento em relação ao problema emergente da aids, que estava sendo bastante divulgado pelos meios de comunicação, subsidiando o medo e a opressão das minorias sociais. A resposta governamental emergiu do setor saúde, que, considerou a aids como uma ameaça à sociedade, constituindo um marco de referenciais éticos, legais e políticos. As decisões adotadas, a partir de então, buscaram envolver a comunidade na resposta à epidemia, legitimando as demandas sociais de grupos minoritários sem a discriminação. Em sintonia com os movimentos internacionais, grupos ativistas se organizaram e constituiram as primeiras respostas não-governamentais ao problema da aids, surgindo, em 1985, o GAPA/SP, que sem local próprio, sem telefone, sem material, mas com voluntários, desempenhou um papel de apoio aos doentes discriminados. O papel das ONG que atuam em aids cresceu em importância, por representarem uma resposta organizada da sociedade civil, para enfrentar a epidemia, que teve reconhecimento na $\mathrm{V}$ Conferência Internacional de AIDS, realizada em Montreal em 1989. As ONG cresceram em número, chegando a mais de trezentas em 1995, destacando-se a atuação da ABIA, do ISER, dos (imupos Gays *, do Pela VIDDA, do Projeto Esperança *, do GIV, do GeMPaC, do TUlIPA, das Casas de Apoio * e dos Grupos Feministas ", além dos GAPA de vários Estados (GALVÃo 1997).

Pela dimensão internacional da epidemia, algumas agências financiadoras passaram a subsidiar as ações em âmbito nacional. Em 1987, a OMS criou o GPA, que estimulou parcerias entre governos e grupos organizados da sociedade, reconhecendo a atuação das ONG nacionais e internacionais. No entanto, mudanças no cenário do

- Militantes gays : grupo Atobá-RJ, Dialogay-SE, Grupo Gay da Bahia-BA, Grupo 28 de Junho-RJ, Grupo Arco-Íris-RJ e Dignidade-PR.

- Resposta comunitária constituidas de grupos religiosos, cuja ênfase é na assistência, composto de espíritas, católicos, protestantes e comunidades-terreiro (candomblé e umbanda).

- São casas como a de Brenda Lee, de propriedade de um travesti, que foram transformadas em local de acolhida aos doentes de aids, sobretudo travestis.

- Militantes feministas : grupos SOS Corpo-PE, Coletivo Feminista Sexualidade e Saude-SP. Transas do Corpo-GO. Géledes e Estudo e Comunicação em Sexualidade e Reprodução-SP. 
financiamento internacional, como as guerras na Europa Oriental e Africa, provocaram transformações no GPA, que até 1996 estava centralizado na OMS, mudando as prioridades e cortando orçamentos das agências financiadoras para subsidiar o enfrentamento da aids. No Brasil, a USAID e o Banco Mundial têm destinado montantes diferenciados para as atividades desenvolvidas pelas ONG, sendo este último, recentemente, a principal fonte de financiamento das respostas institucionais à epidemia da aids, como o Projeto de Controle da AIDS e DST do Ministério da Saúde, conhecido como "AIDS-I" ${ }^{\otimes}$, que foi subsidiado com a cifra de U\$160 milhões, objetivando a prevenção, os serviços de tratamento, o desenvolvimento institucional e a vigilância epidemiológica (GALVÃO 2000).

Atualmente, o enfrentamento da aids se dá de forma diferente daquela do passado, onde se observa a construção de ações integradas entre o governo e os grupos organizados da sociedade civil, estimulando a gestão da epidemia por projetos, que concorrem entre si, dado que a aids passou a movimentar cifras econômicas consideráveis. Do seu início, na década de 1980, até o final da década de 1990, a aids apresentou uma mudança do padrão epidemiológico, que é bastante documentada pela literatura e pelos Boletins Epidemiológicos de Aids do Ministério da Saúde, relatando os fenômenos de "feminização", de "pauperização", de "heterossexualização", de "juvenilização" e de "interiorização" (PARKER e DE CAMARGO JR 2000; FONSECA et al. 2000; CASTILHO e CHEQUER 1997; SZWARCWALD et al. 1997, 2000; CN-DST/AIDS 2000; BARCELLOS e BASTOS 1996; BASTOS e BARCELLOS 1995).

SZWARCWALD et al (2000) mostraram a distribuição de casos, segundo categoria de exposição, em três períodos: 1987-89, 1990-92 e 1993-96. Considerando todo o Brasil, a categoria de transmissão homossexual/bissexual diminuiu de $52,2 \%$ para $33,1 \%$ e para $23,1 \%$ das notificações, respectivamente, nos períodos considerados; a categoria heterossexual aumentou de $8 \%$, para $14,9 \%$ e para $25,9 \%$; a categoria de usuários de drogas injetáveis apresentou uma oscilação, partindo de $18 \%$,

\footnotetext{
¿Este acordo de empréstimo foi renovado, estando em curso, e é denominado "AIDS-II", com
} 
aumentando para $30,9 \%$ e diminuindo para $24,4 \%$; a categoria parenteral mostrou decréscimo, de $5,6 \%$, para $3,2 \%$ e para $2,3 \%$; finalmente, a categoria de transmissão ignorada aumentou, de $16,2 \%$, para $17,9 \%$ e para $24,3 \%$, respectivamente. Grosso modo, observam-se a diminuição da incidência relativa de casos classificados na subcategoria homossexual/bissexual, o aumento da subcategoria heterossexual e o decréscimo dos casos provocados por transfusões de sangue, sendo este último resultado da melhoria dos procedimentos e do controle de qualidade dos bancos de sangue.

A via de transmissão sexual é a mais freqüente, daí a prevenção da doença depender da construção de uma sexualidade culturalmente estabelecida, para que os programas baseados em informação tenham receptividade e apreensão. Neste contexto, a epidemia da aids possibilitou, nos últimos anos, um avanço na pesquisa comportamental, que permitiu entender a diferença entre a identidade sexual (ativo/passivo, macho/fêmea) e o comportamento sexual (sexo com pessoa do mesmo sexo ou de sexo diferente), principalmente em sociedades tradicionais. Há situações em que um homem assume um comportamento de risco, quando não se entende como homossexual, por ter atuação ativa na relação com outro homem (PARKER 2000). Vale destacar que o Estado de Pernambuco, apesar do aumento do número de casos da categoria heterossexual, ainda apresenta um perfil semelhante àquele do início da epidemia no Brasil, ou seja, um número expressivo de casos da categoria homossexual (CN-DST/AIDS 2001).

A participação da mulher na cadeia de transmissão da aids chama a atenção, que é visível pela diminuição da razão de sexo. Essa razão que já foi de 25:1 em 1985, passou para 2:1 em 1999-2000 (CASTILHO e CHEQUER 1997; CN-DST/AIDS 2000). FONSECA et al. (2000) relatam que os casos notificados do sexo feminino estão relacionados com a via de transmissão heterossexual, predominantemente, e que estas mulheres apresentam baixo grau de escolaridade. PARKER e DE CAMARGO JR (2000) realçaram a relação existente entre a pobreza, a migração/mobilidade, a 
vulnerabilidade ao HIV/aids e a posição das mulheres de pouca escolaridade, frente à nova ordem econômica que se instala: "Trabalhadores migrantes, por exemplo, freqüentam trabalhadoras do sexo com regularidade (freqüentemente, elas próprias também migrantes) efou estabelecem familias secundárias no campo de trabalho ... uma vez que trabalhadores e trabalhadoras migrantes deslocam-se contimuamente entre dois ou mais locais, o HIV pode-se disseminar de áreas com alta incidencia a outras onde a incidència é menor ou mesmo previamente inexistente." Os Autores relatam que as estratégias de prevenção têm pouco impacto, pois baseiam-se na redução do número de parceiros, na promoção do uso de preservativos e no tratamento das infeç̧ões sexualmente transmissíveis, pois as mulheres vulneráveis são pobres e não detêm o poder de negociação nos encontros sexuais.

Dado que a posição do indivíduo na sociedade é um importante preditor de risco para as doenças (FONSECA et al 2000; BORREL 1997), o grau de escolaridade tem sido usado como variável proxis do potencial de engajamento do sistema capitalista informacional (PARKER e DE CAMARGO JR 2000; THUROW 1997), considerando que é o único dado socioeconômico que permanece inalterado durante toda a vida adulta (FONSECA et al. 2000). Os primeiros casos registrados apresentavam um nível de escolaridade maior, em relação às notificações posteriores, passando a incidir nos estratos sociais com desvantagem socioeconômica (CN-DST/AIDS 2000; PARKER e CAMARGO JR 2000: BASTOS c BARCELLOS 1995). Em 1985, 33\% dos casos apresentavam baixa ou nenhuma instrução; em 1997 esse percentual atingiu $72 \%$. No entanto, as notificações com segundo grau e com nível superior, passaram de $67 \%$, em 1985, para 27\%, em 1997 (CENEPI 1999). PARKER e DE CAMARGO JR (2000) relataram o percentual de casos, de 1985 para 1998/99, segundo o grau de escolaridade: analfabetos, de $0,6 \%$ para $4,8 \% ; 1^{\circ}$ grau, de $13,3 \%$ para $55,6 \% ; 2^{\circ}$ grau, $10,2 \%$ para $14,8 \%$, superior, de $20,1 \%$ para $6,6 \%$, es escolaridade ignorada, de $57,4 \%$ para 18,2\%. FONSECA et al (2000) verificaram a tendência crescente da proporção de casos com $1^{\circ}$ grau de escolaridade, atingindo níveis próximos de 70\% em 1996, para individuos entre 20 e 69 anos; para as mulheres, as proporções deste mesmo grupo de escolaridade já ultrapassavam $70 \%$, desde o início da série observada (1986- 
1996). Os Autores destacam ainda o incremento relativo de casos de usuários de drogas injetáveis entre os indivíduos com menor escolaridade, principalmente na região Sudeste e Sul, entre 1989 e 1992. Pelas tendências verificadas, pode-se observar que a aids, dia após dia, incide nas populações tradicionalmente desassistidas, adicionando mais um agravante para aqueles que estão socialmente excluídos (CASTILHO et al 1999).

Até agosto de 1998, a faixa etária de maior incidência de aids era de 25 a 39 anos, destacando que os homossexuais/bissexuais eram mais idosos, enquanto os usuários de drogas injetáveis e os heterossexuais eram mais jovens (CASTILHO et al 1999).

O fenômeno da "interiorização da aids" está relacionado à difusão da epidemia, em direção ao oeste, que é o padrão de ocupação do espaço geográfico brasileiro, incidindo em localidades de pequeno porte populacional (TELLES e NOBRE 1998; BASTOS e BARCELLOS 1995). SZWARCWALD et al (1997) verificaram o aumento do número de municípios notificados com pelo menos um caso, em três períodos: de 1982 a 1986, de 1987 a 1990 e de 1991 a 1994. Os percentuais de municípios com até 50 mil habitantes, observados nestes períodos, respectivamente, foram: 1,8\%, 14,1\% e 33,1\%; para os municípios com mais de 50 mil e até 200 mil habitantes, as proporções foram: $17,9 \%, 68,2 \%$ e $87,9 \%$. Considerando as subcategorias homossexual/bissexual, heterossexual, usuário de drogas injetáveis e ignoradas, no período de 1993-96, dentre as localidades com até 50 mil habitantes ocorreram $17,8 \%, 34,1 \%, 22,9 \%$ e $22 \%$ de casos, respectivamente; dentre as localidades com 50 mil a 200 mil habitantes, $16,7 \%, 29,7 \%, 33,3 \%$ e $18,1 \%$; dentre as localidades com 200 mil a 500 mil habitantes, $18,3 \%, 28,3 \%, 31,8 \%$ e $19,4 \%$; e, finalmente, dentre as localidades com mais de 500 mil habitantes, $28 \%, 22,4 \%, 18,7 \%$ e $28,6 \%$ (SZWARCWALD et al 2000).

Um outro mecanismo, que contribui para os fenômenos citados, é o tráfico de drogas, que configura uma geopolítica própria, articulada com a infra-estrutura de transporte (estradas, aeroportos e portos), para escoar seus "produtos" pelo leste, partindo dos cartéis colombianos, passando pelo Brasil em direção à Europa e 
Estados Unidos (ARBEX JR e TOGNOLLI 1996). Para manter o sistema de escoamento funcionando, foi necessário gerar usuários no trajeto, barateando a droga, para ser consumida pelas pessoas de menor poder aquisitivo, tornando-as parte do processo (ARBEX JR 1993). Assim, associando a diminuição da oferta de trabalho formal à desordem social provocada pelo crime organizado/tráfico, houve a banalisação do consumo de drogas ilícitas, para uso recreacional, pelas camadas desfavorecidas da sociedade (PARKER a CAMARGO JR 2000; BARCELLOS e BASTOS 1996). Dentro deste contexto, o Estado de Santa Catarina destaca-se pelo aumento da proporção de casos notificados da categoria usuários de drogas injetáveis, principalmente entre indivíduos maiores de treze anos, observando-se os seguintes valores: 2,2\% no período de 1980 a $1986,10,4 \%$ de 1987 a $1989,18,8 \%$ de 1990 a 1992 e $22,0 \%$ de 1993 a 1995 (CNDST/AIDS 2001: FERREIRA e VALENTE 1997).

"As mulheres pobres são mais vulneráveis que as que não o são, que as mulheres pobres jovens são mais vulneráveis que as mais velhas pertencentes ao mesmo estrato, que as mulheres pobres jovens e sem alternativas econômicas viáveis além do trabalho com sexo são mais vulneráveis do que aquelas que dispõem de outras opçôes econômicas e assim por diante". Estas palavras permitem figurar os fenômenos de "feminização", de "pauperização", de "heterossexualização", de "juvenilização" e de "imteriorização" da aids, não como eventos isolados ou concomitantes ou em uma mesma sequeencia em todo o território do País, mas como um mosaico, em que há uma interação, um sinergismo, que determina a vulnerabilidade ao HIV/aids que, por sua vez, é motivada pelas desigualdades socioeconômicas (PARKER e CAMARGO JR 2000).

\section{Estudos Ecológicos e Análise Espacial da Aids}

$\mathrm{Na}$ Clínica Médica, o uso da Epidemiologia busca aprimorar o diagnóstico, procurando dar respostas até a dimensão da genética ou à particularização dos porquês da ocorrência de dada doença, em dado indivíduo, em dado tempo. Para a Saúde Pública, o uso da Epidemiologia busca identificar os determinantes da 
incidência de dada doença, em dada população, de dada região, em dado tempo. A primeira, que centra o conhecimento no indivíduo, não contribui para as formulação de estratégias coletivas, de políticas públicas; a segunda, que torna homogêneo o ser humano, leva ao "paradoxo da prevenção", por não considerar a vulnerabilidade individual $^{\circ}$ (ROSE 1995).

A pesquisa epidemiológica clínica busca o conhecimento em nível individual, enfocando os fatores de risco e de prognóstico, em delineamentos observacionais ou experimentais, retrospectivos ou prospectivos. No nível coletivo, o conhecimento epidemiológico tem sido construido por estudos ecológicos que são bastante empregados em pesquisa social, para comparar unidades geopolíticas, levando em conta as características socioeconômicas e de saúde (BORREL 1997). Esses estudos assemelham-se a um "desenho de agregados-observacionais-transversais", que delimitam áreas geográficas para comparar resultados ou para correlacionar dados epidemiológicos aos indicadores de condições de vida ou saúde (ROUQUAYROL e ALMEIDA FILHO 1999). Os desenhos de estudos ecológicos podem ser classificados em dois tipos: (a) por exposição ou (b) por agrupamento. O primeiro tipo é chamado de analítico, quando as unidades ecológicas podem ser agregadas por uma suposta exposição, e de exploratório, quando as unidades não puderem ser identificadas pela suposta exposição, determinando as unidades ecológicas pelo espaço - desenho de múltiplos grupos, pelo tempo - desenho de tendência temporal - ou pela combinação espaço-temporal - desenho misto - (MORGENSTERN 1995). Para BORREL (1997), os estudos ecológicos são aqueles que utilizam a área geográfica como unidade de análise, comparando os indicadores de saúde e os indicadores socioeconômicos.

O estudo da evolução da aids no Brasil considera a distribuição espacial dos casos (PARKER e DE CAMARGO JR 2000) e pode observar a epidemia como um fenômeno integrado ao meio - ecológico, segundo o enfoque da geografia humana (SANTOS 1996). A abordagem ecológica na Epidemiologia permite agregar dimensões sociais ao modelo da doença (DEVER 1984), integrando o estudo epidemiológico à

\footnotetext{
' Geoffrey Rose: "Realistically, many diseases will long continue to call for both approaches, and
} 
análise geográfica, dado que ambos são estudos de correlação (ESTEVE et al 1994). A dimensão geográfica deve ter uma participação no modelo epidemiológico como covariável, e não como integrante da rede de causalidade da epidemia. $\mathrm{O}$ conceito de "espaço-região" é preferivel no caso da epidemia da aids, ao invés da abordagem de "espaço-geometria", por se compatibilizar com as bases teóricas da Geografia Humana, considerando os dados epidemiológicos em agregados socioeconômicos e administrativos (BARCELLOS e MACHADO 1998). O conceito de "espaço-geometria", que busca estabelecer correlações diretas entre a epidemia e o espaço físico, geralmente, condiciona a existência de uma dependência espacial estacionária, como em uma "mancha de vinho que se espalha muma toalha de mesa" (BARCELLOS e BASTOS 1996). Este tipo de dependência é bastante útil em fenômenos em que há uma fonte de exposição com localização fixa, como em estudos de poluição, de radiação entre outras condições. No entanto, no caso da aids, a exposição não advém de uma fonte fixa, mas sim de uma dinâmica construída pelo Homem sobre o território, com um padrão de mobilidade distinto. Para referenciar tal idéia, os resultados do estudo de SZWARCWALD et al (1997) mostraram que não houve influência significativa do componente "vizinho mais próximo", que é uma das formas do "espaço-geométrico", em um modelo espaço-temporal, mas houve efeito significativo do componente autorregressivo (valor no período anterior).

Neste sentido, há uma elaboração materialista que fundamenta as dependências espaciais entre os agregados, conforme a lógica da concentração de capital, chamada de teoria de localidades centrais de Christaller (COSTA 1992). A base desta idéia é a formação de uma malha de municípios em torno de centros regionais - polos comerciais, que suprem as necessidades de localidades menores, tanto de produtos como de serviços, que caracteriza a ocupação do território brasileiro. As dependências de cada agregado se estabelecem em torno das trocas comerciais, sem exclusividade, apresentando uma forma dendrítica, pois os municípios mantêm um sistema de trocas com vários polos regionais, que não seguem, necessariamente, os 
critérios de proximidade usados na abordagem do "espaço-geometria". Outra formulação das localidades centrais considera dois circuitos da economia: um superior, que é intensivo em capitais, mais desenvolvido; e outro inferior, que é intensivo em mão-de-obra. O nível superior destes dois circuitos concentra capital, pelas atividades econômicas desempenhadas, tanto pela produção de bens quanto de serviços, suprindo as necessidades das localidades do nível inferior, sendo ambos interligados $\mathrm{e}$ interdependentes. A forma dendrítica, que apresenta os polos comerciais, nada mais é que uma versão desses dois circuitos. (CORRÊA 1996; SANTOS 1996).

Tanto nos estudos ecológicos quanto nos outros tipo, há o problema da divisão dos estratos sociais, que é um assunto complexo e que merece uma abordagem específica, principalmente quando se trabalha o individuo. Entretanto, em estudos ecológico, onde a unidade de observação é coletiva, pode-se utilizar indicadores compostos, que consideram variáveis de diversas dimensões e que interagem entre si, na busca de uma estratificação da condição de vulnerabilidade social. A discussão a respeito das desvantagens desses indicadores giram em torno de quais variáveis seriam mais representativas das condições estudadas (AKERMAN 1997). Um exemplo de indicador composto bastante usado em estudos ecológicos é o Índice de Desenvolvimento Humano (IDH), que baseia o conceito de desenvolvimento não apenas no crescimento econômico, mas em dimensões relacionadas ao indivíduo: longevidade, educação e renda. Há uma versão do IDH, distribuída pelo Instituto de Pesquisa Econômica Aplicada (IPEA), para cada município, que foi gerado pela sua parceria com o Programa das Nações Unidas para o Desenvolvimento (PNUD), com a Fundação Instituto Brasileiro de Geografia e Estatística (IBGE) e com a Fundação João Pinheiro (FJP). O IDH que o IPEA disponibiliza é constituido pelas seguintes variáveis:

a) longevidade - esperança de vida ao nascer e taxa de mortalidade infantil;

b) educação - porcentagem da população de 25 ou mais anos de idade com menos de quatro anos de estudo, porcentagem da população de 25 ou mais anos de idade com menos de oito anos de estudo, porcentagem da 
população de 25 ou mais anos de idade com mais de onze anos de estudo, taxa de analfabetismo na população de quinze ou mais anos de idade e número médio de anos de estudo da população com 25 ou mais anos de idade;

c) renda - renda familiar per capita média em salários mínimos de setembro de 1991, grau de desigualdade L de THEIL *, porcentagem de pessoas com renda insuficiente, insuficiência média de renda e grau de desigualdade na população com renda insuficiente *

O cálculo do IDH é feito pela média aritmética dos componentes padronizados, ou seja, para cada variável são determinados os valores mínimo e máximo, e o valor padronizado é a fração correspondente dessa amplitude (PNUD 1998).

Os indicadores compostos são medidas quantificadoras de uma construção - $o$ estrato social, que podem ser considerados reducionistas. No entanto, do ponto de vista estatístico, as variáveis socioeconômicas agregadas criam uma "certa quantidade de informação", devido às correlações existentes entre elas (MOOD et al 1974), ou seja, mesmo que as variáveis utilizadas no estudo não sejam as melhores possiveis e nem sejam completamente absurdas, existe sim uma validade implícita nos resultados. Quando o propósito é estudar correlações, os estudos ecológicos se adaptam às análises geográficas de risco - vulnerabilidade (ESTEVE et al 1994), que adotam a estratificação por indicadores compostos representativos, assumindo que há uma probalidade de erro - refutacionismo (ROTHMAN e GREENLAND 1998; LAKATOS e MARCONI 1988).

Além da estratificação social, há outro desafio para os estudos ecológicos em Epidemiologia: a medida de saúde. Normalmente, os estudos consideram a incidência de casos da(s) doença(s) como forma de medir saúde e bem estar, que, por estarem

\footnotetext{
- L de Theil - grau de desigulade de distribuição de renda em que se consideram apenas a renda dos individuos que são membros de familias, que vivem em domicílio particular, excluindo os de renda nula.
}

- Foster J, Greer E, Thorbecke E. A class of decomposable poverty measures. Econometrics 1984; v. 52 . 
inversamente associados, revela o grau de vulnerabilidade de grupos de indivíduos. É freqüente o uso do coeficiente de incidência como medida (TSUTAKAWA et al 1985, ROUQUAYROL e ALMEIDA F $F^{\circ}$ 1999), cuja expressão é dada por

$$
p_{i}=\frac{y_{i}}{n_{i}} \cdot 10^{k}
$$

onde

$i \quad$ indice identificador da unidade de observação

$p_{i} \quad$ coeficiente de incidência na população " $i$ " no periodo de tempo " $t$ "

$y_{i}$ incidência acumulada na populą̧ão " $i$ " no período de tempo " $t$ "

$n_{i} \quad$ total de indivíduos expostos na população " $i$ " no periodo de tempo " $t$ "

$10^{k} \quad$ base, onde $k$ é inteiro positivo

$O$ coeficiente de incidência sofre influência da composição da população, quanto ao sexo, idade, raça etc, pois o agravo poder acometer em especial um determinado(s) estrato(s) demográfico(s), recomendando-se o uso de coeficientes padronizados - SMR (DEVER 1984; ROTHMAN e GREENLAND 1998). Este procedimento de padronização adota uma população referência, empírica, segundo dois métodos: a) direto, que considera os coeficientes específicos do municipio, por estrato, e calcula os valores esperados para a população referência, nos mesmos estratos; e b) indireto, que considera os coeficientes especificos da população de referência e obtém os valores estimados para a população do municipio (ROUQUAYROL e ALMEIDA Fo 1999; DEVER 1984; ROTHMAN e GREENLAND 1998)

Pode-se empregar a razão de incidências para comparar grupos, mesmo que um deles sejam uma população referência, surgindo assim uma forma de risco relativo, em que o numerador é dado pelo valor observado e o denominador pelo valor esperado ESTEVE et al (1994) mostraram a relação existente entre o valores observados e o esperados na composição do SMR e que é o estimador de máximo-verossimilhança do risco relativo, dado pelas seguintes expressões 


$$
E_{d i r}=\sum_{j=1}^{k} p_{j} \cdot N_{j} \quad E_{\text {ind }}=\sum_{j=1}^{k} P_{j} \cdot n_{j} \quad S M R=\frac{y}{E}
$$

onde:

y número observado de casos

$P_{j} \quad$ coeficiente de incidência do estrato " $j$ " da população hipotética

$N_{j} \quad$ tamanho populacional do estrato " $j "$ da população hipotética

$p_{j} \quad$ coeficiente de incidência do estrato " $j$ " da população observada

$n_{j} \quad$ tamanho populacional do estrato " $j$ " da população observada

$E_{\text {ind }} \quad$ valor esperado da população hipotética - método indireto

$E_{d i r} \quad$ valor esperado da população observada - método direto

li valor esperado, pelo método direto ou indireto

O uso de coeficientes permite adotar a distribuição de probabilidade binomial, quando a população exposta é conhecida - população fechada, recomendando-se a distribuição de Poisson ou quando se conhece o tamanho da população exposta e/ou quando o risco é baixo. Nestes casos, podem ser usados os modelos de regressão logística ou de Poisson (ESTEVE et al 1994; ROTHMAN e GREENLAND 1998). Essas variáveis aleatórias apresentam a característica de terem a variância proporcional ao tamanho da população e, quando o evento tem probabilidade e população pequenas, o valor esperado influencia no valor do SMR, caracterizando a problema das pequenas áreas nas análises espaciais (BAILEY e GATHRELL 1995, ESTEVE et al 1994. BERNARDINELLI e MONTOMOLI 1992, CLAYTON e KALDOR 1987, TSUTAKAWA et al 1985. MOOD et al 1974).

Nos estudos espacial, várias técnicas estatísticas têm sido empregadas na identificação de áreas com excesso de risco de uma doença, para obter uma geografia da epidemia, considerando áreas heterogêneas, tanto fisica quanto socialmente, e variável aleatória de Poisson. Houve época em que se usava o mapa de significância, que consistia no valor " $p$ " ( $p$-value) do evento observado, para cada unidade ecológica, mapeando os valores menores de $5 \%$. Tal procedimento é bastante 
criticável, pois a variável aleatória está sujeita à influência do tamanho da população e do risco de cada área, chamados de mapas de significância (CLAYTON e KALDOR 1987). O uso do SMR é uma alternativa para os mapas de significância, mas não são recomendados quando há heterogeneidade de risco, origenando o problema da variação extra de Poisson, combinando a associação do evento de aleatório com a variação do parâmetro de risco (GILKS et al 1996, BAILEY e GATHRELL 1995).

Um outro instrumento estatístico é o estimador CuSum, do inglês "cumulative sum", cuja utilidade é fazer o acompanhamento temporal do processo (SANCHES 2000, ROSSI et al 1999; WILLIANS et al, 1992), que se baseia na diferença entre o valor de risco observado e de referência, detectando mudanças não aleatórias do comportamento temporal. ROSSI et al (1999) relataram três dificuldades de aplicação do estimador CuSum: (1) quando a população varia, ou seja, é do tipo aberta; (2) há heterogeneidade de risco; (3) ocorre sazonalidade na série temporal do valor de referência. Assim, no caso de estudos espaciais da aids, usando dados de fontes secundárias e informações censitárias, deve considerar duas dessas dificuldades: população aberta e risco heterogêneo.

Além da simplicidade do método, o uso de medidas repetidas no tempo possibilita o controle da variabilidade intra-unidade. Assim, o uso do estimador CuSum contribui para o controle das dificuldades citadas por ROSSI at al (1999), assumindo que, aleatoriamente, os valores do SMR podem ser momentaneamente altos. A expressão do estimador CuSum é dada por

$$
C u S u m=\sum_{t=1}^{T}\left(s m r_{i t}-S M R_{j \mid i, t}\right)
$$

onde

$s m r_{n} \quad$ risco relativo da população " $i$ " no instante " $t$ "

$S M R_{\mid l, t}$ risco relativo da população referência " $j$ ", relativa ao municipio " $i$ " no instante " $t$ "

$T$ número de períodos de tempo observados: $T=\{1990,1991 \ldots 1998\}$ 
Quando a estimativa do CuSum for "próximo" de zero, pode-se considerar a casualidade da série temporal; quando não for "próximo" de zero, pode-se dizer que a série apresentou tendência, em relação aos valores referência. 


\section{OBJETIVOS}

\section{Objetivo Geral}

- Caracterizar a epidemia da aids no Brasil, no período de 1990 a 1998, usando os municípios brasileiros como unidade de observação, segundo categoriade exposição ao HIV, sexo, idade, escolaridade e tamanhos dos municípios.

\section{Objetivos Específicos}

1. Usar um índice baseado na média de estimadores CuSum de cada categoria de exposição ao HIV e, por meio de uma abordagem espaço-temporal da epidemia baseada em localidades centrais, identificar municípios de alta incidência de aids.

2. Realizar um estudo de correlação entre o índice proposto e o Índice de Desenvolvimento Humano, considerando seus componentes: longevidade, educação e renda.

3. Mapear os resultados observados pelo índice proposto.

4. Usar a medida proposta no item (1) para estudar a epidemia de aids nos Estados de São Paulo, Pernambuco e Santa Catarina. 


\section{METODOLOGIA}

\section{Informações e Estudo Ecológico}

O estudo considerou a divisão político-administrativa da União Federativa do Brasil - mumicípios, na definição das unidades ecológicas da pesquisa. Pode se fazer uma critica ao critério de agregação, considerando que o fenômeno espacial da aids não se modifica de um limite de município para outro; entretanto, este critério representa a divisão politico-administrativa, que é adotado pelos institutos de pesquisa e órgãos oficiais, como CN-DST/AIDS, IBGE, IPEA e INPE. Então, neste estudo assumiu-se que as informações dos municípios refletem a construção social de uma comunidade no espaço.

Utilizou-se o banco de dados de casos notificados à CN-DST/AIDS, obtido por meio da internet [URL: http://www.aids.gov.br/], contendo todos os registros até maio de 2000, em que foram considerados somente os casos registrados entre 1 de janeiro de 1990 a 31 de dezembro de 1998. Os registros de 1999 e de 2000 foram desconsiderados devido à característica de atraso de notificação do sistema de informações, mesmo assim os números de casos de 1997 e 1998 são menores do que os de 1996, não sendo indicativo da diminuição da incidência e sim do retardo da informação. As informações consideradas do banco de dados foram:

- código do município de residência

- categoria de transmissão

- data do diagnóstico

- idade

- sexo

- escolaridade

O estudo considerou o reagrupamento da categoria de transmissão, da ficha de notificação, segundo o critério apresentado no anexo 1, para se ter grupos de 
exposição únicos, a partir de uma hierarquização dos individuos que pertecem a mais de uma categoria de exposição. Os grupos de exposição são:

- usuários de drogas injetáveis

- homossexuais e bissexuais

- hemofilicos e transfundidos

- heterossexuais

- perinatais

- ignorados

A variável-resposta foi definida pela contagem do número de casos novos, em cada ano e segundo o grupo de exposição, em cada unidade ecológica, obtendo-se as séries de SMR anuais. O total de registros utilizados foi de 155551 casos, em 5054 municipios

A informações censitárias das unidades ecológicas foram obtidas do IBGE, via internet [URL: http://www.ibge.gov.br/], considerando o censo de 1991, as projeções populacionais de 1992 a 1995, o levantamento de 1996 e as projeções populacionais de 1997 a 1999. Os municípios foram estratificados segundo o tamanho da população em $1996 \mathrm{em}$ :

- menores de cinqüenta mil habitantes

- entre cinqüenta mil e duzentos mil habitantes

- entre duzentos mil e quinhentos mil habitantes

- maiores que quinhentos mil

Foram consideradas as seguintas faixas etárias:

- de 0 a 14 anos

- de 15 a 29 anos

- de 30 a 44 anos

- de 45 a 59 anos

- acima de 60 anos de idade. 
Consideraram-se os seguintes estratos de escolaridade

- analfabeto

- da $1^{\mathrm{a}}$ à $4^{\mathrm{a}}$ série do $1^{\circ}$ grau

- da $5^{\mathrm{a}}$ à $8^{\mathrm{a}}$ série do $1^{\circ}$ grau

- $2^{\circ}$ grau

- superior

- ignorado

O estudo espacial foi estruturado com a base cartográfica digital fornecida pelo INPE, pela internet [URL: http://www.inpe.br/], que considera a malha políticoadministrativa vigente em 1997, considerando 5540 municípios, permitindo definir uma abordagem de áreas poligonais irregulares - perímetros de municípios.

Neste estudo a abordagem espacial não foi do tipo "espaço-geometria", conforme citado por BARCELLOS e MACHADO (1998). Optou-se pela ótica da geografia humana, do "espaço-região", assumindo que a epidemia de aids não de difunde como a mancha de vinho na toalha de mesa, ou seja, a dependência espacial não deve se basear no critério de proximidade - distância euclideana de centróides. Essa abordagem possibilita usar indicadores de socioeconômicos, que refletem o desenvolvimento das construções do humanas sobre o espaço geográfico. Então, foram consideradas neste estudo os dados do IDH, de cada unidade ecológica-políticoadministrativa, fornecidas pelo IPEA, pela internet [URL: http://www.ipea.gov.br/], tanto na forma de valor médio quanto em componentes longevidade, educação e renda. $\mathrm{O} I D H$ foi estratificado em

- "baixo desenvolvimento humano" : $0,0 \leq \mathrm{IDH}<0,5$

- "médio desenvolvimento humano" : $0.5 \leq \mathrm{IDH}<0,8$

- "alto desenvolvimento humano" : $0.8 \leq \mathrm{IDH}<1,0$

O estudo espacial empregou o software SPRING do INPE, obtido pela internet [URL: http://www.dpi.inpe.br/], para gerar os mapas temáticos da epidemia da aids. 
Foram contruidos mapas temáticos de $\mathrm{IDH}$, de risco relativo e de índice proposto (média dos estimadores (uSum). A manipulação dos arquivos de dados (CNDST/AIDS, IBGE, IPEA e INPE) utilizou o campo "código do município de residência" como a chave de relacionamento, para usar o software SPRING *.

Uma abordagem estatística descritiva foi realizada, considerando as incidência espaço-temporais da aids, segundo as categorias de macro-regiões, de tamanho populacional em 1996, de faixas etárias, de sexo e de escolaridade e de IDH. Os resultados descritivos foram apresentados na forma de tabelas, gráficos e cartogramas.

\section{Índice de Risco de Aids nos Municipios}

A medida proposta neste trabalho baseia-se no risco relativo, que são empregados na estimativa CuSum, para cada município, segundo categoriade exposição ao HIV. O método considera riscos relativos (municípios e populações de referência), em cada ano de diagnóstico, de 1990 a 1998, totalizando os valores algébricos da diferença entre eles. Assim, o risco relativo de cada município foi obtido pela razão entre o número de casos observados $\left(y_{i}\right)$ e esperados $\left(e_{i}\right)$, como mostra a expressão [2]. Esses valores esperados foram obtidos do total de municípios que notificaram caso(s) de aids, da mesma categoria de tamanho populacional (população em 1996) e macro-região do município. Esse referênciamento é compatível com a teoria de localidades centrais, buscando abranger as diferenças regionais do País. Da mesma forma, o risco relativo da população de referência foi obtido pela razão entre o número de casos da população de referência e o valor esperado, que adotou a população brasileira, segundo categoriade tamanho populacional. As expressões dessas medidas de risco são apresentadas a seguir

\footnotetext{
- Salume JN. Camargo ECG. Motta M. Um guia prático para integrar tabela externa de atributos no sistema Spring. [online] 2000; Instituto Nacional de Pesquisas Espaciais INPE. Disponivel em <URL: http://www.dpi.inpe.br/> [2000 dezembro 10].
} 


$$
\begin{gathered}
s m r_{i t}=\frac{y_{i t}}{e_{i t}} \Rightarrow e_{i t}=\hat{\pi}_{i t} \cdot n_{i t} \\
\hat{\pi}_{i t}=\frac{\text { total de casos na pop. referência de } i \text { em } t}{\text { total de habitantes na pop. referência de } i \text { em } t}
\end{gathered}
$$

\begin{tabular}{|c|c|}
\hline$m r_{i t}$ & $\begin{array}{l}\text { estimativa do risco relativo do municipio " } i \text { " no ano } \\
\text { diagnóstico " } r \text { " }\end{array}$ \\
\hline 'it & $\begin{array}{l}\text { número de casos observados no município " } i \text { " no ano } \\
\text { diagnóstico " } i \text { " }\end{array}$ \\
\hline$e_{i t}$ & $\begin{array}{l}\text { valor esperado do município " } i \text { " no ano de diagnóstico " } " \text { " } \\
\text { coeficiente de incidência da população de referência, par }\end{array}$ \\
\hline & cípio " $i$ " no ano de diagnóstico " $t$ " \\
\hline
\end{tabular}

onde

De maneira semelhante, o risco relativo referência, a ser usado no cálculo da soma acumulada, foi obtido pelo coeficiente de incidência da população hipotética (valor observado) correspondente ao município e o valor esperado proveniente do agrupamanto da população da macro-região a que pertence, como segue

$$
\begin{gathered}
S M R_{J(i, t)}=\frac{Y_{J t}}{E_{\jmath(i, t)}} \Rightarrow E_{J(i, t)}=\Pi_{\jmath(i, t)} \cdot N_{J(i, t)} \\
\hat{\Pi}_{J(i, t)}=\frac{\text { no. de casos na pop. referência de } j, \text { dado } i \text { e } t}{\text { no. habitantes na pop. referência de } j, \text { dado } i \text { e } t}
\end{gathered}
$$

onde
$S M R_{j \mid(i, t) t}$ estimativa do risco relativo da população de referência " $j$ " do município " $i$ " no ano de diagnóstico " $t$ "
$Y_{j \mid(i, t)} \quad$ número de casos observados na população de referência do município " $i$ " no ano de diagnóstico " $t$ "
$E_{j \mid(i, t)} \quad$ valor esperado da população de referência do município " $i$ " no ano de diagnóstico " $\boldsymbol{l}$ "
$\hat{\Pi}_{j k t, t)} \quad$ coeficiente de incidência da população nacional, para o município " $i$ ", no ano de diagnóstico " $\boldsymbol{l}$ "
$N_{j \mid(i, t)} \quad$ total da população de referência “ $j$ ”, do municipio “ $i$ ", no ano de diagnóstico " $i$ " 
O cálculo dos valores esperados utilizaram os tamanhos populacionais fornecidos pelo IBGE, do censo demográfico de 1991, do levantamento de 1996 e das projeções dos anos de 1993 a 1995 e de 1997 a 1999. Este trabalho considerou como coeficiente de incidência a razão do número de casos acumulados em dado período anual e a população ao final do mesmo periodo. Tal estratégia busca utilizar somente as informações do censo demográfico de 1991 no estudo.

O cálculo da estimativa de CuSum, dada pela expressão [3], foi realizado para cada categoria de exposição $(k-\sigma)$, formando os " $k$ " componentes do índice proposto, após terem sido padronizados. A padronização consiste em aplicar uma transformação aos dados originais (números reais), cujo contra-domínio é o intervalo $[0 ; 1]$, usando os seguintes passos:

1. ordenar os valores originais, obtidos na estimativa de $\mathrm{CuSum}_{\mathrm{ik}}$

2. determinar os valores mínimo e máximo

3. calcular $\varphi\left(C_{\left.\text {US } u m_{i k}\right)}\right)$ pela expressão

$$
\varphi\left(\text { CuSum }_{i k}\right)=\frac{\text { CuSum }_{i k}-\min _{l}\left(\text { CuSum }_{i k}\right)}{\max _{1}\left(\text { CuSum }_{i k}\right)-\min \left(\text { CuSum }_{i k}\right)}
$$

onde

$$
\begin{aligned}
& \varphi\left(\text { CuSum }_{i k}\right) \quad \text { estimador CuSum padronizado do município " } i \text { " } \\
& \text { da categoria de exposição " } k \text { " } \\
& \text { CuSum }_{\iota k} \quad \text { estimador CuSum do municipio " } i \text { " da categoria } \\
& \text { de exposição “ } k \text { " } \\
& \max _{f}\left(C_{1} \text { Sum }_{i k}\right) \quad \text { maior estimativa de CuSum }{ }_{i k} \text { dentre os "I" } \\
& \text { municípios da categoria de exposição " } k \text { " } \\
& \min _{\Lambda}\left(\mathrm{CuSum}_{i k}\right) \quad \text { menor estimativa de CuSum }{ }_{i k} \text { dentre os "I" } \\
& \text { municípios da categoria de exposição “ } k \text { ” }
\end{aligned}
$$


Após a transformação de padronização - $\varphi\left(\right.$.) - dos estimadores CuSum $_{\mathrm{ik}}$, o índice proposto é definido como a média aritmética dos " $k$ " componentes (grupos de exposição), em cada município “ $i$ ", resultando em um escore unidimensional $\left(\delta_{i}\right)$, que é o indice proposto por este trabalho, como segue

$$
\hat{\delta}_{i}=\frac{1}{6} \sum_{k=1}^{6} \varphi\left(\text { CuSum }_{i k}\right)
$$

A interpretação dessa medida $-\hat{\delta}_{i}$ - revela que, quanto maior o valor do índice, maior terá sido o impacto da epidemia sobre determinada área - município, denotando alta incidência de aids. $O$ valor zero do índice proposto não representa ausência da risco, pois o índice somente considerou as unidades com pelo menos um caso notificado no segmento, mas indica a menor incidência observada. Assim, este indice serve para classificar as regiões de maior/menor incidência, ou de maior/menor risco.

A distribuição dos valores do índice proposto foi feita por estatística descritiva, usando a distribuição de freqüências do índice proposto. Utilizou-se o teste de aderência para verificar se a distribuição é lognormal, devido à assimetria observada na escala original do índice (SHAPIRO e WILKS 1965, ZAR 1996). Usando a distribuição de freqüência observada, foram considerados municípios com alta incidência de aids aqueles cujos índices compuseram a área de 5\% superior.

Usou-se a estatística-teste de Pearson no estudo de correlação, considerando o índice proposto - $\delta-\mathrm{e} O \mathrm{IDH}$, na forma geral, em grupos de exposição, em componentes e por região. Para tanto, o valor do coeficiente de correlação $-r$ - foi obtido pela seguinte expressão geral : 


$$
r=\frac{\sum_{i=1}^{5054}\left(\hat{\delta}_{i} \cdot \mathrm{IDH}_{i}\right)-\frac{1}{5054} \sum_{i=1}^{5054} \hat{\delta}_{i} \sum_{j=1}^{5054} \mathrm{IDH}}{\sqrt{\left[\sum_{i=1}^{5054} \hat{\delta}_{i}^{2}-\frac{1}{5054}\left(\sum_{i=1}^{5054} \hat{\delta}_{i}\right)^{2}\right] \cdot\left[\sum_{i=1}^{5054} \mathrm{IDH}_{i}^{2}-\frac{1}{5054}\left(\sum_{i=1}^{5054} \mathrm{IDH}_{i}\right)^{2}\right]}}
$$

Pode-se testar hipóteses a respeito do coeficiente de correlação, usando o índice de correlação $-r^{2}$ - para obter o erro padrão e adotar a distribuição t-Student e o estimdor $t_{\mathrm{r}}$ :

$$
\begin{aligned}
& t=\frac{r}{s_{r}} \sim t_{n-2} \\
& s_{r}=\sqrt{\frac{1-r^{2}}{n-2}}
\end{aligned}
$$

Tal medida foi considerada como indicador das relações de dependências existentes entre a epidemia da aids, sobre o território brasileiro, e a qualidade de vida, usando o IDH como um reflexo da geografia humana do fenômeno. 


\section{RESULTADOS}

\section{Descritivos}

A tabela 1 mostra que em 1990 a aids já havia sido notificada por, praticamente, todos os municípios com mais de 200 mil habitantes. Em 1998, todos os municípios entre 50 e 200 mil habitantes já havia diagnosticado ao menos um caso. Nos municípios com menos de 50 mil habitantes, a epidemia de aids tem acumulado ao final de 1998, 35,7\% (N), 54,0\% (NE), 69,1\% (SE), 51,7\% (S) e 55,9\% (CO) dos municipios. Ainda não houve notificação de casos em 231 (N), 657 (NE), 411 (SE), 469 (S) e 178 (CO) localidades de pequeno porte. A tabela mostra que a aids tem sido diagnosticada, ao menos uma vez, por um número crescente de municípios com menos de 50 mil habitantes (em 1996). Pode-se dizer os municípios pequenos, do interior do País, estão apresentando casos de aids, sugerindo a interiorização da epidemia.

Tabela 1 - Distribuição do número acumulado de municipios que notificaram ao menos 1 caso de aids, segundo região, ano de diagnóstico e tamanho populacional. Brasil. 1990-1998.

\begin{tabular}{c|c|rrrrrrrrrrr}
\hline \multirow{2}{*}{$\begin{array}{c}\text { popu- } \\
\text { laçăo } \\
\text { mil }\end{array}$} & 1990 & 1991 & 1992 & 1993 & 1994 & 1995 & 1996 & 1997 & 1998 & $\begin{array}{c}\text { número } \\
\text { de } \\
\text { cidades }\end{array}$ \\
\hline \multirow{2}{*}{$N$} & $<50$ & 9 & 14 & 27 & 39 & 51 & 75 & 96 & 108 & 128 & 359 \\
& $50-200$ & 6 & 11 & 17 & 21 & 23 & 24 & 27 & 27 & 29 & 29 \\
\hline \multirow{2}{*}{ NE } & $<50$ & 151 & 223 & 309 & 385 & 458 & 540 & 638 & 715 & 772 & 1429 \\
& $50-200$ & 63 & 83 & 93 & 99 & 104 & 106 & 106 & 109 & 109 & 109 \\
\hline \multirow{2}{*}{ SE } & $<50$ & 337 & 411 & 513 & 608 & 702 & 766 & 822 & 874 & 920 & 1331 \\
& $50-200$ & 148 & 148 & 151 & 154 & 156 & 156 & 156 & 156 & 156 & 156 \\
\hline \multirow{2}{*}{$\mathrm{S}$} & $<50$ & 110 & 165 & 212 & 257 & 315 & 355 & 415 & 465 & 503 & 972 \\
& $50-200$ & 59 & 64 & 67 & 69 & 70 & 70 & 70 & 70 & 70 & 70 \\
\hline \multirow{2}{*}{$\mathrm{CO}$} & $<50$ & 37 & 58 & 89 & 118 & 150 & 166 & 184 & 215 & 226 & 404 \\
& $50-200$ & 12 & 15 & 17 & 17 & 17 & 17 & 17 & 17 & 17 & 17 \\
\hline
\end{tabular}

* todos os municípios com mais de 200 mil habitantes em 1996 haviam notificado ao menos 1 caso já em 1990, por isso não foram incluidos na tabela. 
A figura 1 apresenta o mapeamento das categorias de $\mathrm{IDH}$, sobre o território brasileiro, possibilitando visualizar que há pelo menos duas realidades dentro do mesmo País: (1) faixa de exclusão de bens e serviços, no Norte e no Nordeste, onde se concentram municípios com baixo desenvolvimento humano; (2) faixa de inclusão de bens e serviços, que vai da região centro-oeste em direção ao litoral atlântico equatoriano (Pará e Amapá) ao litoral atlântico sul (região sul e sudeste). Em 1997 foram instalados 531 novos municípios, que não apresentavam informações.

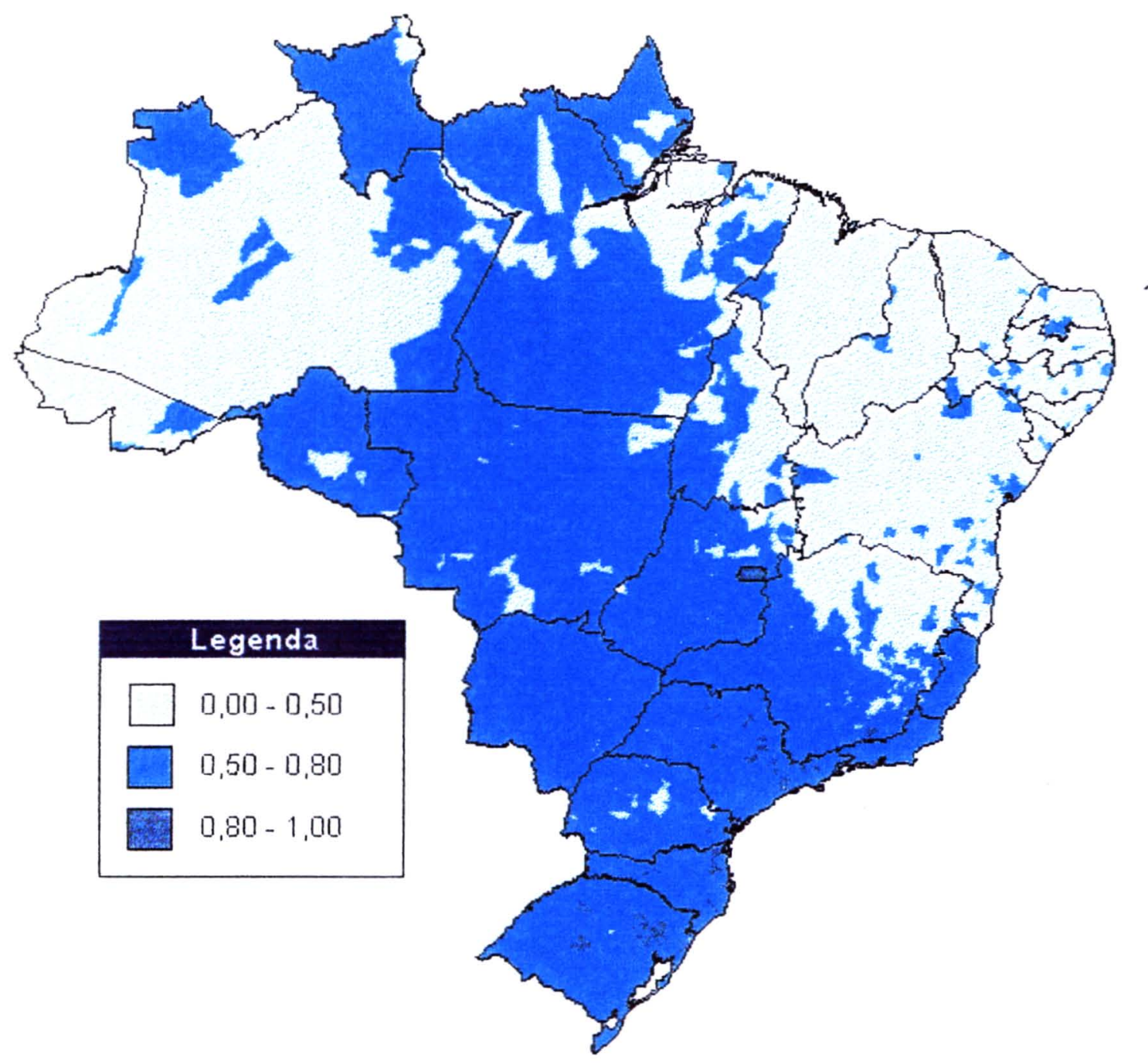

Figura 1 - Distribuição geográfica do Índice de Desenvolvimento Humano - IDH, segundo informações do IPEA. Brasil, 1997. 
A figura 2 apresenta as distribuições de freqüência relativa, por ano de diagnóstico e por região, nos municípios brasileiros em cada estrato de desenvolvimento humano. Esses valores correspondem à distribuição da Tabela 9 do anexo 2. Observa-se que o percentual de unidades da categoria "baixo desenvolvimento humano" - IDH-baixo - se destaca, mas é preciso ressaltar que as regiões norte e nordeste concentram as maiores quantidades desses municípios; da mesma forma, para as regiões sul e sudeste há um maior número de municípios com médio/alto desenvolvimento humano. Assim, a predominância se cria pelo viés de interpretação, podendo sugerir que a epidemia da aids no Norte e Nordeste somente acomete as parcelas mais baixas da comunidade socioeconômica.
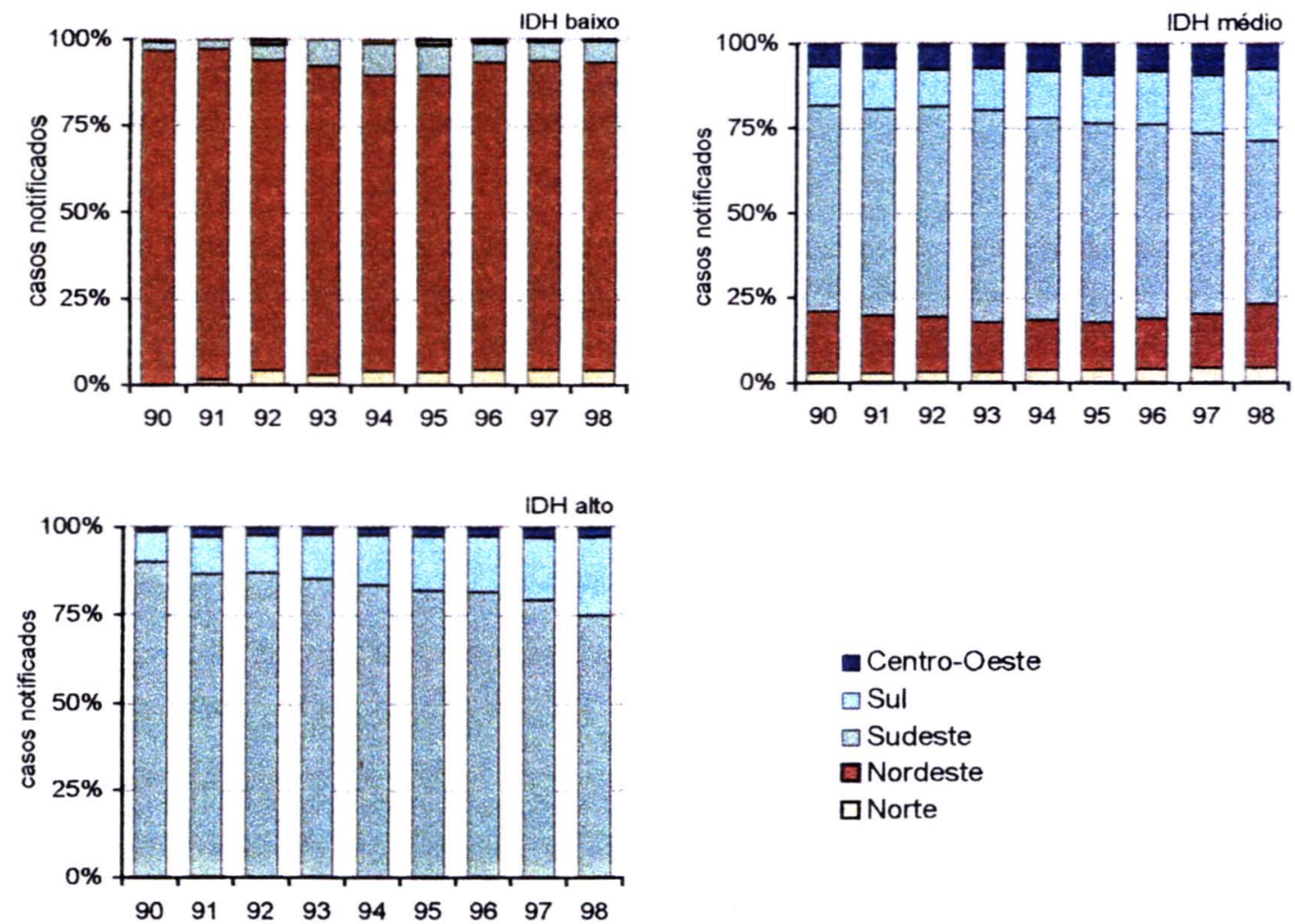

Figura 2 - Distribuição proporcional dos casos de aids, segundo macro-região, estrato de IDH e ano de diagnóstico. Brasil. 1990-1998. 

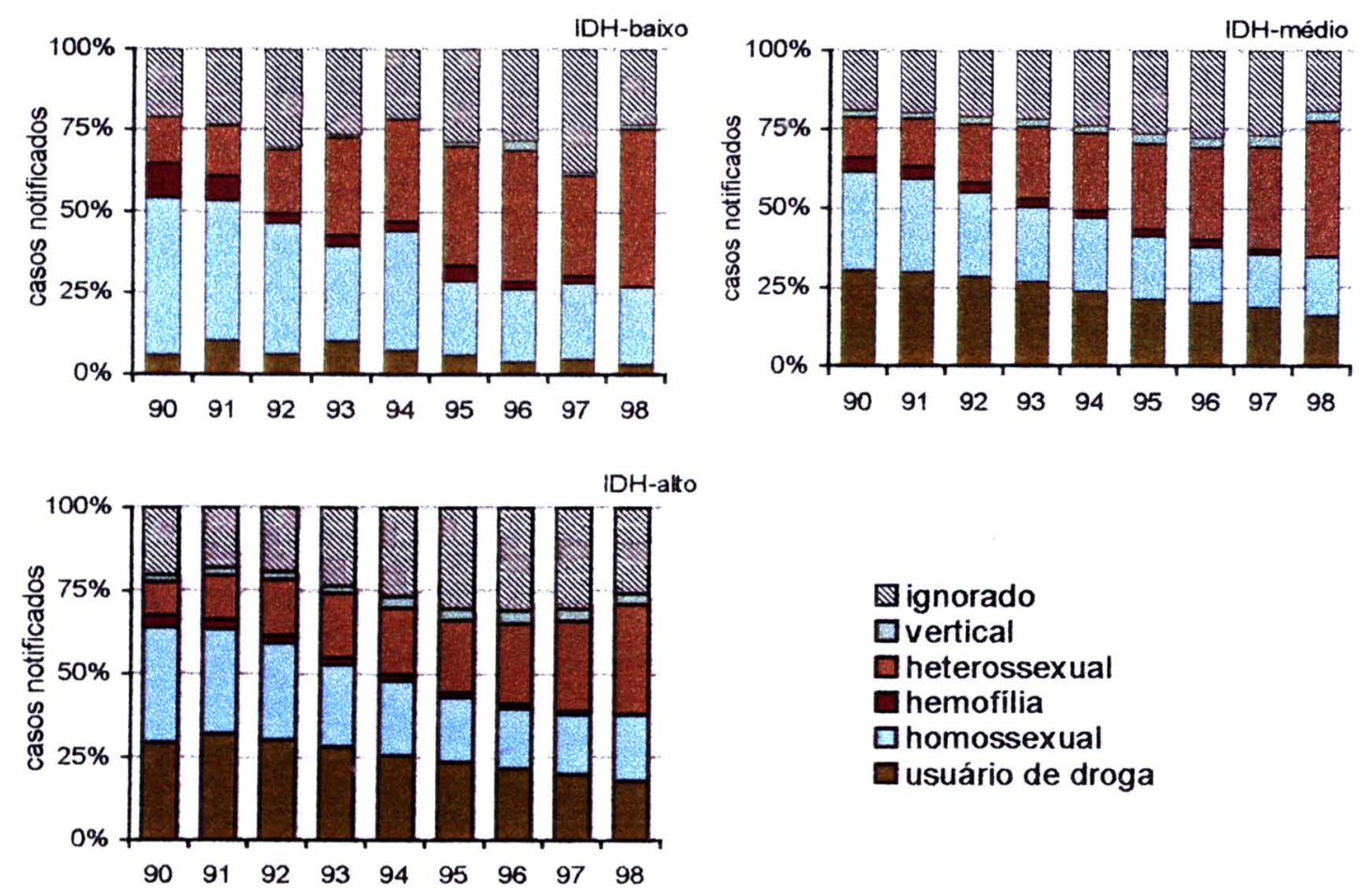

Figura 3 - Distribuição proporcional dos casos de aids, segundo categoriade exposição ao HIV, estratos de desenvolvimento humano e ano de diagnóstico. Brasil. 1990-1998.

A figura 3 mostra a evolução do perfil da epidemia de aids nos estratos de desenvolvimento humano. Pode-se observar o aumento da freqüência relativa da incidência de casos da categoria de exposição heterossexual em todos os estratos de IDH; por outro lado, houve decréscimo da freqüência relativa da incidência de casos da categoria de exposição homossexual em todos os estratos de IDH. Destaca-se a pouca incidência de casos no grupo de usuários de drogas injetáveis, no estrato de baixo desenvolvimento humano - Norte e Nordeste, que não estão incluídas na rota internacional do tráfico de drogas e por não podem consumir a droga recreacional ilícita. Já nos estratos de médio/alto desenolvimento humano, onde há maior poder de compra dessas drogas, há uma fração maior de casos em usuário de drogas injetáveis. Destaca-se ainda, em todos os estratos de IDH, a categoria de exposição ignorada. Os dados relativos à figura 3 estão na tabela 10 do anexo 2 . 



Figura 4 - Distribuição proporcional de casos de aids, segundo macro-região, ano de diagnóstico e categoria de exposição. Brasil. 1990-1998.

A figura 4 mostra as distribuições de freqüências das categorias de exposição, por ano de diagnóstico, cujos valores constam da tabela 10 do anexo 2. Observa-se, para as regiões norte e nordeste, que a fração de casos diagnosticados da categoria de 
exposição de UDI é pequena, quando comparada aos grupos de heterossexuais e homossexuais (transmissão sexual); para as regiões sul, sudeste e centro-oeste a fração do grupo UDI é mais visível, além do grupo heterossexual, que apresenta tendência ao aumento de casos.

A razão de sexo é apresentada na tabela 2 , segundo ano de notificação e classificação de desenvolvimento humano. Não houve um resultado de destaque, entre municípios de desenvolvimento distintos, mostrando uma tendência decrescente entre as razões de sexo .

Tabela 2 - Distribuição de casos de aids, segundo sexo, estrato do IDH e ano de notificação. Brasil. 1990-1998.

\begin{tabular}{|c|c|c|c|c|c|c|c|c|c|c|}
\hline IDH & sexo & 1990 & 1991 & 1992 & 1993 & 1994 & 1995 & 1996 & 1997 & 1998 \\
\hline \multirow{2}{*}{ baixo } & $\underset{f e m}{\operatorname{masc}}$ & $\begin{array}{r}110 \\
14\end{array}$ & $\begin{array}{r}160 \\
30\end{array}$ & $\begin{array}{r}193 \\
27\end{array}$ & $\begin{array}{r}212 \\
62\end{array}$ & $\begin{array}{r}245 \\
58\end{array}$ & $\begin{array}{r}254 \\
88\end{array}$ & $\begin{array}{l}321 \\
135\end{array}$ & $\begin{array}{l}372 \\
137\end{array}$ & $\begin{array}{l}371 \\
190\end{array}$ \\
\hline & ${ }^{*} \mathrm{~m}: \mathrm{f}$ & 7,9 & 5,3 & 7.1 & 3,4 & 4,2 & 2,9 & 2,4 & 2,7 & 2,0 \\
\hline \multirow[t]{2}{*}{ médio } & $\begin{array}{c}\text { masc } \\
\text { fem }\end{array}$ & $\begin{array}{r}2591 \\
510\end{array}$ & $\begin{array}{r}3701 \\
846\end{array}$ & $\begin{array}{l}4668 \\
1284\end{array}$ & $\begin{array}{l}5499 \\
1641\end{array}$ & $\begin{array}{l}6132 \\
1975\end{array}$ & $\begin{array}{l}6578 \\
2347\end{array}$ & $\begin{array}{l}7129 \\
2965\end{array}$ & $\begin{array}{l}6979 \\
3283\end{array}$ & $\begin{array}{l}6878 \\
3442\end{array}$ \\
\hline & m:f & 5,1 & 4,4 & 3,6 & 3,4 & 3,1 & 2,8 & 2,4 & 2,1 & 2,0 \\
\hline \multirow[t]{2}{*}{ alto } & $\begin{array}{c}\text { masc } \\
\text { fem }\end{array}$ & $\begin{array}{r}4779 \\
734\end{array}$ & $\begin{array}{l}5852 \\
1155\end{array}$ & $\begin{array}{l}7037 \\
1622\end{array}$ & $\begin{array}{l}7236 \\
1941\end{array}$ & $\begin{array}{l}7431 \\
2169\end{array}$ & $\begin{array}{l}7701 \\
2625\end{array}$ & $\begin{array}{l}8216 \\
3127\end{array}$ & $\begin{array}{l}7655 \\
3372\end{array}$ & $\begin{array}{l}6816 \\
3185\end{array}$ \\
\hline & m:f & 6,5 & 5,1 & 4,3 & 3,7 & 3,4 & 2,9 & 2,6 & 2,3 & 2,1 \\
\hline \multirow[t]{2}{*}{ geral } & $\begin{array}{c}\text { masc } \\
\text { fem }\end{array}$ & $\begin{array}{l}7480 \\
1258\end{array}$ & $\begin{array}{l}9713 \\
2031\end{array}$ & $\begin{array}{r}11898 \\
2933\end{array}$ & $\begin{array}{r}12947 \\
3644\end{array}$ & $\begin{array}{r}13808 \\
4202\end{array}$ & $\begin{array}{r}14533 \\
5060\end{array}$ & $\begin{array}{r}15666 \\
6227\end{array}$ & $\begin{array}{r}15006 \\
6792\end{array}$ & $\begin{array}{r}14065 \\
6817\end{array}$ \\
\hline & $m: f$ & 5,9 & 4,8 & 4,1 & 3,6 & 3,3 & 2,9 & 2,5 & 2,2 & 2,1 \\
\hline
\end{tabular}

* m:f - é a razão de sexo

Foram encontrados 137 municípios em que a razão de sexo teve um maior número acumulado de casos do sexo feminino em relação ao do sexo masculino, entre 1990 e 1998, dos quais 132 tinham menos de 50 mil habitantes. Nestes municípios o total de casos notificados foi 464 . Outros 275 municípios apresentaram notificações somente de casos do sexo feminino e nenhum caso do sexo masculino, num total de 343 casos, tendo 257 deles menos de 50 mil habitantes. 

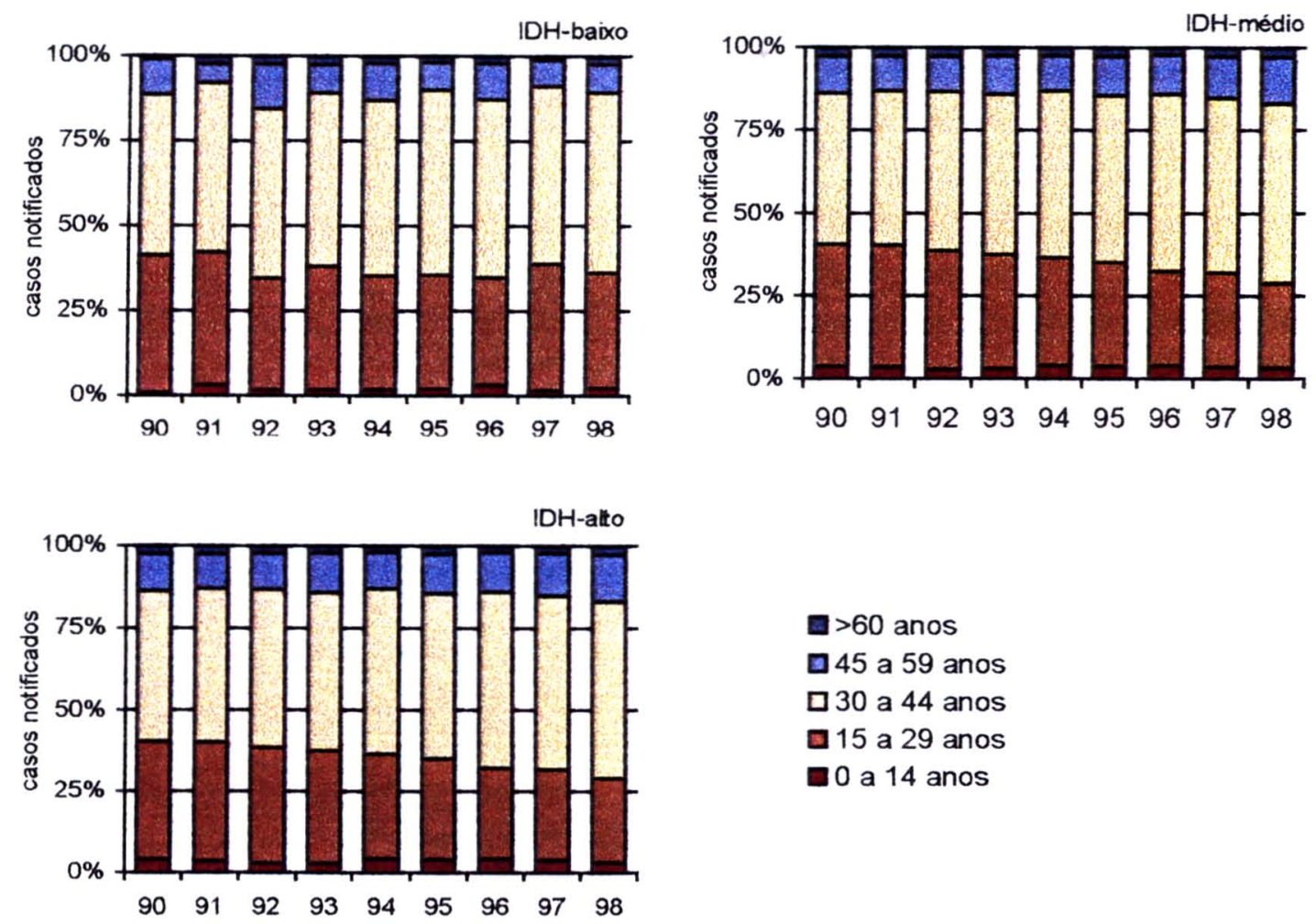

日 $>60$ anos

$\square 45$ a 59 anos

$\square 30$ a 44 anos

$\square 15$ a 29 anos

a 0 a 14 anos

Figura 5 - Distribuição proporcional de casos de aids, segundo faixa etária, estrato do IDH e ano de notificação. Brasil. 1990-1998.

A figura 5 mostra as distribuições percentuais de casos de aids, em cada ano de diagnóstico e por faixas etárias, considerando os estratos de desenvolvimento humano. Os valores absolutos são apresentados na tabela 11 do anexo 2. Pode-se dizer que as distribuições percentuais, que foram geradas pelos estratos de desenvolvimento humano, são homogêneas, ou seja, a incidência de casos entre $30 \mathrm{e}$ 44 anos de idade é predominante, seguida da faixa etária de 15 a 29 anos, independente da classificação de desenvolvimento humano. 

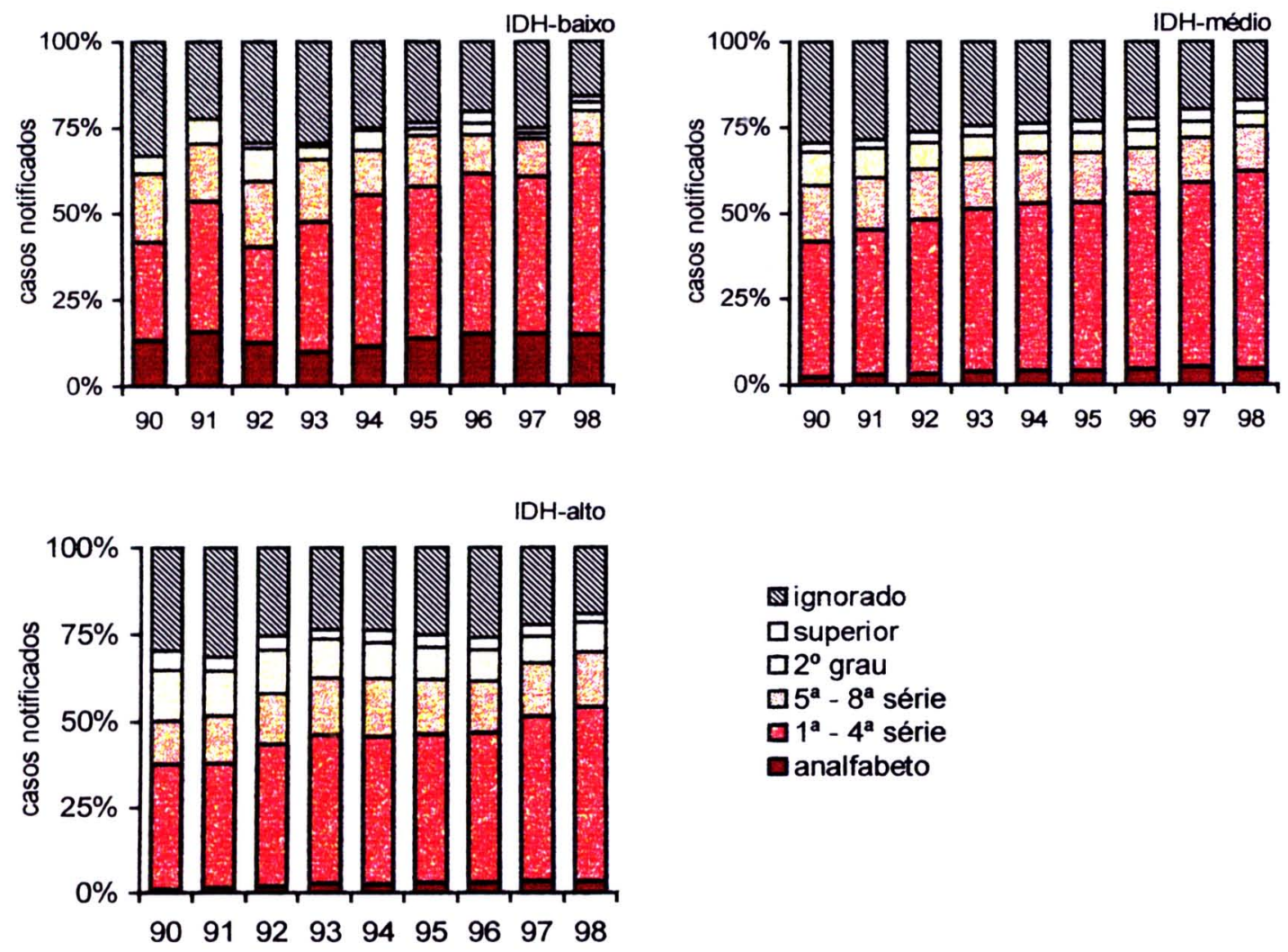

Figura 6 - Distribuição proporcional de casos de aids, segundo escolaridade, estrato do IDH e ano de diagnóstico. Brasil. 1990-1998.

A figura 6 apresenta os resultados relativos dos casos notificados, por ano de diagnóstico e por escolaridade, cujos valores absolutos estão apresentados na tabela 12 do anexo 2. A composição percentual dos padrões de incidência de aids segundo escolaridade é homogênea, para os três estratos de IDH. Observa-se o aumento relativo da escolaridade entre $1^{\mathrm{a}}$ e $4^{\mathrm{a}}$ série do $1^{\circ}$ grau, nos três estratos de IDH. Também há uma parcela expressiva de indivíduos de escolaridade ignorada, mas sugere uma tendência de decréscimo. A parcela de casos de escolaridade analfabeta é mais visível nos municípios do estrato IDH-baixo, que são mais numerosos no Norte e no Nordeste. 
Os casos relacionados à via de transmissão ignorada é de chamar a atenção. Pode-se dizer que o sistema de obtenção de informação falhou em alguma etapa, porque não se conhece outra forma de transmissão, dentro do conhecimento científico vigente. Se for este o caso, o aumento de casos neste grupo pode ser reflexo do descuidado do sistema de coleta de informações. Então, a categoria de exposição ignorado recebeu uma abordagem descritiva à parte, isoladamente. Observa-se, na tabela 3, o fenômeno de feminização, com o declínio da razão de sexo, por ano de diagnóstico, sendo homogênea nos estratos de IDH.

Tabela 3 - Distribuição de casos de aids da categoria de exposição ignorada, segundo sexo, estrato do IDH e ano de diagnóstico. Brasil. 1990-1998.

\begin{tabular}{r|c|rrrrrrrrr}
\hline IDH & sexo & 1990 & 1991 & 1992 & 1993 & 1994 & 1995 & 1996 & 1997 & 1998 \\
\hline \multirow{4}{*}{ baixo } & masc & 21 & 30 & 55 & 57 & 50 & 75 & 96 & 137 & 82 \\
& fem & 5 & 14 & 11 & 15 & 15 & 23 & 33 & 56 & 47 \\
\cline { 2 - 10 } médio & ${ }^{*}$ m:f & 4,2 & 2,1 & 5,0 & 3,8 & 3,3 & 3,3 & 2,9 & 2,4 & 1,7 \\
\hline \multirow{5}{*}{ alto } & masc & 479 & 681 & 946 & 1159 & 1394 & 1698 & 1960 & 1788 & 1314 \\
& fem & 113 & 213 & 300 & 398 & 533 & 654 & 841 & 980 & 680 \\
\cline { 2 - 11 } & m:f & 4,2 & 3,2 & 3,2 & 2,9 & 2,6 & 2,6 & 2,3 & 1,8 & 1,9 \\
\hline \multirow{4}{*}{ total } & masc & 950 & 988 & 1332 & 1661 & 1952 & 2296 & 2548 & 2321 & 1721 \\
& fem & 186 & 284 & 344 & 523 & 644 & 857 & 979 & 1063 & 887 \\
& m:f & 5,1 & 3,5 & 3,9 & 3,2 & 3,0 & 2,7 & 2,6 & 2,2 & 1,9 \\
\hline & masc & 1450 & 1699 & 2333 & 2877 & 3396 & 4060 & 4604 & 4246 & 3117 \\
& fem & 304 & 511 & 655 & 936 & 1192 & 1534 & 1853 & 2099 & 1614 \\
\hline & m:f & 4,8 & 3,3 & 3,6 & 3,1 & 2,8 & 2,6 & 2,5 & 2,0 & 1,9 \\
\hline
\end{tabular}

* m:f - é a razão de sexo 

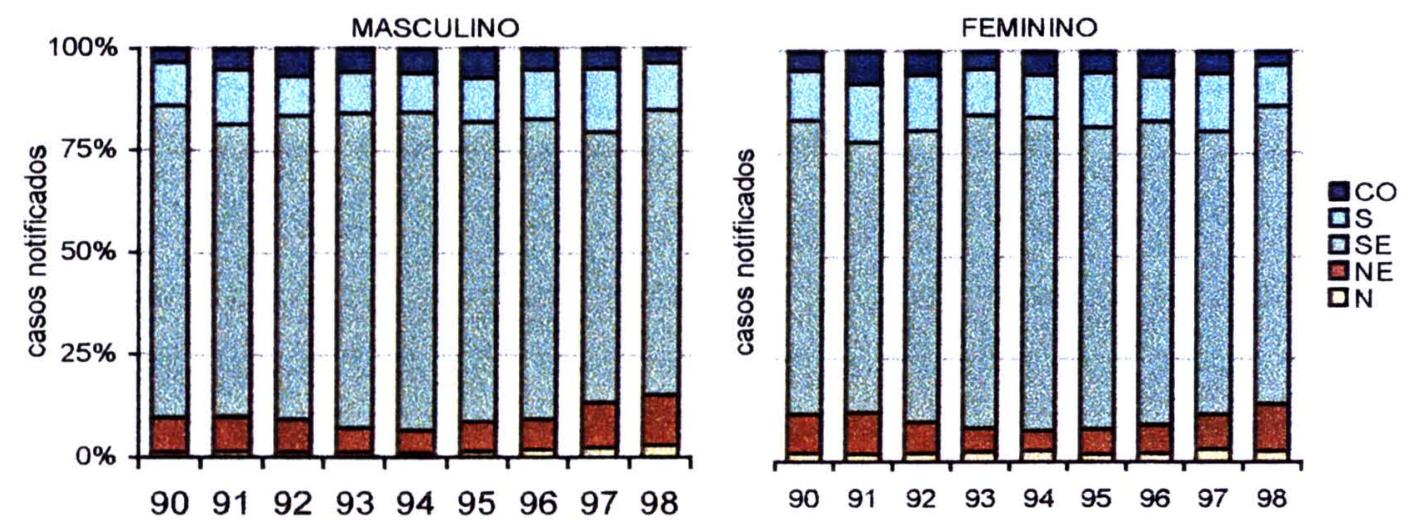

Figura 7 - Distribuição proporcional de casos de aids da categoria de exposição ignorada segundo sexo, macro-região e ano de diagnóstico. Brasil. 1990-1998.

As distribuições de freqüências relativas de casos masculinos e femininos, por região e por ano, são apresentadas na figura 7, cujos valores absolutos estão na tabela 13 do anexo 2 , sugerindo uma homogeneidade de padrões de incidência de casos da categoria de exposição ignorada, por macro-região e ao longo do tempo estudado.
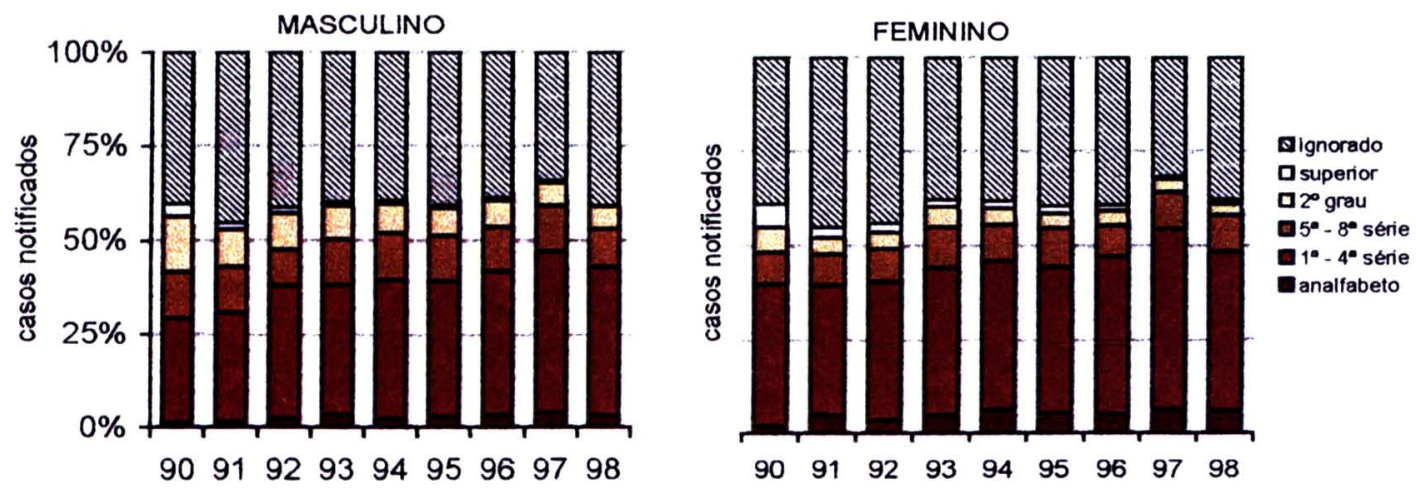

Figura 8 - Distribuição proporcional de casos de aids da categoria de exposição ignorada, segundo sexo, escolaridade e ano de diagnóstico. Brasil. 1990-1998. 
A figura 8 mostra a incidência de notificações da categoria ignorada, para ambos os sexos, em relação à escolaridade. A parcela de escolaridade ignorada, dentro da categoria de exposição ignorada, pode sugerir falha de preenchimento da ficha de notificação. A figura também mostra haver uma homogeneidade de composição do número de casos relativos entre sexos, cujos valores estão na tabela 14 do anexo 2.
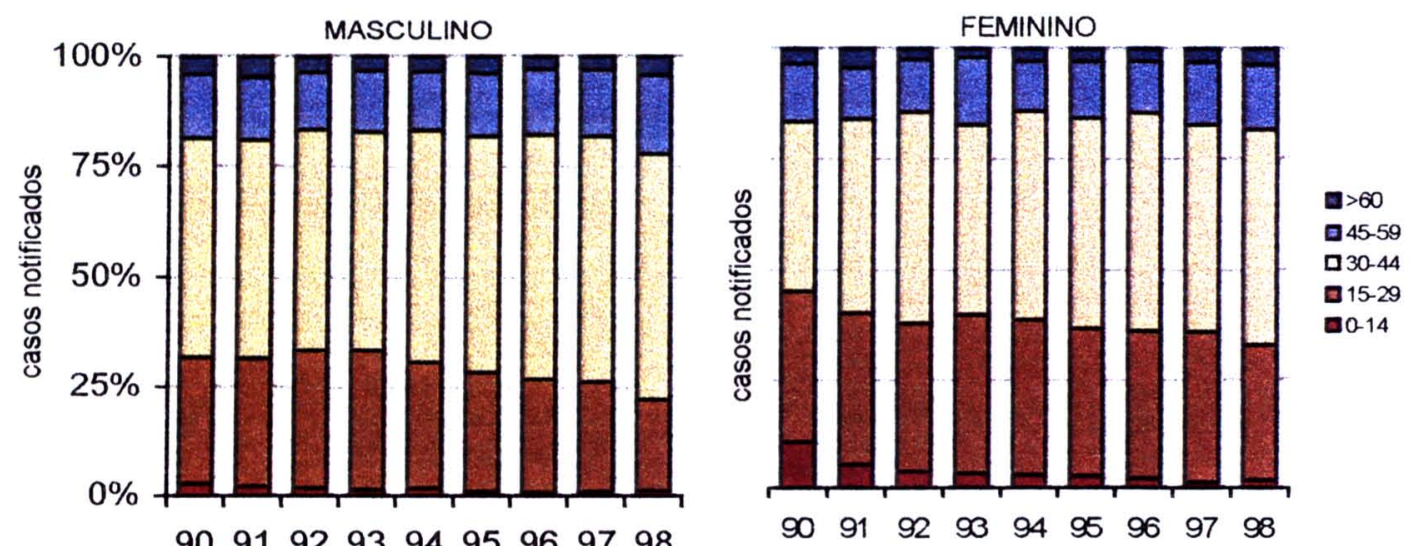

Figura 9 - Distribuição proporcional de casos de aids da categoria de exposição ignorada, segundo sexo, faixa etária e ano de diagnóstico. Brasil. 1990-1998.

A figura 9, cujos valores absolutos estão na tabela 15 do anexo 2 , mostra a homogeneidade entre os padrões de casos notificados na categoria ignorada para ambos os sexos.

\section{Média de Estimadores CuSum}

A distribuição de frequêencia dos valores originais do índice proposto é assimétrica, sendo concentrada à esquerda próximo a zero, devido à baixa incidência de casos em muitos municípios. Essa distribuição foi comparada à distribuição lognormal, pelo teste de Shapiro-Wiks, e rejeitou a hipótese nula com um nível de 
significância descritivo menor que 0,0001 ( $w=0,51)$. Assim, adotpu-se a distribuição de freqüências observadas. $O$ estudo descritivo utilizou os valores mínimo, $1^{\circ}$ quartil, $2^{\circ}$ quartil, $3^{\circ}$ quartil e máximo, para ilustrar a assimetria da distribuição, cujos valores são: 0,$0000 ; 0,0044 ; 0,0112 ; 0,0213$ e 1,0000 , respectivamente. Vale lembrar que os valores mínimo e o máximo possíveis são zero e um A figura 10 apresenta a distribuição de freqüência relativa do logarítmo do índice proposto, onde foram posicionadas linhas verticais relativas aos quantís $5 \%, 25 \%, 50 \%, 75 \%$ e $95 \%$, que ajudaram a localizar as porções superior com maior incidência de aids, a mediana e a distância interquartís. Estes pontos permitem avaliar, visualmente, as medidas exploratórias de posição e de variação. Destacou-se a área correspondente aos valores do índice proposto mais altos.

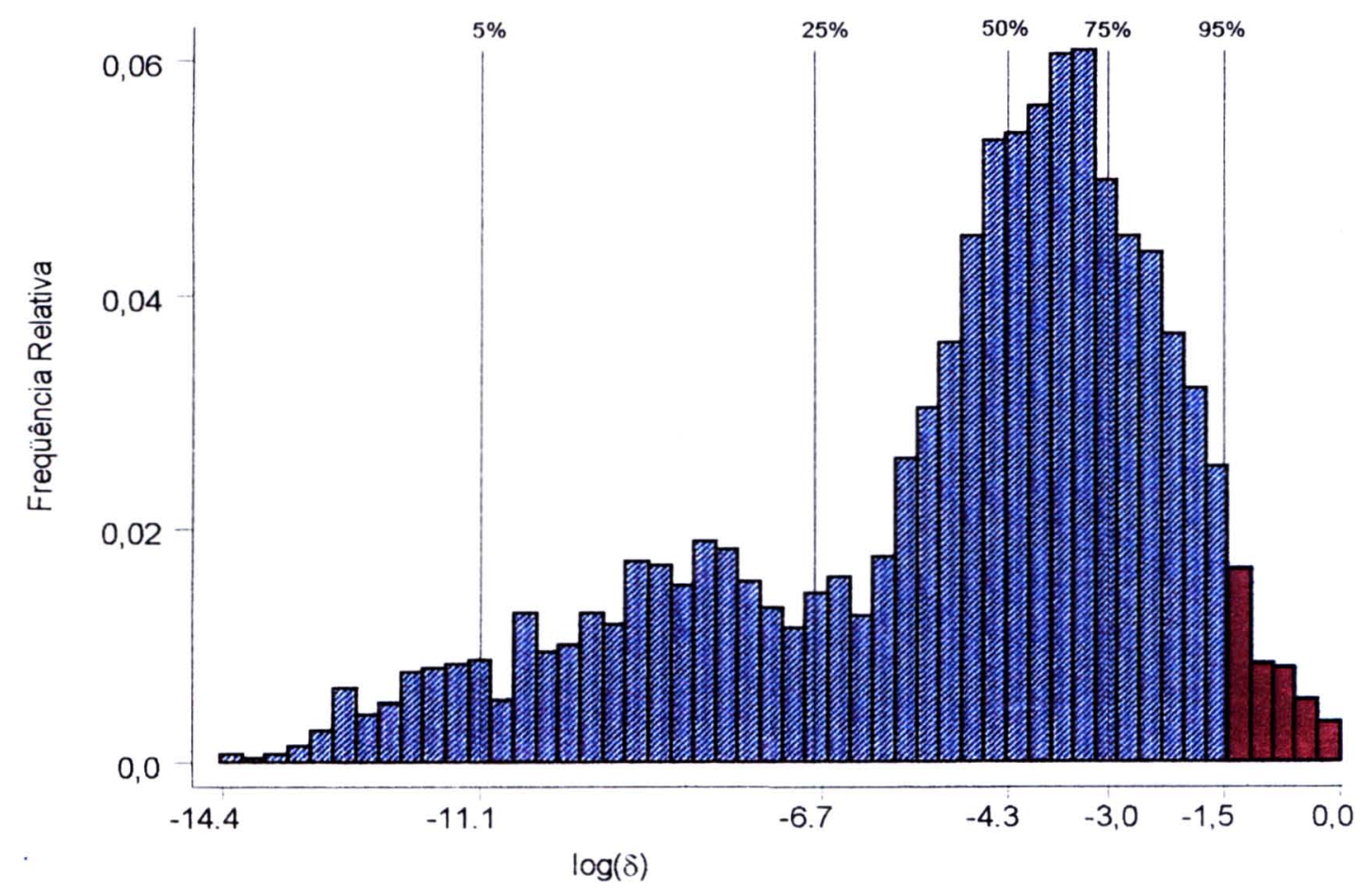

Figura 10 - Distribuição percentual dos valores observados do índice proposto, em escala logarítmica. Brasil. 1990-1998. 
O diagrama que dispõe os pontos coordenados do logarítmo do índice proposto e o IDH possibilita observar a dispersão dos valores de incidência de aids e os estratos de desenvolvimento humano, dados pelo IDH, que referencia os valores 0,5 e 0,8 como divisores para a estratificação em "desenvolvimento humano baixo" (abaixo de 0,5 ), "desenvolvimento humano médio" (entre 0,5 e 0,8 ) e "desenvolvimento humano alto" (acima de 0,8). Desta forma, as figuras 11, 12, 13, 14 e 15 permitem visualizar a dispersão dos pontos, nas cinco regiões brasileiras.

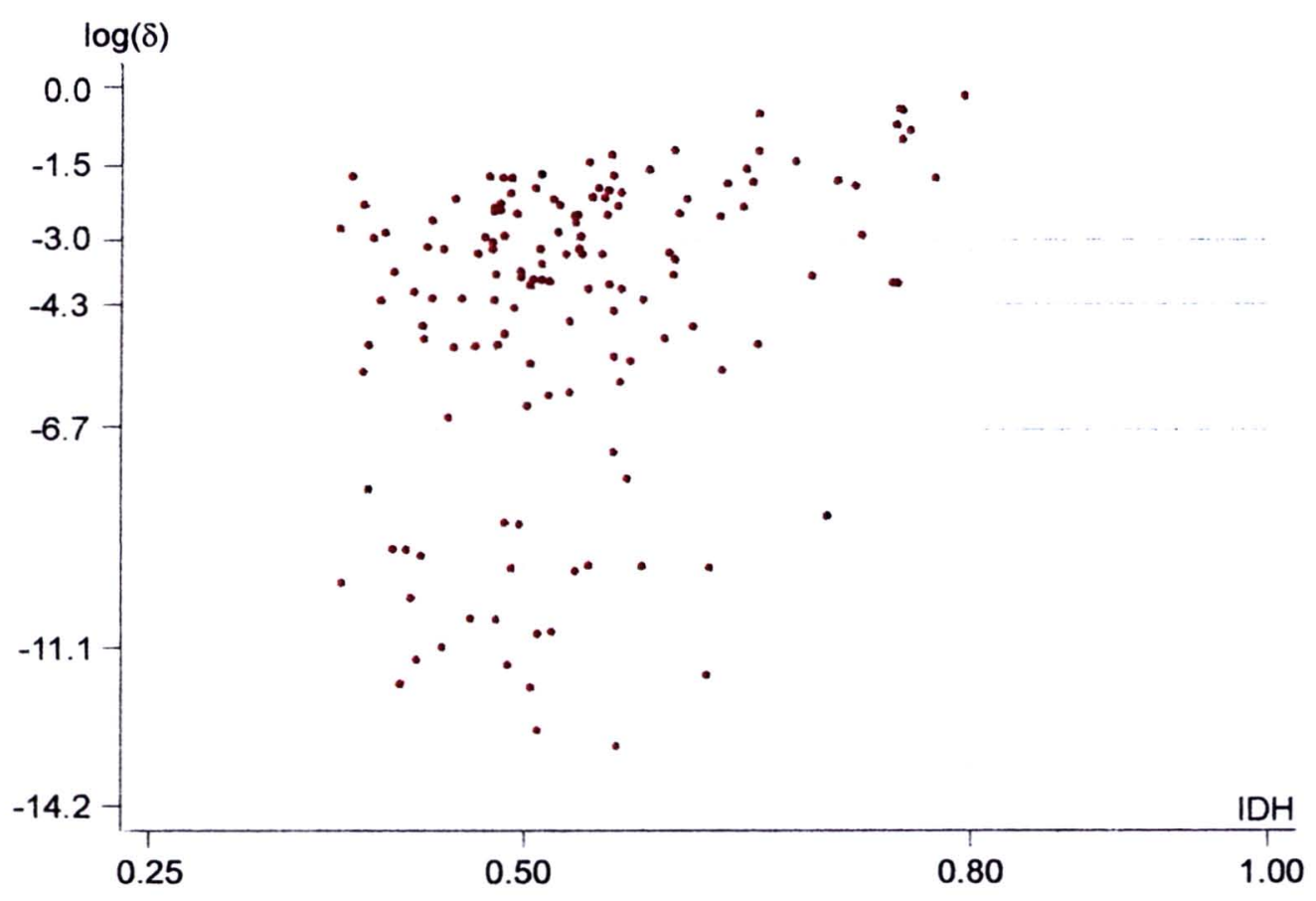

Figura 11 - Distribuição dos pares coordenados do logarítmo do índice proposto e do IDH, para a região norte. Brasil 1990-1998.

A figura 11 mostra a concentração de municípios do estrato de desenvolvimento humano baixo, na região norte, associando-os à medida de incidência da epidemia 
(média de estimadores CuSum). Há duas coleções de municípios alta incidência de aids: um do estrato IDH-baixo e outro do estrato IDH-médio.

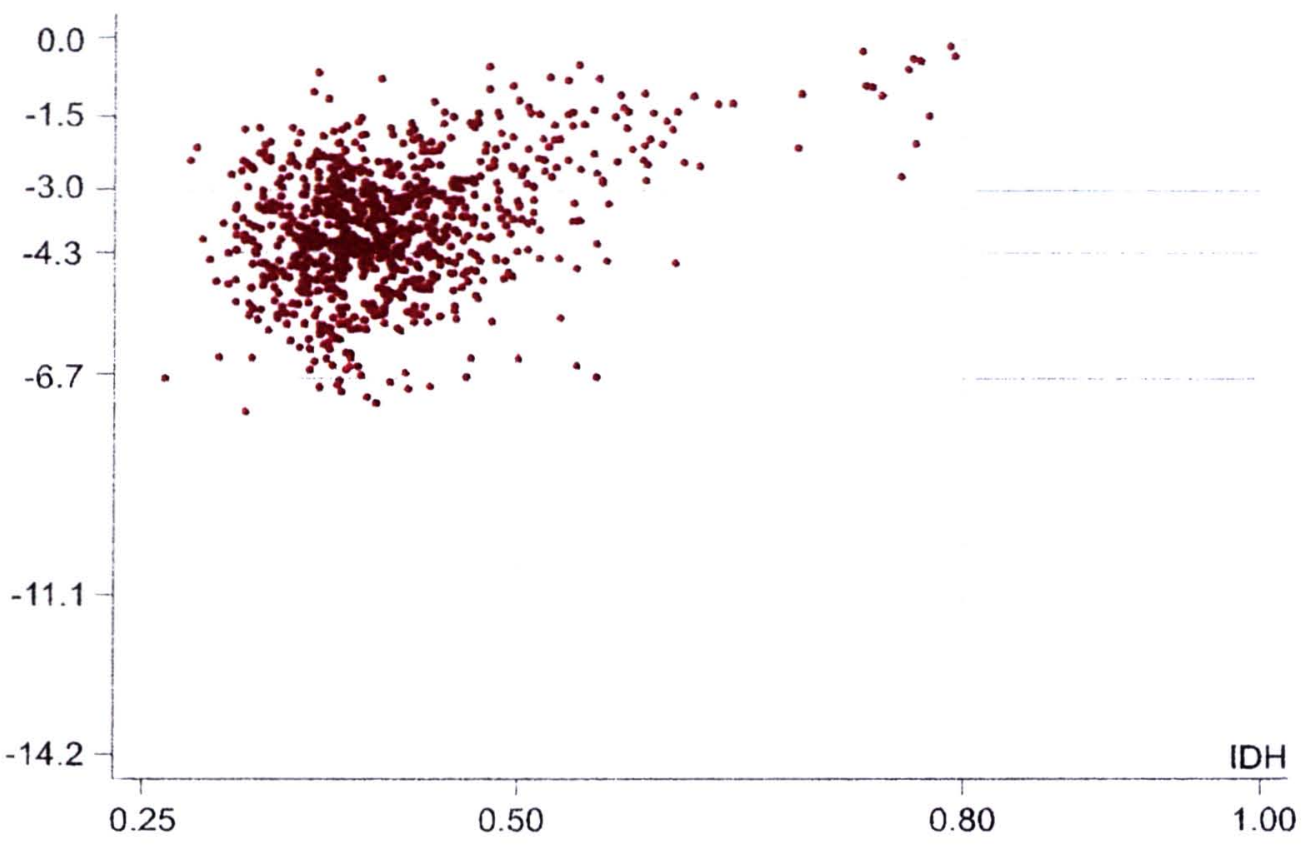

Figura 12 - Distribuição dos pares coordenados do logaritmo do índice proposto e do IDH, para a região nordeste. Brasil 1990-1998. 


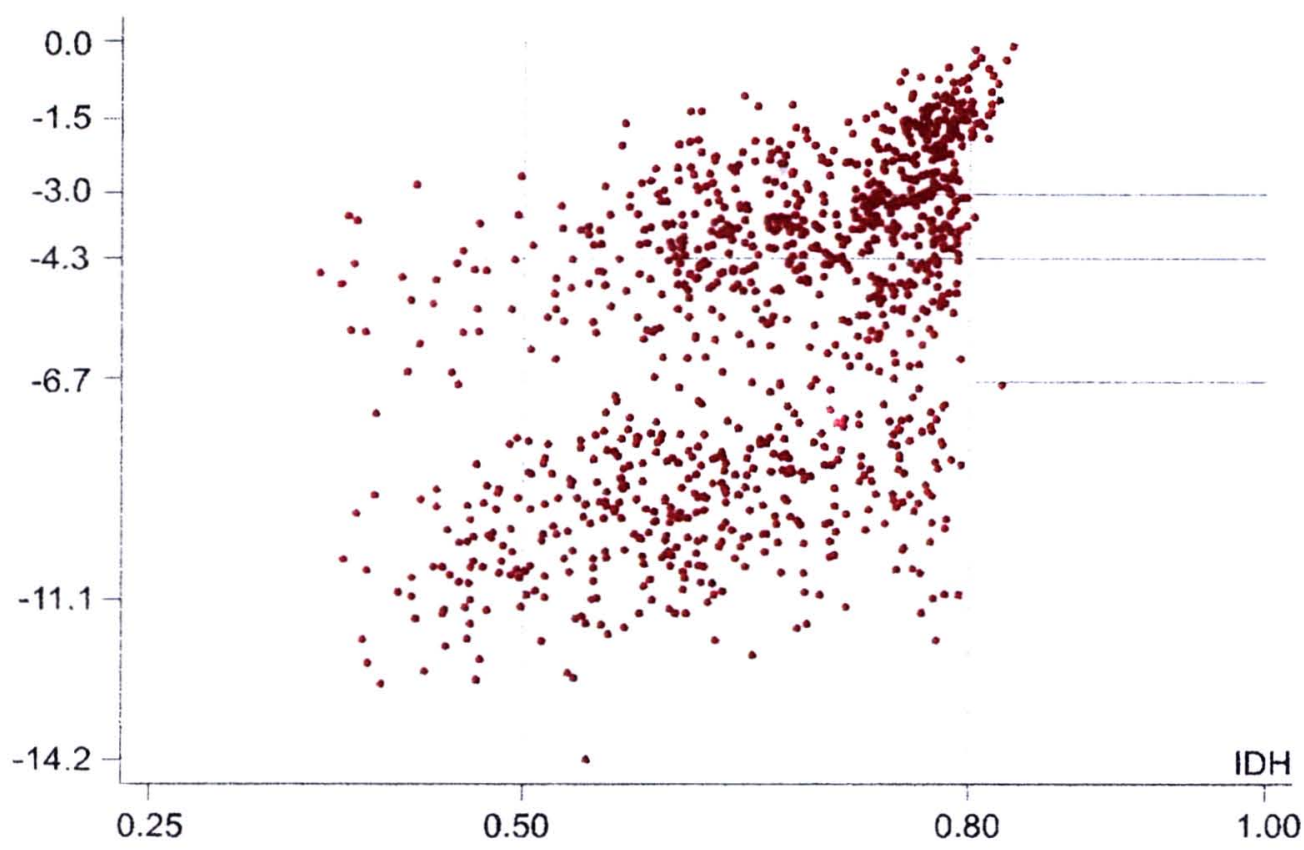

Figura 13 - Distribuição dos pares coordenados do logarítmo do índice proposto e do IDH, para a região sudeste. Brasil 1990-1998.

A figura 12 mostra a dispersão da medida proposta, segundo estratos de IDH, na região nordeste. Observa-se que o estrato de baixo desenvolvimento humano é predominante, apresentando alta incidência de aids.

A figura 13 mostra a dispersão da medida proposta e o IDH, para a região sudeste. A característica da epidemia aqui é ser composta por municípios de maior desenvolvimento humano que as regiões norte e nordeste. $O$ mesmo se observa para as regiões sul e centro-oeste, nas figuras 14 e 15 . Não se quer dizer que a aids, no sul e no sudeste, não acometa a camada mais desfavorecida da população, mas que o perfil socioeconômico dos municípios é diferente. Estas são regiōes que concentram os recursos capitais, fazendo com que o IDH seja mais alto. 


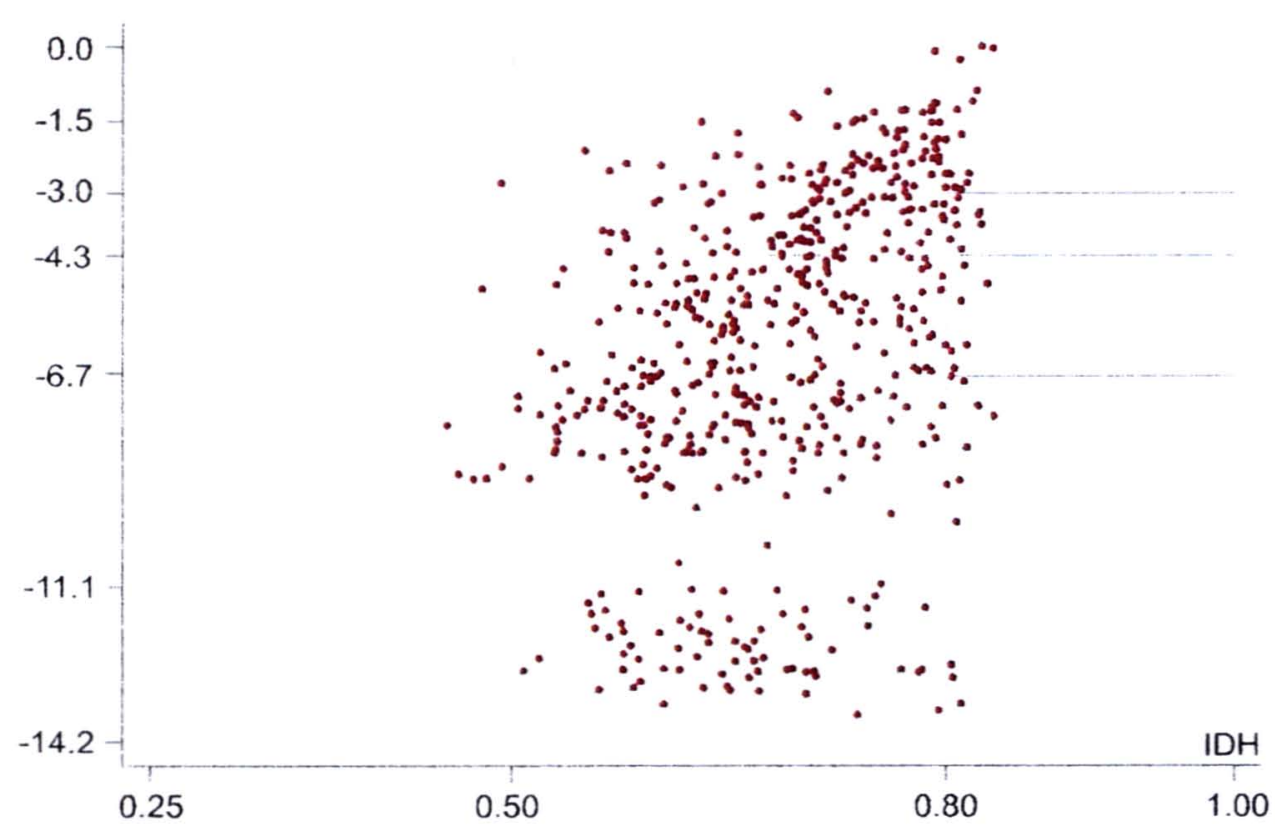

Figura 14 - Distribuição dos pares coordenados do logarítmo do índice proposto e do IDH, para a região sul. Brasil 1990-1998.

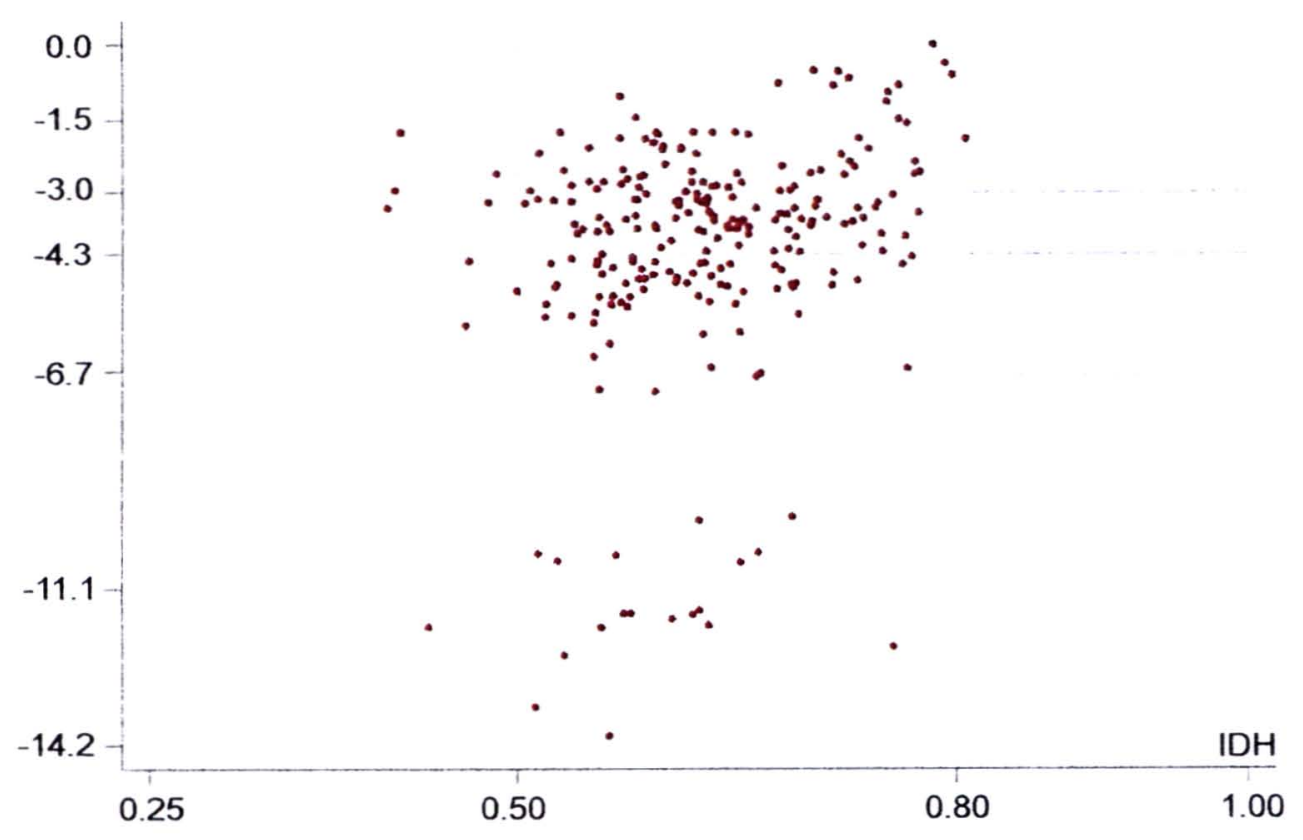

Figura 15 - Distribuição dos pares coordenados do logarítmo do índice proposto e do IDH, para a região centro-oeste. Brasil 1990-1998. 
A tabela 4 apresenta os resultados dos estudos de correlação feitos entre o índice proposto e o IDH. O coeficiente de correlação geral entre o IDH e o índice foi de 0,2136. Quando foram consideradas as regiões separadamente, o índice proposto mostrou uma maior correlação em relação aos componentes "renda" e "educação" do IDH. O estudo de correlação entre os componentes "renda" e "educação" do IDH e os componentes do índice proposto mostraram: no Norte, o maior valor do coeficiente de correlação foi observado em relação ao componente "heterossexual", sendo 0,4445 e 0,3863 , respectivamente; no Nordeste, em relação ao componente "ignorado", sendo 0,4919 e 0,4078 ; no Sudeste, em relação ao componentes "homossexual" $(0,3448)$ e "heterossexual" $(0,4177)$; no Sul, em relação ao componentes "ignorado", sendo 0,2739 e 0,2855 , respectivamente; e, no CentroOeste, em relação ao componente “ignorado", sendo 0,2268 e 0,3031 , respectivamente. 
Tabela 4 - Cocficientes de correlação entre IDH e o índice proposto, segundo macroregião, e as correlações entre as categoria de exposição ao HIV e os componentes do IDH. Brasil. 1990-1998.

\begin{tabular}{|c|c|c|c|c|c|}
\hline REGIÃO & COMPONENTE & LONGEVIDADE & EDUCAÇĀO & RENDA & IDH \\
\hline \multirow[t]{2}{*}{ NORTE } & $\begin{array}{c}\text { Hemofilico } \\
\text { Heterossexual } \\
\text { homossexual } \\
\text { Udi } \\
\text { Vertical } \\
\text { Ignorado }\end{array}$ & $\begin{array}{r}-0,0416 \\
0,0432 \\
0,0521 \\
0,0121 \\
-0,0308 \\
0,1218\end{array}$ & $\begin{array}{l}* 0,1998 \\
* 0,3863 \\
* 0,3777 \\
* 0,3077 \\
* 0,1835 \\
0,2456\end{array}$ & $\begin{array}{l}* 0,2328 \\
* 0,4445 \\
* 0,4227 \\
* 0,3753 \\
* 0,1914 \\
* 0,3431\end{array}$ & $\begin{array}{l}* 0,2350 \\
* 0,4685 \\
* 0,4509 \\
* 0,3854 \\
* 0,1995 \\
* 0,3569\end{array}$ \\
\hline & indice proposto & 0,0437 & $* 0,4437$ & $\star 0,5255$ & * 0,5481 \\
\hline \multirow[t]{2}{*}{ NORDESTE } & $\begin{array}{c}\text { Hemofilico } \\
\text { Heterossexual } \\
\text { homossexual } \\
\text { Udi } \\
\text { Vertical } \\
\text { Ignorado }\end{array}$ & $\begin{array}{l}* 0,1043 \\
* 0,1499 \\
* 0,1256 \\
* 0,1216 \\
* 0,1168 \\
* 0,1389\end{array}$ & $\begin{array}{l}* 0,2733 \\
* 0,4039 \\
* 0,2659 \\
\star 0,2789 \\
* 0,2772 \\
* 0,4078\end{array}$ & $\begin{array}{l}* 0,3314 \\
* 0,4674 \\
* 0,2647 \\
* 0,3610 \\
* 0,3430 \\
* 0,4919\end{array}$ & $\begin{array}{l}* 0,3207 \\
* 0,4602 \\
* 0,2850 \\
* 0,3440 \\
* 0,3315 \\
* 0,4731\end{array}$ \\
\hline & indice proposto & * 0,1869 & 0,4730 & * 0,5550 & 0,5460 \\
\hline \multirow[t]{2}{*}{ SUDESTE } & $\begin{array}{c}\text { Hemofilico } \\
\text { Heterossexual } \\
\text { homossexual } \\
\text { Udi } \\
\text { Vertical } \\
\text { Ignorado }\end{array}$ & $\begin{array}{l}* 0,0692 \\
* 0,1435 \\
* 0,1173 \\
* 0,1370 \\
* 0,0910 \\
0,0299\end{array}$ & $\begin{array}{l}* 0,3246 \\
* 0,3682 \\
* 0,4177 \\
* 0,3365 \\
* 0,3300 \\
* 0,3085\end{array}$ & $\begin{array}{l}* 0,2458 \\
* 0,3178 \\
* 0,3448 \\
* 0,3199 \\
* 0,2835 \\
* 0,2340\end{array}$ & $\begin{array}{l}* 0,2670 \\
* 0,3402 \\
* 0,3682 \\
* 0,3334 \\
* 0,2987 \\
* 0,2491\end{array}$ \\
\hline & indice proposto & $\star 0,1279$ & * 0,4389 & * 0,3698 & * 0,3930 \\
\hline \multirow[t]{2}{*}{ SUL } & $\begin{array}{c}\text { Hemofilico } \\
\text { Heterossexual } \\
\text { homossexual } \\
\text { Udi } \\
\text { Vertical } \\
\text { Ignorado }\end{array}$ & $\begin{array}{l}0,0083 \\
0,0273 \\
0,0316 \\
0,0214 \\
0,0080 \\
0,0361\end{array}$ & $\begin{array}{l}* 0,2581 \\
* 0,2720 \\
* 0,3139 \\
* 0,2125 \\
* 0,2634 \\
* 0,2855\end{array}$ & $\begin{array}{l}* 0,2253 \\
* 0,2531 \\
* 0,2712 \\
* 0,2008 \\
* 0,2304 \\
* 0,2739\end{array}$ & $\begin{array}{l}* 0,2330 \\
* 0,2608 \\
* 0,2852 \\
* 0,2058 \\
* 0,2383 \\
* 0,2810\end{array}$ \\
\hline & indice proposto & 0,0282 & * 0,3357 & 0,3048 & $\star 0,3150$ \\
\hline \multirow[t]{2}{*}{$\begin{array}{l}\text { CENTRO- } \\
\text {-OESTE }\end{array}$} & $\begin{array}{c}\text { Hemofilico } \\
\text { Heterossexual } \\
\text { homossexual } \\
\text { Udi } \\
\text { Vertical } \\
\text { Ignorado }\end{array}$ & $\begin{array}{r}0,0752 \\
* 0,1506 \\
0,1136 \\
\star 0,1908 \\
0,0806 \\
0,1199\end{array}$ & $\begin{array}{l}* 0,2356 \\
* 0,2520 \\
* 0,2851 \\
* 0,1801 \\
* 0,2584 \\
* 0,3031\end{array}$ & $\begin{array}{l}* 0,1619 \\
* 0,1668 \\
* 0,2045 \\
0,0854 \\
* 0,2206 \\
* 0,2268\end{array}$ & $\begin{array}{l}* 0,1983 \\
* 0,2183 \\
* 0,2506 \\
* 0,1428 \\
* 0,2509 \\
* 0,2738\end{array}$ \\
\hline & indice proposto & * 0.1767 & * 0.3611 & * 0.2537 & $* 0.3183$ \\
\hline
\end{tabular}

* resultados significantes $(\alpha=0,05)$ 
As médias de estimadores CuSum por categoria de exposição foram usadas na construção de mapa temático de incidência de aids no Brasil. Da mesma forma, construiu-se o mapa temático de risco relativo, para se ter uma referência do uso do índice proposto. Estes mapas correspondem às figuras $16 \mathrm{e} 17$.

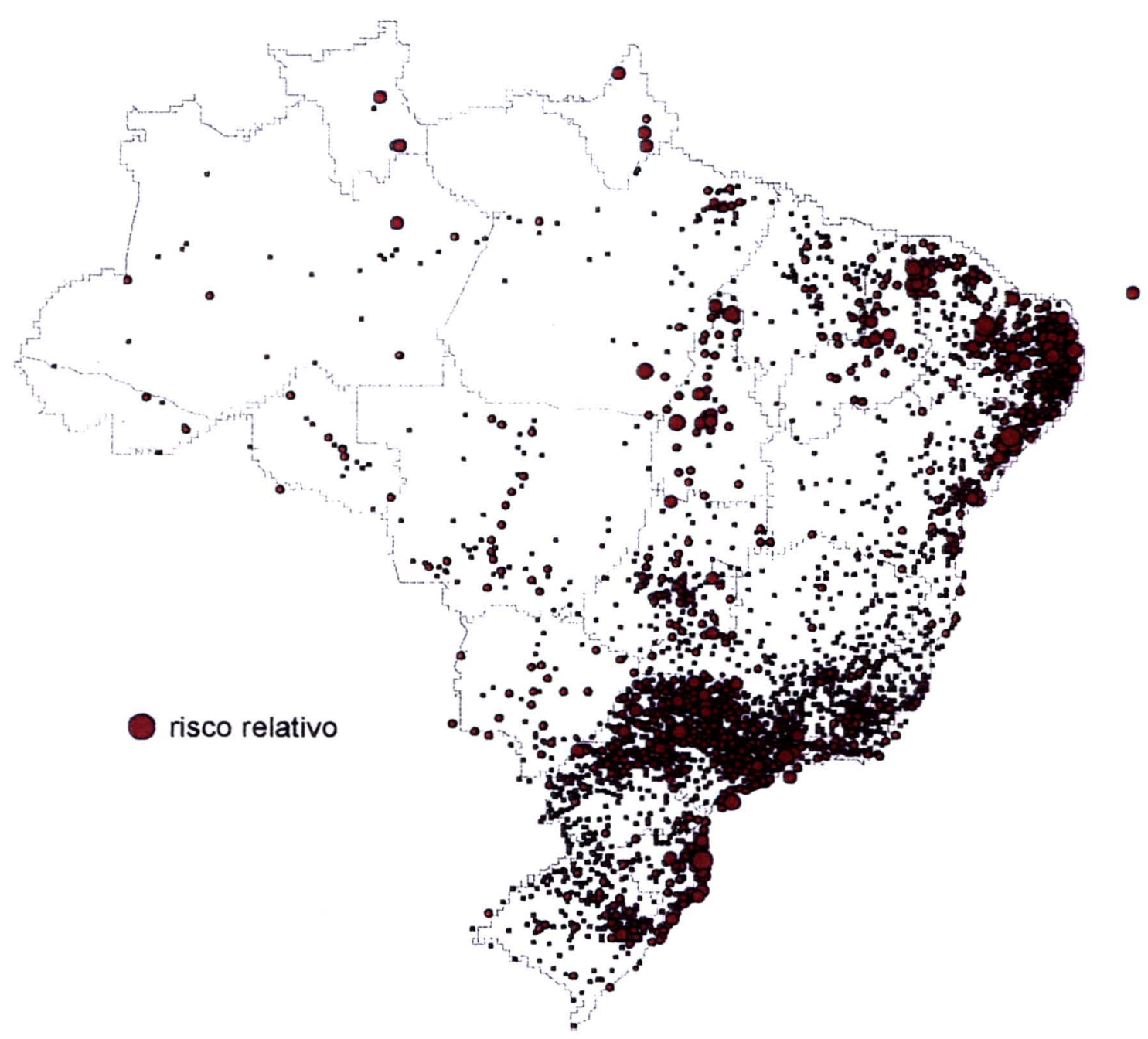

Figura 16 - Mapa temático da distribuição espacial do risco relativo da epidemia de aids. Brasil 1990-1998. 


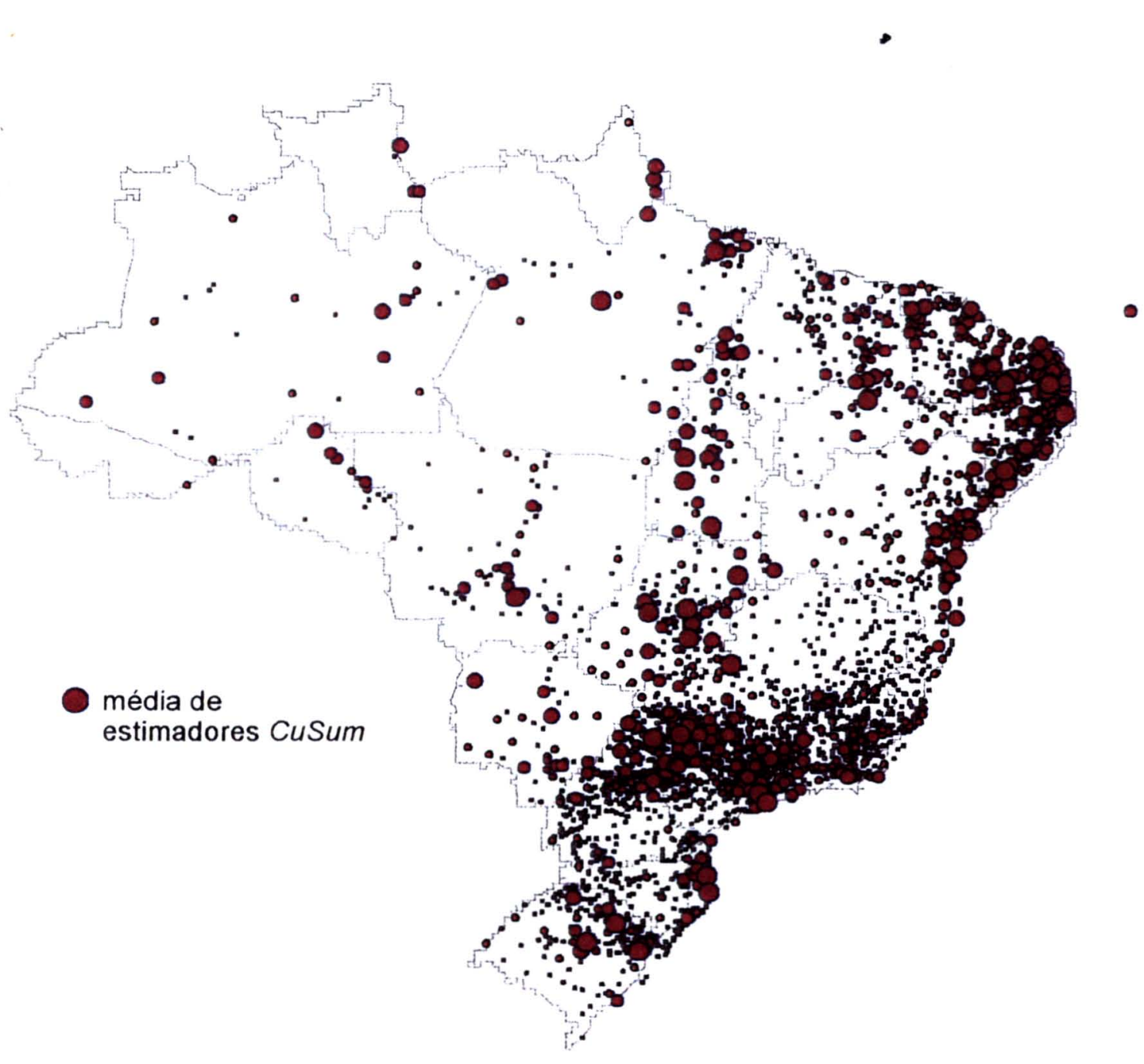

Figura 17 - Mapa temático da distribuição espacial da média dos estimadores CuSum da epidemia de aids. Brasil 1990-1998.

\section{Geografia da Aids no Brasil}

Usando a distribuição de freqüências do índice proposto que gerou da figura 10, foram consideradas áreas de alta incidência de aids as localidades cuja medida era igual ou superior a 0,2099 . Este valor divide o conjunto de dados em $95 \%$ abaixo e $5 \%$ acima, sugerindo o ponto de corte para as áreas de estudo. Assim, o anexo 3 apresenta o nome das localidades que integram esses $5 \%$ de maior atividade de 
notificação, divididos pelo tamanho da população em 1996, em ordem crescente da medida do índice

O mapeamento da distribuição da aids no segmento estudado é apresentado nas figuras $11,12,13,14$ e 15, respeitando a divisão por região. Os valores do índice proposto foi divididos em quartís ( $25 \%, 50 \%$ e $75 \%)$. Os municípios onde não houve notificação de caso de aids apresecem em branco nas figuras.

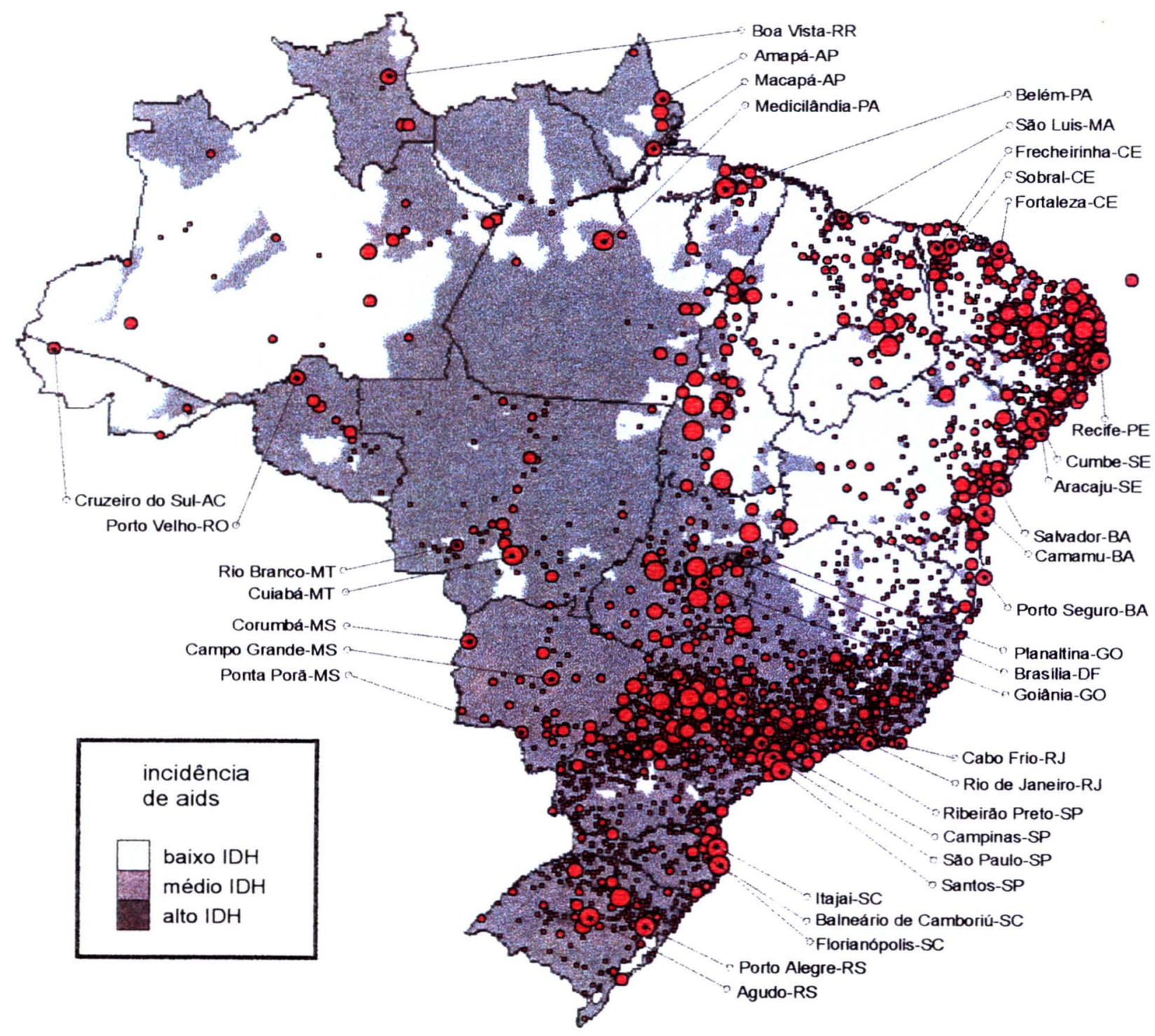

Figura 18 - Mapa temático da distribuição espacial da média dos estimadores CuSum da epidemia de aids e dos estratos de IDH. Brasil 1990-1998. 


\section{Estado de São Paulo}

A figura 19 apresenta a evolução proporcional das sub-epidemias, no Estado de São Paulo, de 1990 a 1998, cujos números absolutos encontram-se na tabela 16 do anexo 2. Observa-se: (a) aumento proporcional de casos da categoria heterossexual; (b) decréscimo proporcional de casos das categorias homossexual, UDI e hemofilia. $\mathrm{O}$ perfil da epidemia no Estado de São Paulo assemelha-se ao apresentado na figura 3, para o estrato de alto desenvolvimento humano. A tabela 5 apresenta a série histórica da razão de sexo para o Estado de São Paulo no período de 1990 a 1998 . Observa-se, em 1998, uma razão de sexo menor que a do Brasil (tabela 2), refletindo a maior incidência de casos do sexo feminino.

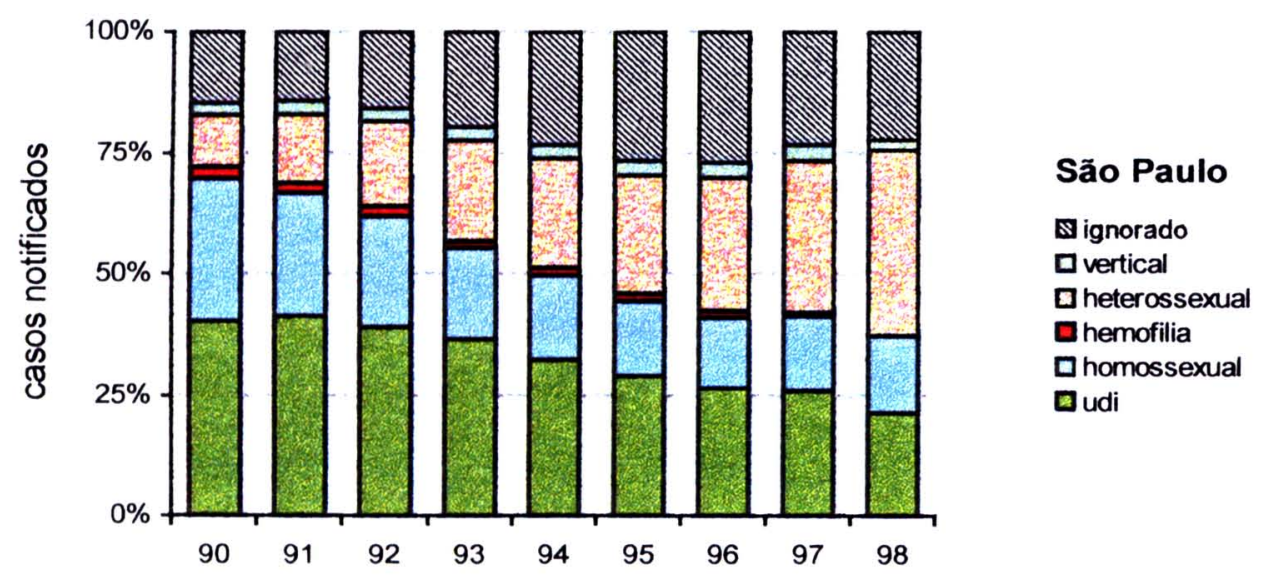

Figura 19 - Distribuição proporcional de casos de aids, segundo categoriade exposição e ano de diagnóstico. São Paulo. 1990-1998.

Tabela 5 - Distribuição de casos de aids segundo sexo e ano de notificação. São Paulo. 1990-1998.

\begin{tabular}{c|rrrrrrrrr}
\hline sexo & 1990 & 1991 & 1992 & 1993 & 1994 & 1995 & 1996 & 1997 & 1998 \\
\hline masc & 4197 & 5334 & 6417 & 6724 & 6827 & 7103 & 7404 & 6460 & 5413 \\
fem & 768 & 1153 & 1652 & 1923 & 2088 & 2509 & 2963 & 2954 & 2794 \\
\hline${ }^{*}$ m:f & 5,5 & 4,6 & 3,9 & 3,5 & 3,3 & 2,8 & 2,5 & 2,2 & 1,9 \\
\hline
\end{tabular}

* m:f - é a razão de sexo 
Pela análise do conteúdo da figura 20 , identifica-se um aumento proporcional de casos da faixa etária entre 30 e 44 anos, cujos números absolutos encontram-se na tabela 17 do anexo 2. Este padrão não difere visualmente daquele apresentado na figura 5 para os estratos médio e alto desenvolvimento humano. $\mathrm{O}$ padrão de escolaridade dos casos notificados no Estado de São Paulo é semelhante ao apresentado na figura 6, para os estratos médio e alto desenvolvimento humano e é mostrado pela figura 21 , cujos números absolutos estão na tabela 18 do anexo 2 .

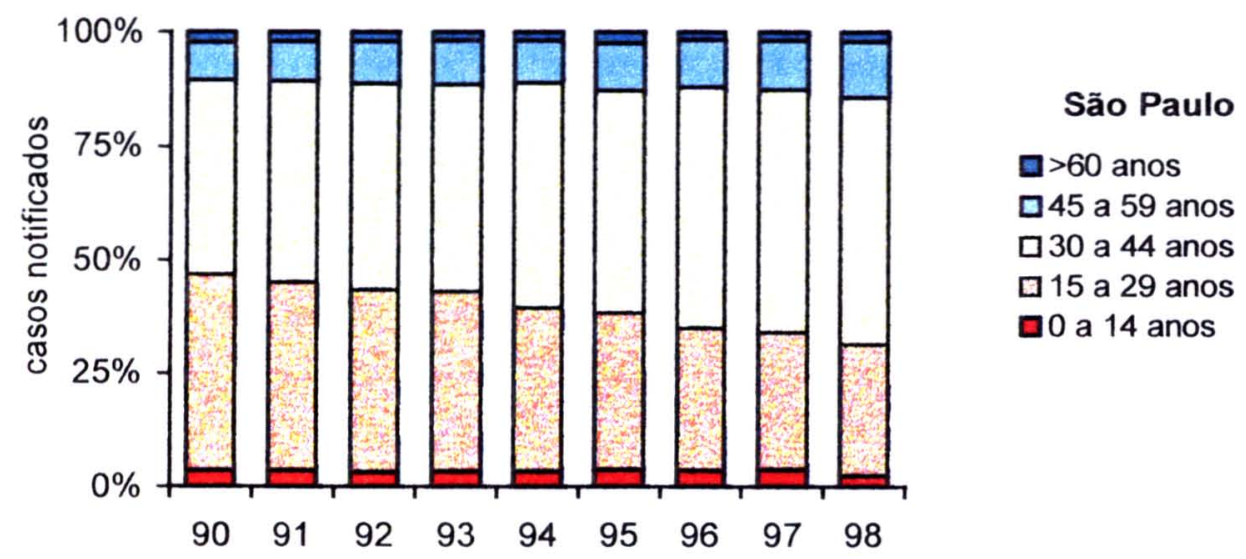

Figura 20 - Distribuição proporcional de casos de aids, segundo faixa etária e ano de diagnóstico. São Paulo. 1990-1998.

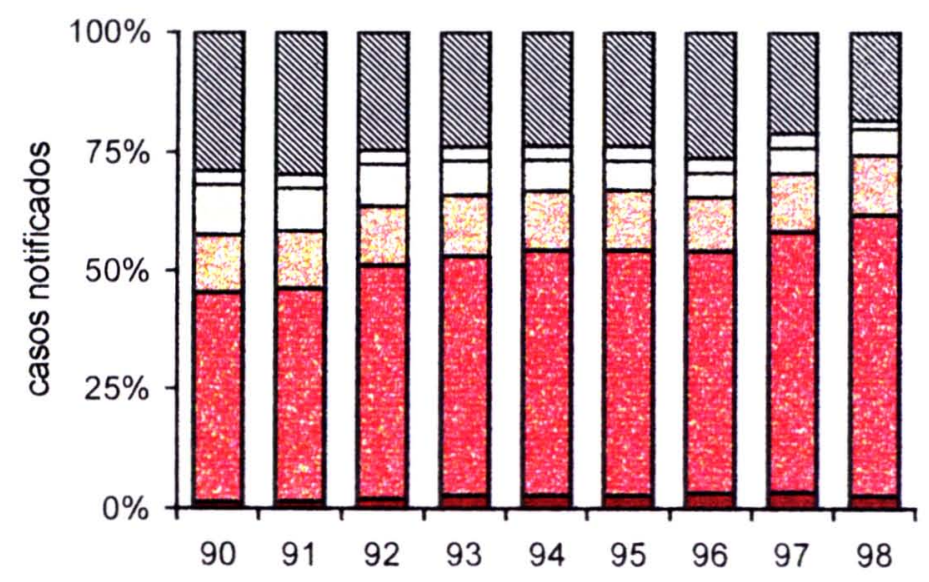

\section{São Paulo}

Qignorado

口superior

$\square 2^{\circ}$ grau

$\square 5^{a}-8^{a}$ série

$\square 1^{a}-4^{a}$ série

aanalfabeto

Figura 21 - Distribuição proporcional de casos de aids, segundo escolaridade e ano de diagnóstico. São Paulo. 1990-1998. 
A figura 22 contempla um mapa temático (estado de São Paulo) da distruição espacial do índice proposto e dos estratos de desenvolvimento humano, podendo ser observado que as áreas de maior incidência de aids encontram-se difusas, partindo do litoral e capital e passando por municípios comercialmente importantes a oeste.

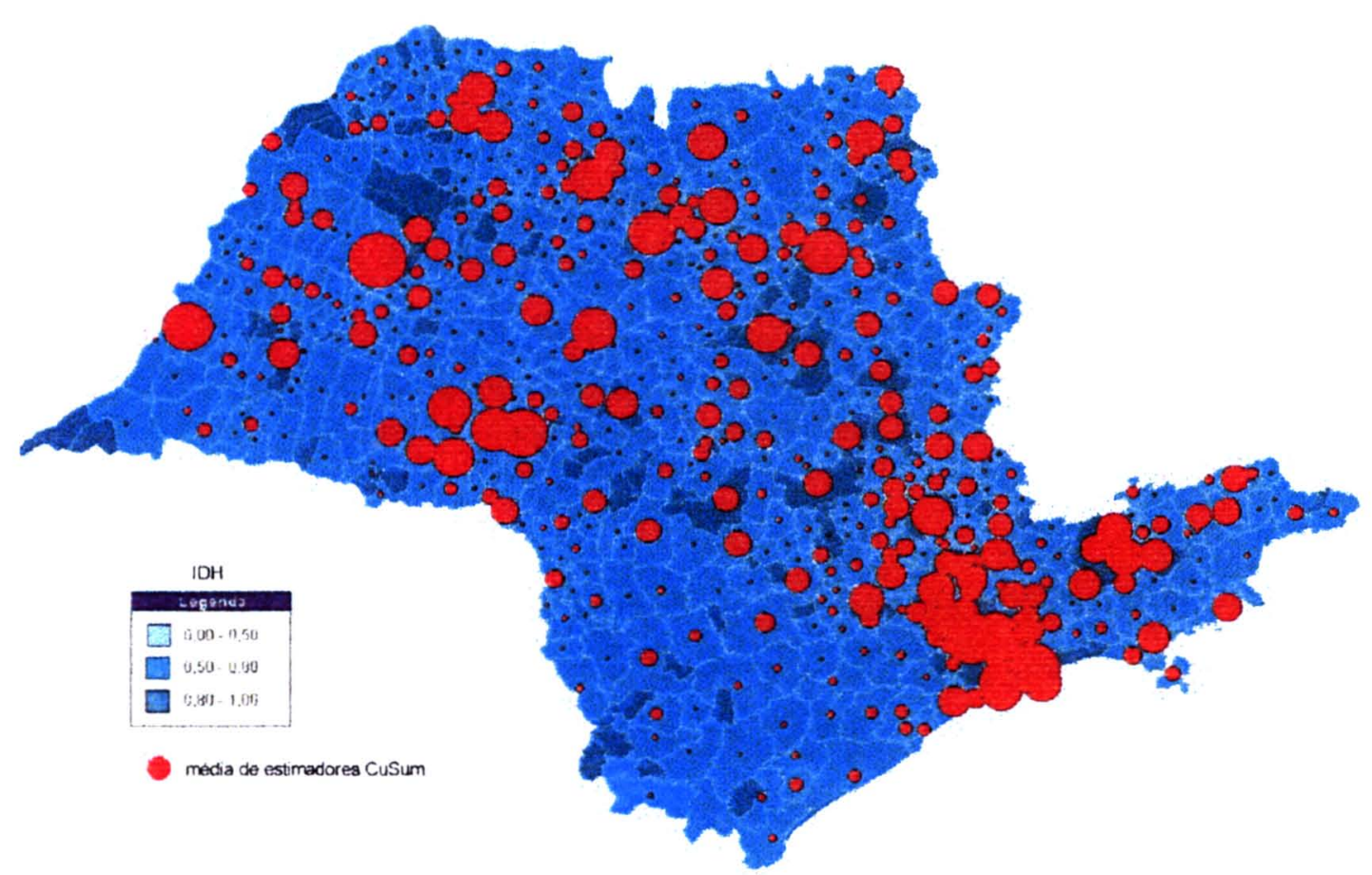

Figura 22 - Mapa temático da distribuição espacial da média dos estimadores CuSum da epidemia de aids e dos estratos de IDH. São Paulo 1990-1998.

\section{Estado de Pernambuco}

A figura 23 apresenta o padrão de incidência de aids em Pernambuco, no período estudado, destacando a proporção de casos referente à categoria de transmissão homossexual, que em outras regiões do País. Os números absolutos estão apresentados na tabela 19 do anexo 2 . 


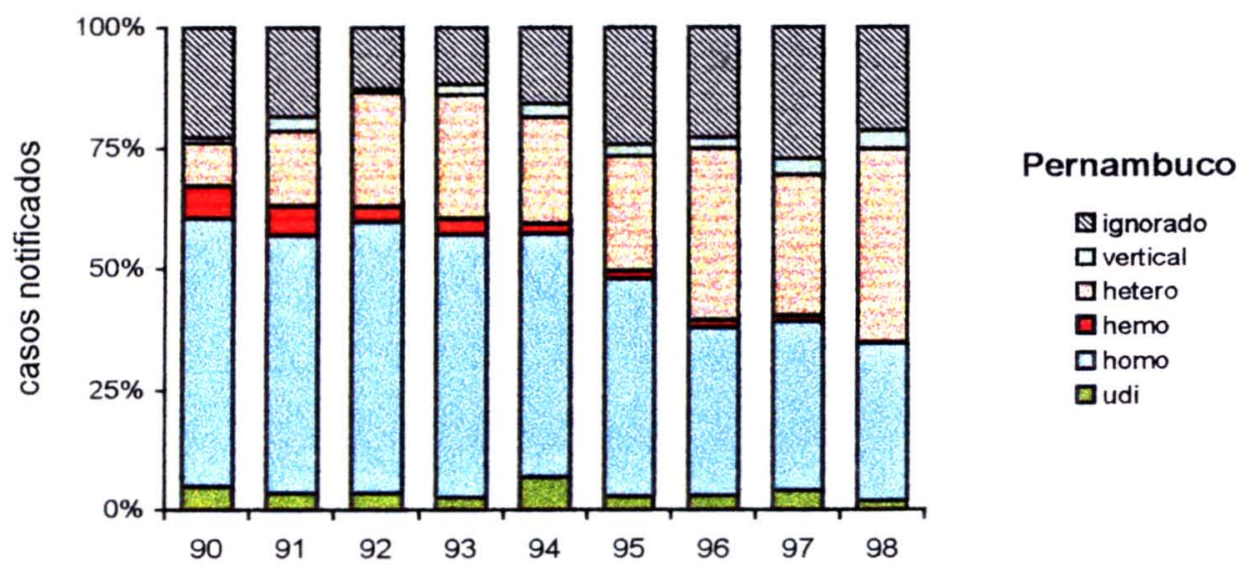

Figura 23 - Distribuição proporcional de casos de aids, segundo categoriade exposição e ano de diagnóstico. Pernambuco. 1990-1998.

A tabela 6 dispõe a razão de sexo, no período de 1990 a 1998, permitindo verificar que, apesar de estar em 2,0 em 1998, a queda dessa proporção foi mais lenta que o padrão do País. Enquanto para o Brasil, em 1995, essa razão era de 2,9 - tabela 2, no Pernambuco era 4,8, tendo iniciado, em 1990, em 9,0. Esses valores refletem a maior incidência de casos notificados do sexo masculino.

Tabela 6 - Distribuição de casos de aids segundo sexo e ano de notificação. Pernambuco. 1990-1998.

\begin{tabular}{c|rrrrrrrrr}
\hline sexo & 1990 & 1991 & 1992 & 1993 & 1994 & 1995 & 1996 & 1997 & 1998 \\
\hline masc & 162 & 189 & 211 & 252 & 283 & 317 & 399 & 394 & 432 \\
fem & 18 & 40 & 41 & 55 & 65 & 66 & 130 & 142 & 212 \\
\hline${ }^{*}$ m:f & 9,0 & 4,7 & 5,1 & 4,6 & 4,4 & 4,8 & 3,1 & 2,8 & 2,0 \\
\hline
\end{tabular}

* m:f - é a razão de sexo

A figura 24 mostra o padrão de incidência por faixa etária, destacando o maior número de casos entre 30 e 44 anos de idade e uma distribuição semelhante à obtida 


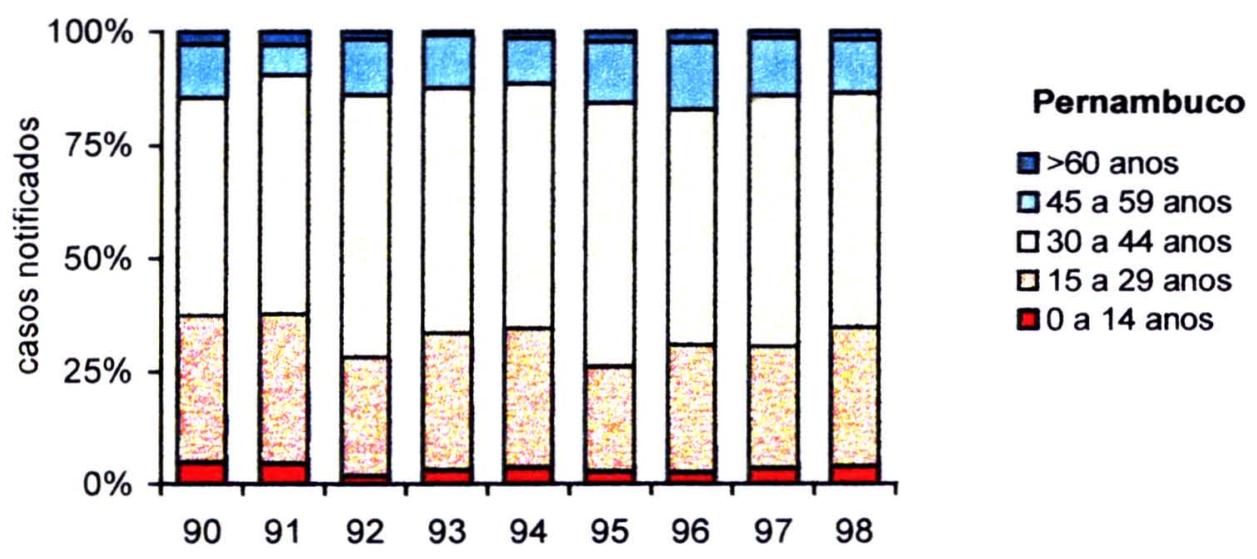

Figura 24 - Distribuição proporcional de casos de aids, segundo faixa etária e ano de diagnóstico. Pernambuco. 1990-1998.

A figura 25, cujos valores absolutos estão na tabela 21 do anexo 2, apresenta 0 padrão da distribuição de escolaridade, no período estudado, mostrando uma parcela crescente de indivíduos analfabetos. Os estratos de escolaridade referentes ao $1^{\circ}$ grau são os mais incidentes.

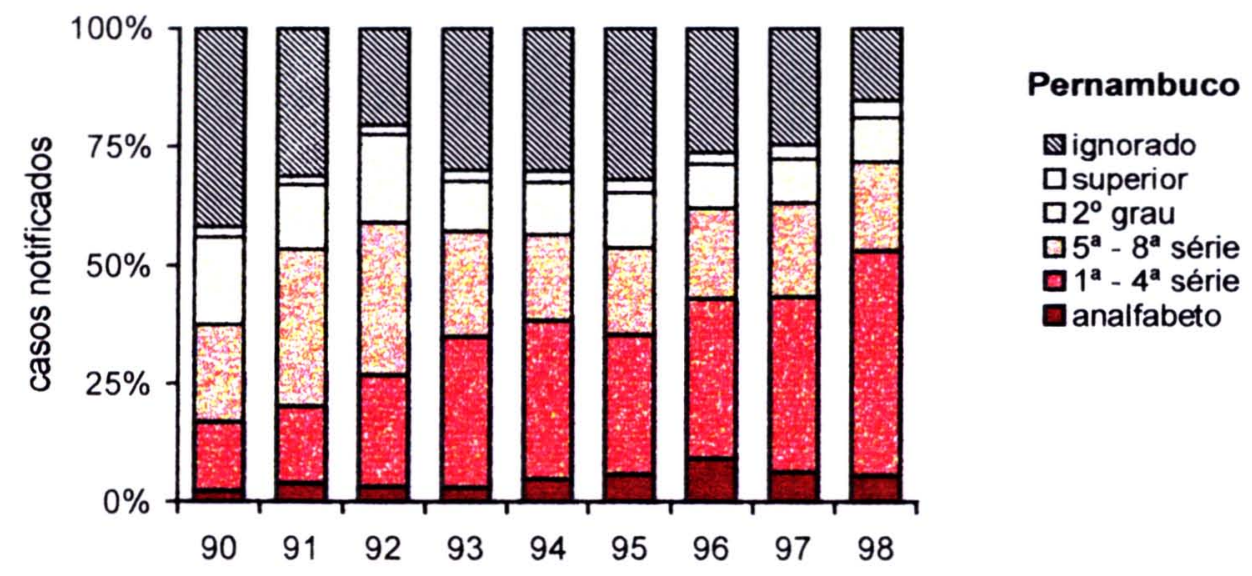

Figura 25 - Distribuição proporcional de casos de aids, segundo escolaridade e ano de diagnóstico. Pernambuco. 1990-1998. 
A figura 26 apresenta um mapa temático (Estado de Pernambuco) de estratos de desnvolvimento humano e do índice proposto, permitindo observar que as áreas de maior incidêcia de aids localizam-se próximo ao litoral. Observa, também, a predominância de áreas de baixo desenvolvimento humano, principalmente a oeste, onde há localidades que não registrou casos.

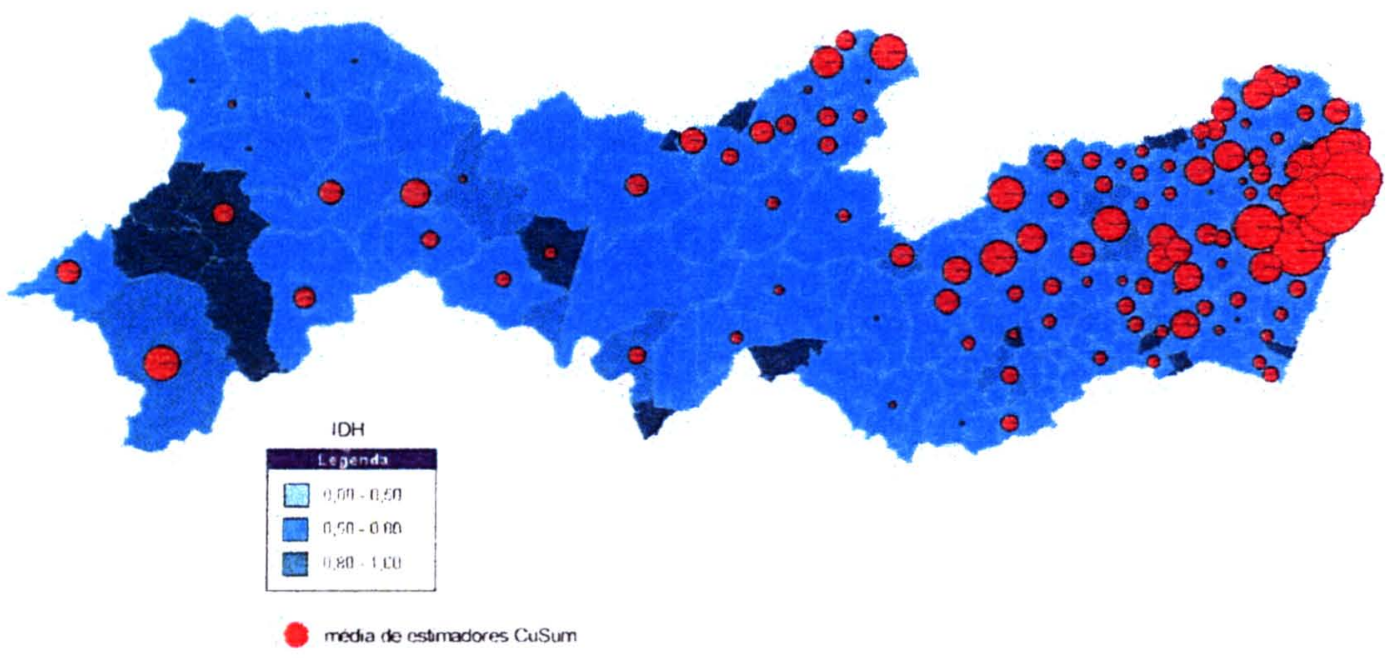

Figura 26 - Mapa temático da distribuição espacial da média dos estimadores CuSum da epidemia de aids e dos estratos de IDH. Pernambuco 1990-1998.

\section{Estado de Santa Catarina}

A figura 27 permite identificar o padrão de incidência por categoria de exposição, para o Estado de Santa Catarina, no período estudado. Pode-se observar a importância dos grupos de transmissão heterosséxual e UDI. Destaca-se, também, a categoria de transmissão ignorada, que bastante baixa, quando comparada ao padrão nacional e aos dois Estados apresentados anteriormente. Aqui, também, há uma proporção pequena de casos notificados na categoria de transmissão ignorada. Os valores absolutos estão na tabela 22 do anexo 2 . 


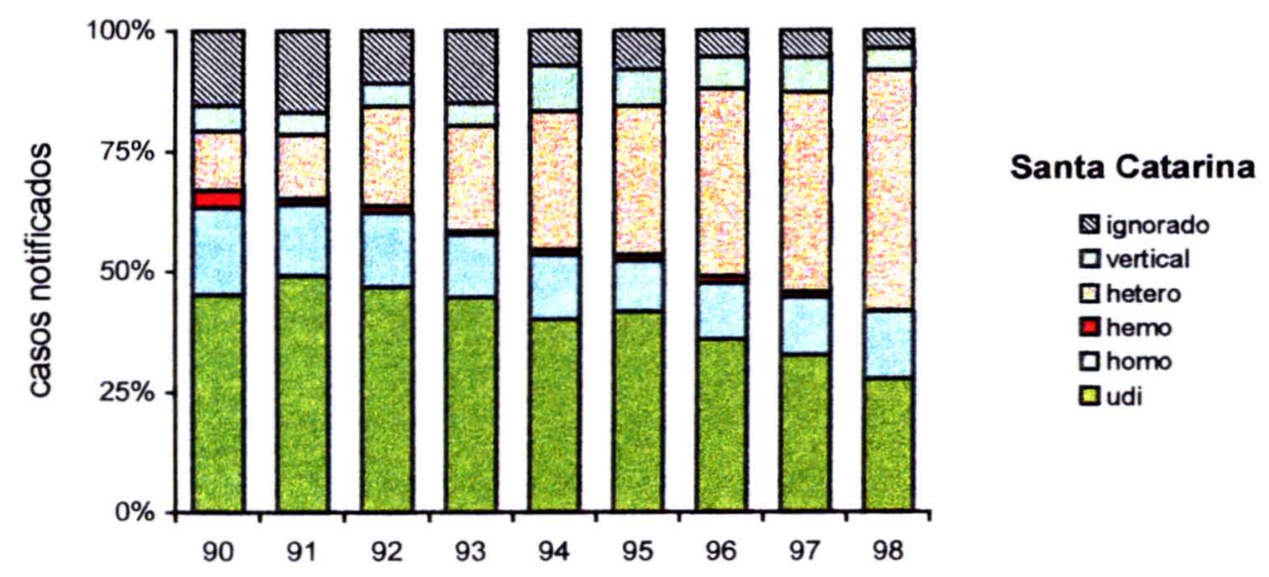

Figura 27 - Distribuição proporcional de casos de aids, segundo categoriade exposição e ano de diagnóstico. Santa Catarina. 1990-1998.

A tabela 7 apresenta a razão de sexo, em que pode-se observar o fenômeno da feminização da epidemia mais evidente que em outros Estados. A figura 28, cujos valores absolutos estão na tabela 23 do anexo 2 , mostra uma proporção de casos na faixa etária entre 30 e 44 anos, seguida da faixa entre 15 e 29 anos.

Tabela 7 - Distribuição de casos de aids segundo sexo e ano de notificação. Santa Catarina. 1990-1998.

\begin{tabular}{c|ccccccccc}
\hline sexo & 1990 & 1991 & 1992 & 1993 & 1994 & 1995 & 1996 & 1997 & 1998 \\
\hline masc & 180 & 252 & 304 & 412 & 519 & 670 & 706 & 666 & 749 \\
fem & 41 & 73 & 106 & 155 & 202 & 259 & 329 & 347 & 409 \\
\hline${ }^{*}$ m:f & 4,4 & 3,5 & 2,9 & 2,7 & 2,6 & 2,6 & 2,1 & 1,9 & 1,8 \\
\hline
\end{tabular}

* m:f - razão de sexo 


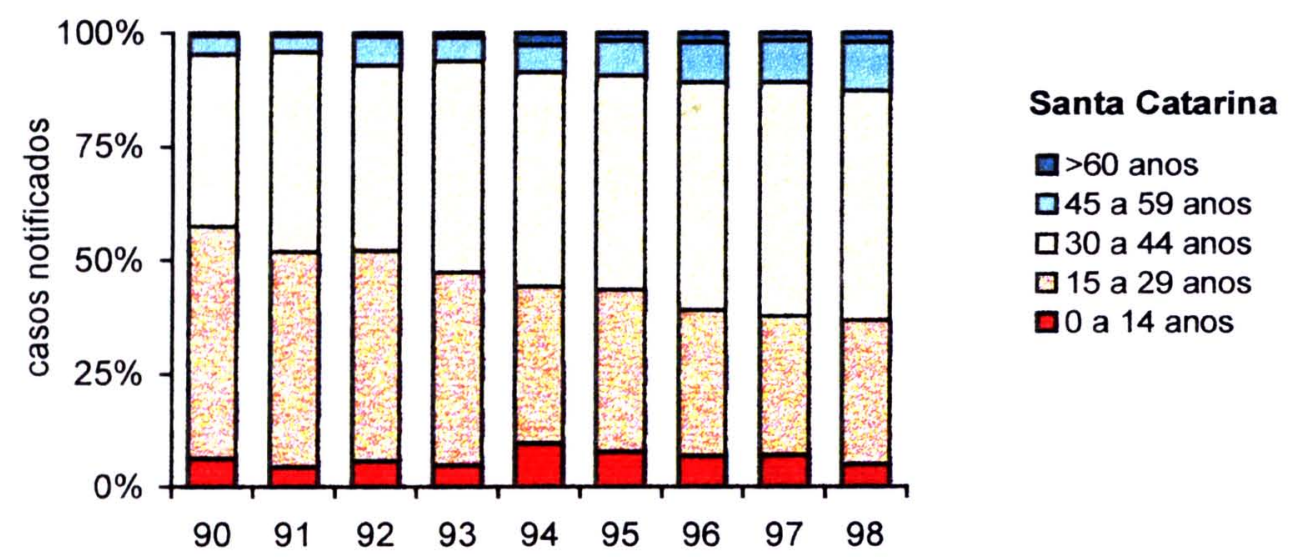

Figura 28 - Distribuição proporcional de casos de aids, segundo faixa etária e ano de diagnóstico. Santa Catarina. 1990-1998.

A figura 29, que tem seus valores absolutos apresentados pela tabela 24 do anexo 2 , aponta para a predominância de indivíduos com baixa escolaridade $-1^{\circ}$ a $4^{\mathrm{a}}$ série, além de um incremento de analfabetos.

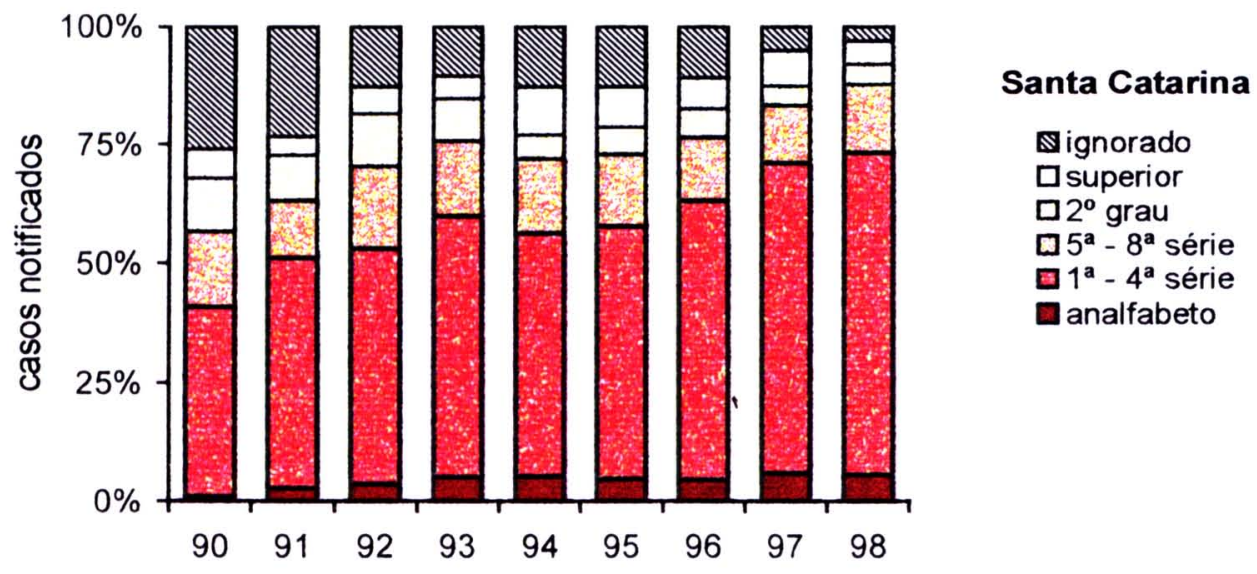

Figura 29 - Distribuição proporcional de casos de aids, segundo escolaridade e ano de diagnóstico. Santa Catarina. 1990-1998. 
A figura 30 corresponde a um mapa temático (Estado de Santa Catarina) dos estratos de desenvolvimento humano e o índice proposto, onde se verificam as maiores incidências de aids próximo ao litoral e na fronteira oeste. Observa-se, também, a predominância de estratos de médio e de alto desenvolvimento humano.

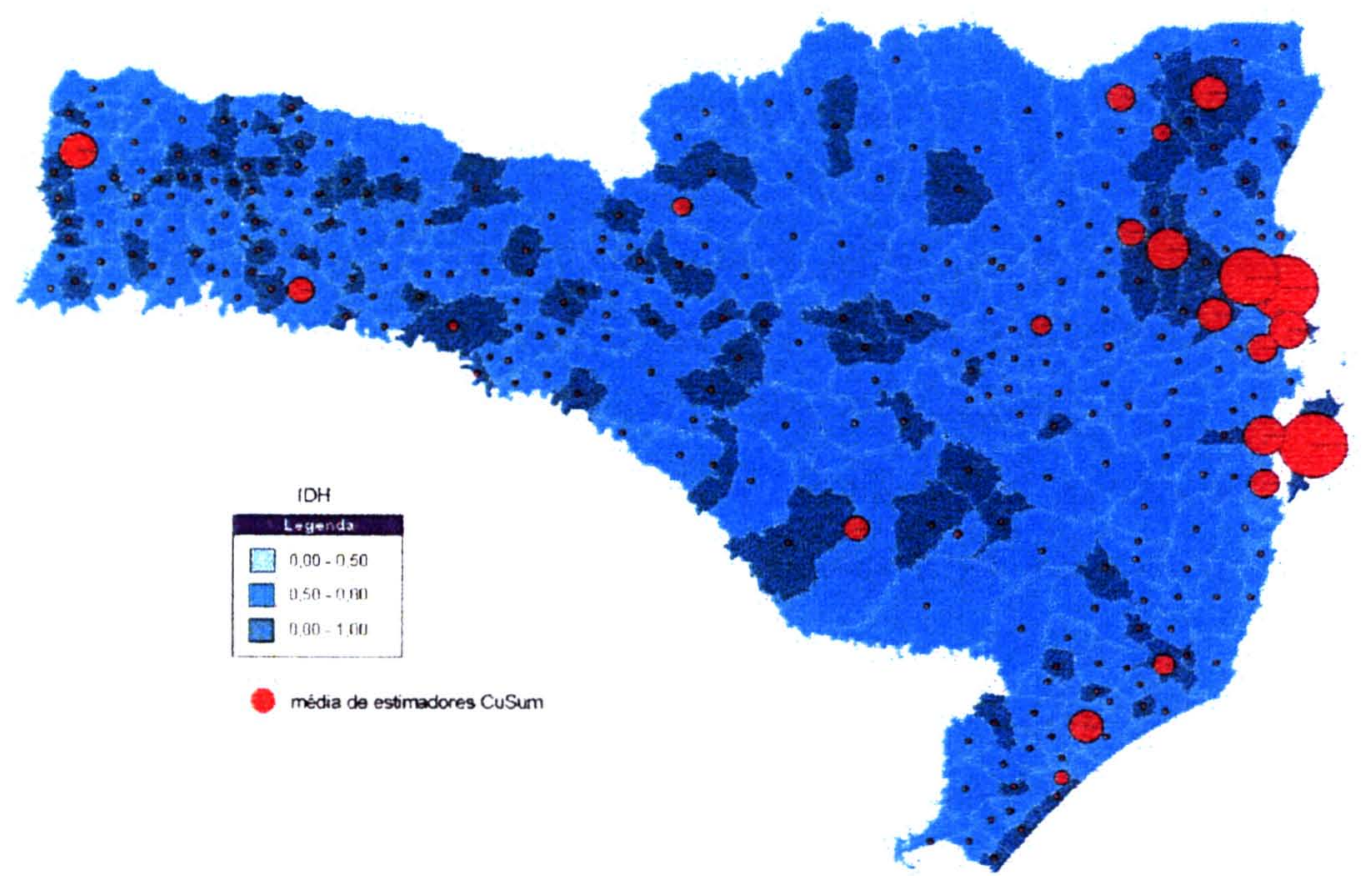

Figura 30 - Mapa temático da distribuição espacial da média dos estimadores CuSum da epidemia de aids e dos estratos de IDH. Santa Catarina 1990-1998. 


\section{DISCUSSÃO}

A experiência de trabalhar com banco de dados públicos remete às questões sobre a qualidade e a padronização da informação. Independentemente das críticas ao sistema de informações, o estudo mostrou ser viável pesquisar usando os produtos disponíveis na internet, como bancos de dados (aids, IDH, tamanho e projeções de populações) quanto de software (SPRING). Por exemplo: o banco de dados disponibilizado pelo IBGE, pela internet, apresentou nomes de localidades com diferenças de digitação, criando erros de integração dos dados do IBGE com os do IPEA, sendo aconselhável depurar os bancos de dados integrados devido ao número grande de municípios (5054). Outra dificuldade é a falta de informação, ou seja, foram instalados 531 novos municípios de 1993 a 1996, sendo que $51,228,133,100$ e 19 localizam-se nas regiões Norte, Nordeste, Sudeste, Sul e Centro-Oeste, respectivamente, que não apresentaram informação alguma sobre o desenvolvimento humano.

No que se refere ao aparecimento da aids, a tabela 1 mostra a experiência dos municípios no segmento do estudo. A doença já havia sido notificada por todos os municípios com mais de 200 mil habitantes, já em 1990, pois os primeiros casos notificados da epidemia ocorreram em metrópoles (São Paulo e Rio de Janeiro). Ao final de 1998, todas as localidades com mais de 50 mil habitantes já haviam notificado ao menos um caso ao Ministério da Saúde, sendo que, nas diversas Regiões, este marco foi alcançado em épocas diferentes: o Norte em 1998, o Nordeste em 1997, o Sudeste em 1994, o Sudeste em em 1994 e o Centro-Oeste em 1992. Os municípios com menos de 50 mil habitantes, que têm menor atividade econômica industrial e/ou comercial, notificaram ao menos um casos de aids em $35,7 \%, 52,4 \%, 68,8 \%, 50,5 \%$ e $55,9 \%$, nas regiões Norte, Nordeste, Sudeste, Sul e Centro-Oeste, respectivamente. Essas configurações mostram a dinâmica da epidemia, partindo dos grandes centros, e se difundindo pelo território, tomando a região Sudeste como a porta de entrada do vírus no País, hipoteticamente. Por outro lado, deve ser considerado o problema de 
subnotificação, que pode ser motivada pela falta de infra-estrutura dos serviços de saúde, que é predominante nas localidades de menor importância econômica.

O uso do índice de desenvolvimento humano permitiu observar o fenômeno espacial da aids, em relação às diferentes características socioeconômicas do País. A figura 1 mostra a distribuição espacial de duas realidades: (1) dos municípios com IDH-baixo, que se concentram nas regiões Norte e Nordeste; e (2) dos municípios com IDH-médio/alto, englobando a maioria das cidades das regiões Sul, Sudeste e CentroOeste. Como o IDH é um índice composto pelas dimensões "longevidade", "educação" e "renda", deve ser considerado que a concentração de econômica influem nesta medida. Assim, os municípios que apresentam atividade econômica, seja no setor primário, secundário ou terciário, terão receberam uma classificação de desenvolvimento humano melhorada. É fato que essa dicotomia socioeconômica motivou o surgimento de características epidemiológicas distintas para a aids. Os municípios do estrato de IDH-baixo, principalmente no Norte e Nordeste, apresentaram padrões epidemiológicos em que a via de transmissão sexual homossexual/bissexual e heterossexual - tem predominância, quando comparados aos padrões das regiões Sul, Sudeste e Centro-Oeste, que apresentam uma parcela de usuário de drogas injetáveis importante, além das categorais de transmissão sexual.

A figura 2 dá margem à interpretações equivocadas, considerando que o Nordeste apresentaram os maiores percentuais de municípios com IDH-baixo. Tal referência pode levar ao julgamento precipitado de que a aids no Nordeste incide, com mais força, nas camadas mais desfavorecidas. É preciso lembrar que, no caso do Nordeste, a maioria dos municípios apresentaram IDH-baixo, como se verifica na figura 1. O mesmo pode ser dito da região Sudeste, que apresentou o maior percentual de municípios com IDH-alto. A aids acontece quando há comportamento social de risco e não em grupos de risco.

A vantagem de se utilizar o IDH é poder incluir a dimensão socioeconômica na interpretação dos resultados, considerando os estratos de desenvolvimento humano que é internacionalmente aceito. A figura 1 ilustra o perfil de desenvolvimento humano no Brasil, em relação à epidemia de aids, relacionando-se à incidência anual 
nos três estratos do IDH, onde se observam as diferenças sociais entre as Regiões - as inequiidades. Já na figura 2 , é possível observar que há diferenças de perfil entre os estratos de desenvolvimento humano, considerando as categorias de exposição. Podese verificar que a epidemia nos municipios do estrato IDH-baixo apresentam uma fração pequena da categoria de exposição UDI, em contraste ao perfil epidemiológico das localidades de médio/alto desenvolvimento. Como a maior parte das localidades do estrato IDH-baixo fica no Norte e no Nordeste, que fica fora do roteiro de escoamento do tráfico, e associando-se ao fato de que população do estrato IDHbaixo não ter poder aquisitivo para o consumo, pode-se compreender as diferenças dos perfis, neste contexto. Na mesma figura pode-se observar a predominância da via de transmissão sexual para as localidades do estrato IDH-baixo, além da incidência relativa baixa em UDI's, pois a falta de uma oferta de trabalho formal, que atenda às necessidades essenciais, faz com que o comércio do sexo seja a solução mais freqüente para as privações, dentre aqueles que não têm capacidade de negociação no sistema de vida moderno, em concordância com PARKER (2000). Tais afirmativas são fundamentadas pelas figuras 1,3 e 18, em que se verificaram os estratos socioeconômicos mais baixos e os valores mais altos do índice proposto de incidência de aids. O termo "pauperização" da epidemia é uma referência à incidência de casos nas camadas desfavorecidas da população.

A "feminização" pode ser visualizada pela tabela 2 , onde cada estrato de desenvolvimento humano apresenta um tendência decrescente da razão de sexo, indicando a entrada das mulheres na cadeia de transmissão da aids. De maneira geral, a proporção de casos masculinos, em relação aos femininos, nos estratos de desenvolvimento baixo, médio e alto, caiu de 7,9, 5, 1 e 6,5 , para $2,0,2,0$ e 2,1 , respectivamente. Sem considerar os estratos de $\mathrm{IDH}$, a razão caiu de 5,9 para 2,1. A inversão dessa razão foi observada em 412 municipio, sendo que 389 tinham população inferior a 50 mil habitantes, onde a epidemia começou a ser notificada mais tarde. Deve-se considerar o total de casos acumulados por estes municípios foi 807 , que representa $0,5 \%$ da casuística. 
A figura 5 mostra a tendência crescente da incidência de casos na faixa etária entre 30 e 44 anos, que é mais evidente nos estratos de desenvolvimento humano médio e alto. $\mathrm{O}$ estrato etário entre 15 e 44 anos representa a grande maioria dos casos, pode-se dizer que as pessoas estão se infectando na fase produtiva da vida. Deve-se lembrar que via de transmissão sexual é a mais freqüente no perfil epidemiológico encontrado na figura 3 , associando-se o exposto pela figura 6, que mostra a distribuição de escolaridade, dentre os casos, considerando os estratos de desenvolvimento, evidenciando a baixa escolaridade, analfabetos e $1^{a}$ a $4^{a}$ série do $1^{o}$ grau, em ascenção. No estrato IDH-baixo há uma fração mais expressiva de analfabetos, dado que a taxa de analfabetismo influencia no IDH; no entanto, é nos estratos IDH-médio e alto que percebe-se uma tendência de aumento de casos relativos à falta de escolaridade - instrução. Estas são as evidencias de que os programas baseados na difusão de conhecimento, isto é, conscientização de risco, não estão atingindo a camada mais necessitada.

Os casos notificados como sendo da via de transmissão ignorada são os desafios dos epidemiologistas, pois estão sempre presentes nas estatísticas de perfil da epidemia e não apresentam tendência de queda. Pode-se abordar este fato por duas formas: (1) pode haver uma outra forma de transmissão do HIV, que é desconhecida; e (2) há falhas no processo de instrução do sistema de informações, que pode ser origenário do entrevistado, ou do entrevistador ou do próprio serviço de saúde. Respeitando o pensamento de Popper, onde não há verdades absolutas, pode-se dizer com fundamento metodológico que a primeira forma é pouco provável, devendo centralizar a atenção na crítica construtiva dos serviços de informação. A melhoria dos instrumentos de coleta de informações, pois, devido ao potencial estigmatizante da doença, pode haver o preenchimento inadequado da ficha de notificação ou o informante pode querer, consciente ou inconscientemente, ocultar dados importantes. A avaliação individualizada deste grupo, por região, escolaridade e faixa etária, não mostrou diferenças entre os padrões epidemiológicos por sexo, como apresentado nas figuras 7, 8 e 9. Observou-se que a proporção de casos com escolaridade ignorada é maior na categoria de exposição ignorada, como mostram as figuras 6 e 8 . O padrão 
de distribuição de escolaridade desses casos não diferem do total, que considera todas as categorias de exposição, observando-se a maior incidência entre $1^{a}$ e $4^{a}$ série do $1^{o}$ grau, além da expressiva quantidade de relatos com escolaridade ignorada. Já para os estratos de faixa etária, destacou-se a incidência em indivíduos com idade entre 30 e 44 anos, havendo uma tendência de aumento nos estratos de 15 a 29 e de 45 a 59 anos. A razão de sexo não apresentou diferenças, seguindo a proporcionalidade observada para os dados em geral, ou seja, situa-se próximo de 2:1 ao final de 1998 .

Com repeito ao índice proposto, pode-se dizer que os valores tiveram uma tendência em concentrar-se próximo à origem - zero, por haver muitos municípios com poucos casos notificados. O maior problema deste tipo de estudo é a variação do SMR, que resulta em valores excessivamente altos, quando se obtêm um valor esperados menor que hum, gerando valores superestimados do risco relativo. Tal fenômeno é conhecido como variação-estra de Poisson. $O$ índice proposto busca controlar esta propriedade, pela partição dos casos de aids notificados, segundo grupos de exposição, além da partição temporal. O uso de estimadores CuSum, que mede a variabilidade em torno de parâmetros de referência oscilantes - risco espaçotemporal heterogêneo, permitiu gerar mapas temáticos compatíveis com a teoria de localidades centrais, sendo uma provável fonte de interpretações qualitativas.

Adotou-se a abordagem freqüentista para identificar os municípios de maior incidência de aids, usando o limite superior de 5\%. Esses municípios foram listados no anexo 3, juntamente, com os projetos financiados em aids, de 1993 a 1997, em parceria com o CN-DSTIAIDS e ONG * . Verificou-se que, dos municípios com mais de 500 mil habitantes listados como de alta incidência pelo índice proposto, somente três não apresentaram projetos: Nova Iguaçu (RJ), Maceió (AL) e Natal (RN). Isso demonstra que há, em várias regiões, grupos organizados da sociedade civil para o enfrentamento da epidemia. Houve municípios, que foram classificados como de alta incidência, que não apresentaram projetos financiados: Nova Iguaçú (RJ), Maceió (AL) e Natal (RN).

\footnotetext{
* http://www.aids.gov.br/
} 
Cabe lembrar o papel das ONG no enfrentamento da epidemia, que foi reconhecido internacionalmente, principalmente aquelas localizadas nas área de alto risco. Sua atuação depende da cultura organizacional local, que motivou sua criação Em concordância com GALVÃO (1997), a aids passou a movimentar cifras volumosas de recursos financeiros, devido à uma preocupação internacional e governamental eminentes, requerendo a gestão da epidemia por projetos, que concorrem entre si. Como a epidemia deve avançar ainda mais nos próximos anos e os recursos financeiros não devem acompanhar esse aumento na mesma proporção, é natural que as idéias mais bem estruturadas, de grupos organizados com maior capacidade de gerar resultados devam obter sucesso na gestão de futuros projetos de enfrentamento da epidemia.

Considerando os Estados de São Paulo, Pernambuco e Santa Catarina, isoladamente, verificaram-se padrões epidemiológicos diferentes, referêntes à composição da epidemia em sua subcategorias. A propósito, deve ser destacado que o quarto objetivo específico desta tese foi estabelecido sob a hipótese de que esta constatação deveria ocorrer, tendo-se como pressuposto os diferenciais observados entre as estatísticas descritivas da epidemia nestes estados.

Os Estados de São Paulo e de Santa Catarina localizam-se na parte do País com maior desenvolvimento humano - IDH, mostrando uma epidemia composta por uma expressiva parcela da subcategoria UDI (figuras 19 e 27), além do aumento relativo de casos por transmissão heterossexual. Há duas diferenças nos padrões epidemiológicos destes Estados: (1) Santa Catarina apresenta uma proporção de casos com escolaridade ignorada menor que a de São Paulo (figuras 21 e 29); e (2) Santa Catarina apresenta uma proporção de casos de aids por transmissão ignorada menor que São Paulo. Estas diferenças podem ser indicadoras de um preenchimento mais adequado da ficha de notificação em Santa Catarina. Assim, usando este mesmo argumento, pode-se dizer que o padrão do serviço de informação de saúde de São Paulo assemelha-se ao de Pernambuco (figuras 19, 21, 23 e 25). Vale destacar que a composição da epidemia no Estado de Pernambuco apresenta uma parcela expressiva 
de casos notificados pela via de transmissão homossexual, além de poucos casos da categoria UDI (figura 23).

Os mapas temáticos destes Estados (figuras 22, 26 e 30) permitem algumas interpretações qualitativas. São Paulo, que inciou a notificação de casos em 1980, apresentou o maior número de notificações, sendo o cenário de uma doença que depende do convívio social das pessoas. Pode-se dizer que, pela característica de desenvolvimento industrial do Estado, a epidemia adquiriu mobilidade devido às trocas humanas estimuladas por atividade econômica, dentro do âmbito da infraestrutura de comércio estabelecida na ocupação do espaço geográfico. Em Pernambuco, a epidemia ainda apresentou uma parcela importante de casos por transmissão homossexual, além de localizar-se principalmente no litoral, onde há atividade econômica terciária - turismo. Em Santa Catarina a epidemia localizou-se no litoral, onde há atividade turística, e, também, houve uma parcela importante de casos da categora UDI.

Os resultados obtidos pelo índice proposto (em escala logaritmica) foi mapeado nas figuras 11-15, que referem-se às macro-regiões, em função do IDH. Nessas figuras foi possível identificar municípios com alta incidência $\mathrm{e}$ de baixo desenvolvimento humano, por macro-região. O mapa temático da figura 16 mostrou a distribuiçào espacial do risco relativo. Como relatado, o risco relativo sofre influência do tamanho populacional, principalmente quando o coeficiente de incidência é baixo, gerando valores superestimatidos. $O$ mapa da figura 17 mostrou a distribuição espacial da medida proposta, visualizando as unidades de maior incidência. $\mathrm{O}$ mapa do risco relativo pareceu ser menos visualmente discriminante que $\mathrm{o}$ índice proposto.

A figura 18 mostrou a distribuição espacial da aids no País, observando que o padrão de incidência de aids não reflete um fenômeno contínuo sobre o espaço. A distribuição parece um mosaico, que se adeqüa à lógica das localidades centrais, dos polos regionais, onde as transações comerciais de bens e de serviços acontecem, na forma de uma rede dendrítica, conforme CORRÊA (1996) relata em sua obra. Assim, outros critérios de dependência merecem ser considerados no caso da epidemia de 
aids, quando se planeja um estudos espaciais. $O$ estudo de correlação entre a medida da epidemia e o IDH mostrou valores significativos para as regiões Norte $(r=0,548 I)$, Nordeste $(r-0,5460)$, Sudeste $(r=0,3930)$, Sul $(r=0,3150)$ e Centro-Oeste $(r=0,3183)$, mostrando uma dependência social constituída (longevidade, renda $\mathrm{e}$ educação). Observa-se que as maiores incidências encontram-se nas localidades de maior importância socioeconômica, considerando a teoria de localidades centrais. Esses valores de correlação aumentam quando se consideram os componentes "renda" e "educação" do IDH-IPEA, em cada uma das regiões, permitindo identificar o modelo espaço-temporal da epidemia, até com o recorte empirico, como tendo diversas dimensões. 


\section{CONCLUSÕES}

1. A epidemia da aids, no Brasil, no período de 1990 a 1998, mostrou padrões de incidência diferentes, segundo as macro-regiões.

2. Confirmaram-se os fenômenos relatados na literatura, como a "feminização", a “interiorização" e a "pauperização".

3. O uso da média de estimadores CuSum por gupos de exposição possibilitou a identificação das localidades com alta incidência da aids, numa abordagem espaço-temporal.

4. $\mathrm{O}$ estudo de correlação mostrou correlações positivas e significativas entre a medida proposta e o IDH-IPEA, assim como para com os componentes "renda" $\mathrm{e}$ "educação", principalmente.

5. O estudo espaço-temporal gerou mapas temáticos que mostram a distribuição geográfica da epidemia da aids, ajudando a destacar as localidades de maior incidência, por meio dos valores observados para o índice proposto.

6. Os Estados de São Paulo, Pernambuco e Santa Catarina apresentaram diferentes padrões epidemiológicos. 


\section{REFERÊNCIAS BIBLIGRÁFICAS}

Ackerman M. Metodologia de construção de indicadores compostos: um exercício de negociação intersetorial. In: ABRASCO. Condições de vida e situação de Saúde. Rio de Janeiro, Biblioteca Lincoln de Freitas Filho; 1997 p.95-113.

Arbex Jr J. Narcotráfico: um jogo de poder nas Américas. São Paulo: Moderna, 1993.

Arbex Jr J, Tognolli CJ. O século do crime. São Paulo: Jinking editores asociados Itda, 1996.

Bailey TC, Gathrell AC. Interactive spatial data analysis. Essex: Longman Scientific \& Technical; 1995.

Barcellos C, Bastos FI Redes sociais e difusão da aids no Brasil. Bol Oficina Sanit Panam 1996; 121(1): 11-24.

Barcellos C, Machado JMH. A organização espacial condiciona as relações ente ambiente e Saúde: o exemplo da exposição ao mercúrio em uma fábrica de lâmpadas fluorescentes. Ciência \& Saúde Coletiva 1998; 3(2): 103-13.

Bastos F1, Barcellos C. Geografia social da aids no Brasil. Rev Saúde Pública 1995; 29(1): 52-62.

Bernardinelli L, Montomoli C. Empirical Bayes versus fully bayesian analyisis of geographical variation in disease risk. Statist.Med. 1992; 11: 983-1007.

Borrel C. Métodos utilizados no estudo das desigualdades sociais em Saúde. In: ABRASCO. Condições de vida e situação de Saúde. Rio de Janeiro, Biblioteca Lincoln de Freitas Filho; 1997 p. 167-95.

Castilho EA, Chequer P. A epidemia da aids no Brasil. In: A epidemia da aids no Brasil: situação e tendências. Brasília: Ministério da Saúde-Coordenação Nacional de DST e Aids; 1997. p.9-12.

Castilho EA, Chequer P, Szwarcwald CL. A aids no Brasil. In: Rouquayrol E, Almeida N. Epidemiologia \& Saúde. Rio de Janeiro: editora Médica e Científica, p. 271-84; 1999.

[CENEPI] Centro Nacional de Epidemiologia da Fundação Nacional de Saúde.

Guia de vigilância epidemiológica: sindrome da imunodeficiência adquirida. [texto online] Disponível em <URL: http://www.funasa.gov.br/> [1999 agosto 20].

Clayton D, Kaldor J. Empirical Bayes estimates of age-standardized relative risks for use in disease mapping. Biometrics 1987; 43: 671-81.

[CN-DST/AIDS] Coordenação Nacional de DST e Aids do Ministérios da Saúde. Boletim Epidemiológico. [periódico on line] 2000; XIII (1). Disponível em <URL: http://www.aids.gov.br/> [2000 julho 9]. 
[CN-DST/AIDS] Coordenação Nacional de DST e Aids do Ministérios da Saúde.

Boletim Epidemiológico. [periódico on line] 2001; XIV (1). Disponível em

$<$ URL: http://www.aids.gov.br/> [2001 novembro 11].

Corrêa RL. Trajetórias geográficas. Rio de Janeiro: Bertrand Brasil; 1996.

Costa WM. Geografia política e geopolítica. São Paulo: HUCITEC; 1992.

Dever GE. A Epidemiologia na administração dos serviços de Saúde. São Paulo: Pioneira-PROAHSA; 1984.

Esteve J, Benhamou E, Raymond L. Descriptive epidemiology. Lyon: IARC Scientific Publications; 1994.

Ferreira J, Valente JG. Região Sul. In: A epidemia da aids no Brasil: situação e tendências. Brasília: Ministério da Saúde-Coordenação Nacional de DST e Aids; 1997. p.9-12.

Fonseca MG, Bastos FI, Derrico M, de Andrade CLT, Travassos C, Szwarcwald CL. AIDS e grau de escolaridade no Brasil: evolução temporal de 1986 a 1996. [periódico online] Cad Saúde Pública 2000; 16 (sup.1): 77-87. Disponível em < URL: http://www.scielo.br/> [2000 outubro 27].

Galvão J. As respostas religiosas frente à epidemia de HIV/aids no Brasil. In: Parker R. Políticas, instituições e aids: enfrentando a epidemia no Brasil. Rio de Janeiro: Jorge Zahar Editor: ABIA; 1997.

Gilks WR, Richardson S, Spiegelhalter DJ. Markov chain monte carlo in practive. Florida: Chapman \& Hall; 1996

Lakatos EM, Marconi MA. Metodologia científica. São Paulo: Editora Atlas; 1988.

Mood AM, Graybill FA, Boes DC. Introduction to the theory of statistics. Singapure; $3^{\text {th }}$ ed, McGraw Hill; 1974.

Morgenstern H. Ecologic studies in epidemiology: concepts, principles, and methods. Annu.Rev.Public Health 1995; 16: 61-81.

Parker R, Bastos C, Galvão J, Pedrosa JS. A aids no Brasil. Rio de Janeiro: RelumeDumará Editores; 1994.

Parker R. Na contramãoda aids: sexualidade, intervenção, política. Rio de Janeiro: ABIA; São Paulo: Editora 34; 2000

Parker R, de Camargo Jr KR. Pobreza e HIV/aids: aspectos antropológicos e sociológicos. [periódico online] Cad Saúde Pública 2000; 16 (sup.1): 89-

102. Disponível em < URL: http://www.scielo.br/> [2000 outubro 27].

[PNUD] Programa das Nações Unidas para o Desenvolvimento. Atlas do desenvolvimento humano no Brasil. [programa de computador]. Brasília:IPEA/FIBGE/FJP; 1998. 
Rose G. Sick individuals and sick populations. In: Pan American Health Organizatin. The challenge of epidemiology: issues and selected readings. Washington; 1995. p.829-37.

Rossi G, Lampugnani L, Marchi M. An approximate cusum procedure for surveillance of health events. Statist.Med. 1999; 18: 2111-2122.

Rothman KJ, Greenland S. Modern epidemiology. Philadelphia: 2nd edition, Lippincott-Raven Publishers; 1998.

Rouquayrol MZ, Almeida Filho N. Epidemiologia e Saúde. Rio de Janeiro: 5a. Edição, MEDSI Editora Médica e Científica Ltda; 1999.

Sanches $O$. Princípios básicos de procedimentos estatísticos aplicados na análise de dados de vigilância em saúde pública: uma revisão. [periódico online] Cad Saúde Pública 2000; 16 (2): 317-33. Disponível em <URL:

http://www.scielo.br/ $>$ [2000 outubro 27]

Santos M. Por uma geografia nova: da crítica da geografia a uma geografia crítica. $4^{a}$ edição; São Paulo: HUCITEC; 1996.

Shapiro SS, Wilks MB. An analysis of variance test for normality. Biometrika 1965; 52: 591-611.

Szwarcwald CL, Bastos FI, Andrade CLT, Castilho EA. Aids: o mapa ecológico do Brasil, 1982-1994. In: A epidemia da aids no Brasil: situação e tendências. Brasília: Ministério da Saúde-Coordenação Nacional de DST e Aids; 1997. p. 27-44.

Thurow LC. O futuro do capitalismo: como as forças econômicas moldam o mundo de amanhã. $2^{\mathbf{a}}$ edição; Rio de Janeiro: Rocco; 1997.

Telles P, Nobre FF. Um estudo da difusão espacial da aids no Brasil. In: IV Congresso Brasileiro de Epidemiologia; 1998 Ago 1-5; Rio de Janeiro, Brasil.

Tsutakawa RK, Shoop GL, Marienfeld C. Empirical Bayes estimation of cancer nortality rates. Statist.Med. 1985; 4: 201-12.

Zar JH. Biostatistical analysis. $3^{\text {th }}$ edition; New Jersey: Prentice Hall, Inc.; 1996.

Williams SM, Parry BR, Schlup MM. Quality control: an application of the cusum. BMJ 1992; 304: 1359-61 
ANEXO 1 - Critério de hierarquização das categorias de exposição ao HIV

Tabela - Critério de hierarquização dos individuos que pertenciam a mais de um categoria de exposição ao HIV.

\begin{tabular}{|c|c|}
\hline GRUPO & CATEGORIAS * \\
\hline $\begin{array}{c}\text { Usuário de } \\
\text { Droga } \\
\text { Injetável }\end{array}$ & $\begin{array}{l}11 \text { - Homo/Drogas } \\
14 \text { - Homo/Drogas/Hemof } \\
15 \text { - Homo/Drogas/Transf } \\
21 \text { - Bi/Drogas } \\
24 \text { - Bi/Drogas/Hemof } \\
25 \text { - Bi/Drogas/Transf } \\
31 \text { - Hetero/Drogas } \\
34 \text { - Hetero/Drogas/Hemof } \\
35 \text { - Hetero/Drogas/Transf } \\
40 \text { - Drogas } \\
41 \text { - Drogas/Hemof } \\
42 \text { - Drogas/Transf } \\
61 \text { - Drogas Transf/ } \\
64 \text { - Drogas/Homo/Transf } \\
65 \text { - Drogas/Bi/Transf } \\
67 \text { - Drogas/Hetero/Transf }\end{array}$ \\
\hline $\begin{array}{l}\text { Homossexual } \\
\text { Bissexual }\end{array}$ & $\begin{array}{l}10-\text { Homo } \\
12-\text { Homo/Hemof } \\
13-\text { Homo/Transf } \\
20-\mathrm{Bi} \\
22-\mathrm{Bi} / \text { Homof } \\
23-\mathrm{Bi} / T r a n s f \\
62-\text { Homo/Transfusão } \\
63-\mathrm{Bi} / \text { Transfusão }\end{array}$ \\
\hline $\begin{array}{c}\text { Transfusão } \\
\text { Hemofilia }\end{array}$ & $\begin{array}{l}32 \text { - Hetero/Hemof } \\
33 \text { - Hetero/Transf } \\
50 \text { - Hemof } \\
60-\text { Transf } \\
66 \text { - Transf/Hetero }\end{array}$ \\
\hline Heterossexual & 30 - Hetero \\
\hline Vertical & 80 - Perinatal \\
\hline Ignorado & 90 - Ignorado \\
\hline
\end{tabular}

* Categoria de Transmissão da ficha de notificação. 
ANEXO 2 - Tabelas de resultados

Tabela 8 - Distribuição de casos de aids, segundo $\mathrm{IDH}$, região e ano de notificação de aids. Brasil. 1990-1998.

\begin{tabular}{|c|c|c|c|c|c|c|c|c|c|c|}
\hline IDH & Região & 1990 & 1991 & 1992 & 1993 & 1994 & 1995 & 1996 & 1997 & 1998 \\
\hline baixo & $\begin{array}{c}\text { Norte } \\
\text { Nordeste } \\
\text { Sudeste } \\
\text { Sul } \\
\text { Centro-Oeste }\end{array}$ & $\begin{array}{r}120 \\
3 \\
1\end{array}$ & $\begin{array}{r}3 \\
182 \\
5\end{array}$ & $\begin{array}{r}9 \\
198 \\
10 \\
3\end{array}$ & $\begin{array}{r}8 \\
245 \\
21\end{array}$ & $\begin{array}{r}12 \\
260 \\
27 \\
4\end{array}$ & $\begin{array}{r}13 \\
293 \\
30 \\
6\end{array}$ & $\begin{array}{r}20 \\
406 \\
24 \\
4 \\
2\end{array}$ & $\begin{array}{r}22 \\
456 \\
29 \\
\\
2\end{array}$ & $\begin{array}{r}24 \\
501 \\
34 \\
1 \\
1\end{array}$ \\
\hline médio & $\begin{array}{c}\text { Norte } \\
\text { Nordeste } \\
\text { Sudeste } \\
\text { Sul } \\
\text { Centro-Oeste }\end{array}$ & $\begin{array}{r}92 \\
559 \\
1878 \\
361 \\
211\end{array}$ & $\begin{array}{r}131 \\
777 \\
2749 \\
553 \\
337\end{array}$ & $\begin{array}{r}190 \\
969 \\
3681 \\
635 \\
477\end{array}$ & $\begin{array}{r}223 \\
1046 \\
4471 \\
877 \\
523\end{array}$ & $\begin{array}{r}304 \\
1183 \\
4832 \\
1112 \\
676\end{array}$ & $\begin{array}{r}347 \\
1245 \\
5237 \\
1256 \\
840\end{array}$ & $\begin{array}{r}407 \\
1496 \\
5789 \\
1565 \\
837\end{array}$ & $\begin{array}{r}472 \\
1626 \\
5436 \\
1752 \\
976\end{array}$ & $\begin{array}{r}466 \\
1951 \\
4913 \\
2184 \\
806\end{array}$ \\
\hline alto & $\begin{array}{c}\text { Norte } \\
\text { Nordeste } \\
\text { Sudeste } \\
\text { Sul } \\
\text { Centro-Oeste }\end{array}$ & $\begin{array}{r}5052 \\
477 \\
84\end{array}$ & $\begin{array}{r}6055 \\
736 \\
206\end{array}$ & $\begin{array}{r}7524 \\
911 \\
224\end{array}$ & $\begin{array}{r}7800 \\
1159 \\
218\end{array}$ & $\begin{array}{r}8001 \\
1358 \\
241\end{array}$ & $\begin{array}{r}8436 \\
1622 \\
268\end{array}$ & $\begin{array}{r}9224 \\
1822 \\
297\end{array}$ & $\begin{array}{r}8722 \\
1970 \\
335\end{array}$ & $\begin{array}{r}7484 \\
2229 \\
288\end{array}$ \\
\hline
\end{tabular}

Tabela 9 - Distribuição da incidência de casos de aids, segundo ano de notificação, categoria de exposição e IDH. Brasil. 1990-1998.

\begin{tabular}{|c|c|c|c|c|c|c|c|c|c|c|}
\hline IDH & grupo & 1990 & 1991 & 1992 & 1993 & 1994 & 1995 & 1996 & 1997 & 1998 \\
\hline $\begin{array}{l}\text { 옹 } \\
\text { ำ }\end{array}$ & $\begin{array}{c}\text { udi } \\
\text { homo } \\
\text { hemo } \\
\text { hetero } \\
\text { vertical } \\
\text { ignorado }\end{array}$ & $\begin{array}{r}7 \\
60 \\
13 \\
18 \\
\\
26\end{array}$ & $\begin{array}{r}19 \\
82 \\
15 \\
29 \\
1 \\
44\end{array}$ & $\begin{array}{r}13 \\
89 \\
6 \\
44 \\
2 \\
66\end{array}$ & $\begin{array}{r}27 \\
80 \\
10 \\
82 \\
3 \\
72\end{array}$ & $\begin{array}{r}22 \\
111 \\
9 \\
95 \\
1 \\
65\end{array}$ & $\begin{array}{r}19 \\
78 \\
17 \\
125 \\
5 \\
98\end{array}$ & $\begin{array}{r}17 \\
101 \\
12 \\
184 \\
13 \\
129\end{array}$ & $\begin{array}{r}22 \\
120 \\
12 \\
157 \\
5 \\
193\end{array}$ & $\begin{array}{r}16 \\
135 \\
1 \\
271 \\
9 \\
129\end{array}$ \\
\hline$\frac{\text { 응 }}{\text { 올 }}$ & $\begin{array}{c}\text { udi } \\
\text { homo } \\
\text { hemo } \\
\text { hetero } \\
\text { vertical } \\
\text { ignorado }\end{array}$ & $\begin{array}{r}937 \\
966 \\
147 \\
398 \\
61 \\
592\end{array}$ & $\begin{array}{r}1360 \\
1334 \\
186 \\
673 \\
100 \\
894\end{array}$ & $\begin{array}{r}1672 \\
1588 \\
196 \\
1093 \\
157 \\
1246\end{array}$ & $\begin{array}{r}1908 \\
1672 \\
189 \\
1629 \\
185 \\
1557\end{array}$ & $\begin{array}{r}1907 \\
1886 \\
180 \\
1997 \\
210 \\
1927\end{array}$ & $\begin{array}{r}1886 \\
1751 \\
217 \\
2439 \\
280 \\
2352\end{array}$ & $\begin{array}{r}2018 \\
1786 \\
218 \\
2943 \\
328 \\
2801\end{array}$ & $\begin{array}{r}1911 \\
1719 \\
139 \\
3331 \\
394 \\
2768\end{array}$ & $\begin{array}{r}1636 \\
1938 \\
28 \\
4374 \\
350 \\
1994\end{array}$ \\
\hline$\frac{\rho}{\pi}$ & $\begin{array}{c}\text { udi } \\
\text { homo } \\
\text { hemo } \\
\text { hetero } \\
\text { vertical } \\
\text { ignorado }\end{array}$ & $\begin{array}{r}1652 \\
1937 \\
204 \\
554 \\
130 \\
1136\end{array}$ & $\begin{array}{r}2243 \\
2200 \\
201 \\
922 \\
169 \\
1272\end{array}$ & $\begin{array}{r}2608 \\
2518 \\
188 \\
1474 \\
195 \\
1676\end{array}$ & $\begin{array}{r}2581 \\
2259 \\
186 \\
1757 \\
210 \\
2184\end{array}$ & $\begin{array}{r}2435 \\
2156 \\
177 \\
1909 \\
327 \\
2596\end{array}$ & $\begin{array}{r}2430 \\
1992 \\
163 \\
2223 \\
365 \\
3153\end{array}$ & $\begin{array}{r}2438 \\
2044 \\
174 \\
2726 \\
434 \\
3527\end{array}$ & $\begin{array}{r}2199 \\
1977 \\
112 \\
2969 \\
386 \\
3384\end{array}$ & $\begin{array}{r}1774 \\
2012 \\
17 \\
3308 \\
282 \\
2608\end{array}$ \\
\hline
\end{tabular}


Tabela 10 - Distribuição de casos de aids, segundo região, categoria de exposição e ano de notificação. Brasil. 1990-1998.

\begin{tabular}{|c|c|c|c|c|c|c|c|c|c|c|}
\hline Regiăo & grupo & 1990 & 1991 & 1992 & 1993 & 1994 & 1995 & 1996 & 1997 & 1998 \\
\hline Norte & $\begin{array}{c}\text { udi } \\
\text { homo } \\
\text { hemo } \\
\text { hetero } \\
\text { vertical } \\
\text { ignorado }\end{array}$ & $\begin{array}{r}12 \\
37 \\
4 \\
17 \\
\\
22\end{array}$ & $\begin{array}{r}5 \\
64 \\
8 \\
23 \\
\\
34\end{array}$ & $\begin{array}{r}25 \\
96 \\
6 \\
32 \\
1 \\
39\end{array}$ & $\begin{array}{r}17 \\
93 \\
9 \\
56 \\
3 \\
56\end{array}$ & $\begin{array}{r}26 \\
118 \\
12 \\
91 \\
7 \\
66\end{array}$ & $\begin{array}{r}31 \\
106 \\
16 \\
116 \\
11 \\
86\end{array}$ & $\begin{array}{r}32 \\
128 \\
15 \\
122 \\
17 \\
120\end{array}$ & $\begin{array}{r}30 \\
141 \\
13 \\
149 \\
11 \\
157\end{array}$ & $\begin{array}{r}25 \\
129 \\
1 \\
196 \\
21 \\
130\end{array}$ \\
\hline Nordeste & $\begin{array}{c}\text { udi } \\
\text { homo } \\
\text { hemo } \\
\text { hetero } \\
\text { vertical } \\
\text { ignorado }\end{array}$ & $\begin{array}{r}89 \\
338 \\
33 \\
65 \\
5 \\
150\end{array}$ & $\begin{array}{r}114 \\
476 \\
55 \\
110 \\
13 \\
191\end{array}$ & $\begin{array}{r}112 \\
556 \\
32 \\
221 \\
15 \\
235\end{array}$ & $\begin{array}{r}142 \\
551 \\
36 \\
318 \\
25 \\
227\end{array}$ & $\begin{array}{r}125 \\
657 \\
38 \\
364 \\
19 \\
243\end{array}$ & $\begin{array}{r}107 \\
556 \\
57 \\
412 \\
23 \\
390\end{array}$ & $\begin{array}{r}136 \\
629 \\
50 \\
589 \\
38 \\
469\end{array}$ & $\begin{array}{r}154 \\
602 \\
28 \\
606 \\
52 \\
654\end{array}$ & $\begin{array}{r}106 \\
769 \\
9 \\
960 \\
55 \\
575\end{array}$ \\
\hline Sudeste & $\begin{array}{c}\text { udi } \\
\text { homo } \\
\text { hemo } \\
\text { hetero } \\
\text { vertical } \\
\text { ignorado }\end{array}$ & $\begin{array}{r}2215 \\
2207 \\
293 \\
762 \\
152 \\
1334\end{array}$ & $\begin{array}{r}2949 \\
2530 \\
297 \\
1295 \\
216 \\
1553\end{array}$ & $\begin{array}{r}3496 \\
2957 \\
321 \\
2000 \\
269 \\
2212\end{array}$ & $\begin{array}{r}3561 \\
2752 \\
298 \\
2506 \\
285 \\
2958\end{array}$ & $\begin{array}{r}3315 \\
2723 \\
258 \\
2722 \\
357 \\
3586\end{array}$ & $\begin{array}{r}3199 \\
2546 \\
275 \\
3250 \\
419 \\
4151\end{array}$ & $\begin{array}{r}3207 \\
2568 \\
256 \\
3886 \\
470 \\
4827\end{array}$ & $\begin{array}{r}2853 \\
2399 \\
163 \\
4168 \\
482 \\
4340\end{array}$ & $\begin{array}{r}2096 \\
2269 \\
28 \\
4492 \\
326 \\
3407\end{array}$ \\
\hline Sul & $\begin{array}{c}\text { udi } \\
\text { homo } \\
\text { hemo } \\
\text { hetero } \\
\text { vertical } \\
\text { ignorado }\end{array}$ & $\begin{array}{r}225 \\
274 \\
28 \\
90 \\
30 \\
193\end{array}$ & $\begin{array}{r}408 \\
376 \\
30 \\
142 \\
33 \\
302\end{array}$ & $\begin{array}{r}521 \\
395 \\
22 \\
245 \\
56 \\
318\end{array}$ & $\begin{array}{r}636 \\
472 \\
31 \\
454 \\
67 \\
399\end{array}$ & $\begin{array}{r}720 \\
507 \\
44 \\
631 \\
144 \\
456\end{array}$ & $\begin{array}{r}853 \\
434 \\
33 \\
754 \\
170 \\
649\end{array}$ & $\begin{array}{r}924 \\
451 \\
60 \\
987 \\
225 \\
774\end{array}$ & $\begin{array}{r}951 \\
471 \\
43 \\
1101 \\
220 \\
980\end{array}$ & $\begin{array}{r}1066 \\
773 \\
4 \\
1901 \\
211 \\
527\end{array}$ \\
\hline $\begin{array}{l}\text { Centro- } \\
\text {-Oeste }\end{array}$ & $\begin{array}{c}\text { udi } \\
\text { homo } \\
\text { hemo } \\
\text { hetero } \\
\text { vertical } \\
\text { ignorado }\end{array}$ & $\begin{array}{r}63 \\
112 \\
9 \\
41 \\
6 \\
64\end{array}$ & $\begin{array}{r}149 \\
177 \\
14 \\
62 \\
8 \\
133\end{array}$ & $\begin{array}{r}151 \\
202 \\
14 \\
122 \\
16 \\
200\end{array}$ & $\begin{array}{r}181 \\
162 \\
13 \\
153 \\
20 \\
214\end{array}$ & $\begin{array}{r}199 \\
175 \\
19 \\
229 \\
14 \\
282\end{array}$ & $\begin{array}{r}172 \\
208 \\
24 \\
299 \\
31 \\
385\end{array}$ & $\begin{array}{r}194 \\
185 \\
28 \\
342 \\
28 \\
364\end{array}$ & $\begin{array}{r}177 \\
247 \\
20 \\
525 \\
34 \\
336\end{array}$ & $\begin{array}{r}174 \\
206 \\
5 \\
526 \\
39 \\
168\end{array}$ \\
\hline
\end{tabular}


Tabela 11 - Distribuição de casos, segundo IDH, faixa etária e ano de notificação. Brasil. 1990-1998.

\begin{tabular}{|c|c|c|c|c|c|c|c|c|c|c|}
\hline IDH & $\begin{array}{l}\text { faixa } \\
\text { etária } \\
\text { (anos) }\end{array}$ & 1990 & 1991 & 1992 & 1993 & 1994 & 1995 & 1996 & 1997 & 1998 \\
\hline \multirow{5}{*}{ baixo } & $0 \vdash 15$ & 1 & 6 & 4 & 5 & 5 & 7 & 15 & 8 & 12 \\
\hline & $15+29$ & 50 & 74 & 72 & 99 & 102 & 114 & 144 & 189 & 190 \\
\hline & $30 \vdash 44$ & 59 & 95 & 110 & 140 & 157 & 187 & 240 & 268 & 299 \\
\hline & $45 \vdash 59$ & 13 & 11 & 29 & 23 & 33 & 28 & 48 & 39 & 48 \\
\hline & $\geq 60$ & 1 & 4 & 5 & 7 & 6 & 6 & 9 & 5 & 12 \\
\hline \multirow{5}{*}{ médio } & $0 \vdash 15$ & 123 & 159 & 215 & 235 & 268 & 335 & 371 & 435 & 388 \\
\hline & $15 \vdash 29$ & 1371 & 1910 & 2442 & 2877 & 2994 & 3066 & 3352 & 3308 & 3231 \\
\hline & $30 \vdash 44$ & 1303 & 2062 & 2738 & 3257 & 3901 & 4398 & 5048 & 5186 & 5266 \\
\hline & $45 \vdash 59$ & 242 & 353 & 472 & 669 & 797 & 960 & 1125 & 1156 & 1230 \\
\hline & $\geq 60$ & 62 & 63 & 85 & 102 & 147 & 166 & 198 & 177 & 205 \\
\hline \multirow{5}{*}{ alto } & $0 \vdash-15$ & 226 & 251 & 256 & 277 & 401 & 424 & 492 & 428 & 327 \\
\hline & $15 \vdash 29$ & 2046 & 2569 & 3074 & 3156 & 3104 & 3190 & 3178 & 3085 & 2579 \\
\hline & $30 \vdash 44$ & 2568 & 3284 & 4186 & 4448 & 4856 & 5225 & 6081 & 5844 & 5413 \\
\hline & $45 \vdash 59$ & 633 & 728 & 938 & 1086 & 1034 & 1229 & 1359 & 1409 & 1400 \\
\hline & $\geq 60$ & 140 & 175 & 205 & 210 & 205 & 258 & 233 & 261 & 282 \\
\hline
\end{tabular}

Tabela 12 - Distribuição de casos de aids, segundo IDH, escolaridade e ano de notificação. Brasil. 1990-1998.

\begin{tabular}{|c|c|c|c|c|c|c|c|c|c|c|}
\hline IDH & $\begin{array}{l}\text { escola- } \\
\text { ridade }\end{array}$ & 1990 & 1991 & 1992 & 1993 & 1994 & 1995 & 1996 & 1997 & 1998 \\
\hline \multirow{6}{*}{ baixo } & analfabeto & 15 & 26 & 19 & 23 & 32 & 43 & 67 & 72 & 80 \\
\hline & $1^{\prime}-4^{\prime}$ série & 33 & 63 & 43 & 90 & 123 & 142 & 208 & 222 & 305 \\
\hline & $5^{\circ}-8^{a}$ série & 23 & 28 & 29 & 43 & 36 & 47 & 50 & 53 & 52 \\
\hline & $2^{\circ}$ grau & 6 & 12 & 15 & 9 & 16 & 7 & 15 & 8 & 14 \\
\hline & superior & & & 2 & 2 & 2 & 6 & 14 & 8 & 10 \\
\hline & ignorado & 38 & 37 & 45 & 70 & 70 & 75 & 91 & 121 & 87 \\
\hline \multirow{6}{*}{ médio } & analfabeto & 70 & 134 & 190 & 272 & 327 & 361 & 473 & 527 & 471 \\
\hline & $1^{\circ}-4^{\circ}$ série & 1223 & 1905 & 2654 & 3366 & 3921 & 4325 & 5101 & 5428 & 5862 \\
\hline & $5^{\circ}-8^{a}$ série & 503 & 690 & 879 & 1042 & 1198 & 1310 & 1347 & 1342 & 1316 \\
\hline & $2^{\circ} \mathrm{grau}$ & 295 & 391 & 463 & 479 & 477 & 521 & 507 & 459 & 446 \\
\hline & superior & 84 & 107 & 188 & 200 & 228 & 306 & 332 & 373 & 327 \\
\hline & ignorado & 911 & 1293 & 1552 & 1741 & 1913 & 2040 & 2253 & 1993 & 1757 \\
\hline \multirow{6}{*}{ alto } & analfabeto & 60 & 107 & 168 & 240 & 241 & 305 & 337 & 378 & 322 \\
\hline & $1^{*}-4^{\circ}$ série & 2041 & 2538 & 3557 & 3970 & 4120 & 4459 & 4949 & 5279 & 5036 \\
\hline & $5^{\circ}-8^{a}$ série & 700 & 967 & 1267 & 1500 & 1592 & 1617 & 1687 & 1687 & 1570 \\
\hline & $2^{*}$ grau & 821 & 902 & 1086 & 1017 & 977 & 947 & 1003 & 845 & 842 \\
\hline & superior & 321 & 287 & 341 & 252 & 336 & 371 & 418 & 371 & 249 \\
\hline & ignorado & 1657 & 2195 & 2175 & 2148 & 2289 & 2596 & 2912 & 2435 & 1884 \\
\hline
\end{tabular}


Tabela 13 - Distribuição de casos de aids, segundo sexo, região e ano de notificação de aids, para a categoria de exposição ignorada. Brasil. 1990-1998.

\begin{tabular}{r|c|rrrrrrrrr}
\hline sexo & Região & 1990 & 1991 & 1992 & 1993 & 1994 & 1995 & 1996 & 1997 & 1998 \\
\hline \multirow{6}{*}{ masc } & Norte & 16 & 25 & 26 & 33 & 35 & 60 & 81 & 95 & 87 \\
& Nordeste & 121 & 140 & 186 & 173 & 184 & 294 & 342 & 470 & 388 \\
& Sudeste & 1113 & 1217 & 1746 & 2233 & 2660 & 3015 & 3426 & 2861 & 2211 \\
& Sul & 156 & 229 & 229 & 293 & 330 & 442 & 567 & 676 & 360 \\
& Centro-Oeste & 49 & 91 & 161 & 171 & 210 & 302 & 245 & 216 & 113 \\
\hline \multirow{6}{*}{ fem } & Norte & 6 & 9 & 13 & 23 & 31 & 26 & 39 & 62 & 43 \\
& Nordeste & 29 & 51 & 49 & 54 & 59 & 96 & 127 & 184 & 187 \\
& Sudeste & 221 & 336 & 466 & 725 & 926 & 1136 & 1401 & 1479 & 1196 \\
& Sul & 37 & 73 & 89 & 106 & 126 & 207 & 207 & 304 & 167 \\
& Centro-Oeste & 15 & 42 & 39 & 43 & 72 & 119 & 119 & 120 & 55 \\
\hline
\end{tabular}

Tabela 14 - Distribuição de casos de aids, segundo sexo, escolaridade e ano de notificação, para a categoria de exposição ignorada. . Brasil. 1990-1998.

\begin{tabular}{|c|c|c|c|c|c|c|c|c|c|c|}
\hline sexo & $\begin{array}{l}\text { escola- } \\
\text { ridade }\end{array}$ & 1990 & 1991 & 1992 & 1993 & 1994 & 1995 & 1996 & 1997 & 1998 \\
\hline \multirow{6}{*}{ masc } & analfabeto & 18 & 27 & 56 & 100 & 83 & 117 & 144 & 178 & 97 \\
\hline & $1^{*}-4^{*}$ série & 407 & 490 & 827 & 997 & 1265 & 1487 & 1792 & 1832 & 1240 \\
\hline & $5^{\circ}-8^{a}$ série & 174 & 211 & 227 & 357 & 418 & 484 & 543 & 519 & 307 \\
\hline & $2^{\circ} \mathrm{grau}$ & 214 & 167 & 224 & 252 & 265 & 300 & 327 & 255 & 179 \\
\hline & superior & 51 & 26 & 34 & 31 & 33 & 27 & 27 & 24 & 12 \\
\hline & ignorado & 581 & 768 & 963 & 1147 & 1337 & 1668 & 1795 & 1457 & 1264 \\
\hline \multirow{6}{*}{ fem } & analfabeto & 5 & 24 & 22 & 45 & 74 & 79 & 92 & 129 & 92 \\
\hline & $1^{\circ}-4^{\circ}$ série & 117 & 177 & 241 & 369 & 483 & 602 & 793 & 1030 & 697 \\
\hline & $5^{\circ}-8^{a}$ série & 26 & 41 & 57 & 101 & 115 & 159 & 158 & 207 & 151 \\
\hline & $2^{\circ} \mathrm{grau}$ & 20 & 23 & 28 & 52 & 53 & 61 & 71 & 73 & 50 \\
\hline & superior & 19 & 13 & 16 & 16 & 23 & 32 & 29 & 13 & 19 \\
\hline & ignorado & 119 & 229 & 285 & 356 & 461 & 607 & 734 & 675 & 612 \\
\hline
\end{tabular}

Tabela 15 - Distribuição de casos de aids, scgundo sexo, faixa etária e ano de notificação, para a catcgoria de exposição ignorada. Brasil. 1990-1998.

\begin{tabular}{r|c|rrrrrrrrr}
\hline \multirow{2}{*}{ sexo } & $\begin{array}{c}\text { faixa } \\
\text { etária } \\
\text { (anos) }\end{array}$ & $\mathbf{1 9 9 0}$ & $\mathbf{1 9 9 1}$ & $\mathbf{1 9 9 2}$ & $\mathbf{1 9 9 3}$ & $\mathbf{1 9 9 4}$ & $\mathbf{1 9 9 5}$ & $\mathbf{1 9 9 6}$ & $\mathbf{1 9 9 7}$ & 1998 \\
\hline \multirow{6}{*}{ masc } & $0 \vdash 15$ & 37 & 35 & 41 & 38 & 58 & 38 & 37 & 36 & 36 \\
& $15 \vdash 29$ & 425 & 501 & 738 & 925 & 983 & 1121 & 1202 & 1088 & 656 \\
& $30 \vdash 44$ & 722 & 838 & 1173 & 1437 & 1800 & 2204 & 2589 & 2406 & 1759 \\
& $45 \vdash 59$ & 213 & 251 & 311 & 408 & 460 & 593 & 708 & 656 & 573 \\
& $\geq 60$ & 58 & 77 & 85 & 95 & 118 & 157 & 125 & 132 & 135 \\
\hline \multirow{6}{*}{ fem } & $0 \vdash 15$ & 32 & 28 & 25 & 34 & 37 & 44 & 43 & 27 & 33 \\
& $15 \vdash 29$ & 106 & 177 & 223 & 344 & 430 & 522 & 635 & 739 & 507 \\
& $30 \vdash 44$ & 118 & 223 & 311 & 406 & 570 & 733 & 934 & 1006 & 801 \\
& $45 \vdash 59$ & 41 & 60 & 80 & 147 & 142 & 203 & 227 & 310 & 246 \\
& $\geq 60$ & 11 & 23 & 17 & 20 & 35 & 46 & 54 & 67 & 61 \\
\hline
\end{tabular}


Tabela 16 - Distribuição da incidência de casos de aids, segundo ano de notificação e categoria de exposição. São Paulo. 1990-1998.

\begin{tabular}{c|rrrrrrrrr}
\hline grupo & 1990 & 1991 & 1992 & 1993 & 1994 & 1995 & 1996 & 1997 & 1998 \\
\hline udi & 2005 & 2683 & 3149 & 3155 & 2888 & 2797 & 2754 & 2435 & 1752 \\
homo & 1447 & 1633 & 1835 & 1621 & 1542 & 1465 & 1501 & 1460 & 1295 \\
hemo & 125 & 150 & 173 & 143 & 140 & 162 & 132 & 69 & 15 \\
hetero & 541 & 924 & 1421 & 1794 & 2023 & 2329 & 2853 & 2952 & 3146 \\
vertical & 125 & 181 & 215 & 232 & 255 & 301 & 325 & 315 & 171 \\
ignorado & 722 & 916 & 1276 & 1702 & 2067 & 2558 & 2802 & 2183 & 1828 \\
\hline
\end{tabular}

Tabela 17 - Distribuição de casos, segundo faixa etária e ano de notificação. São Paulo. 1990-1998.

\begin{tabular}{c|rrrrrrrrr}
\hline $\begin{array}{c}\text { faixa } \\
\text { etária } \\
\text { (anos) }\end{array}$ & $\mathbf{1 9 9 0}$ & $\mathbf{1 9 9 1}$ & $\mathbf{1 9 9 2}$ & $\mathbf{1 9 9 3}$ & $\mathbf{1 9 9 4}$ & $\mathbf{1 9 9 5}$ & $\mathbf{1 9 9 6}$ & $\mathbf{1 9 9 7}$ & $\mathbf{1 9 9 8}$ \\
\hline $0 \vdash-15$ & 173 & 230 & 264 & 287 & 300 & 357 & 375 & 343 & 205 \\
$15 \vdash 29$ & 2152 & 2701 & 3234 & 3440 & 3217 & 3330 & 3252 & 2866 & 2373 \\
$30 \vdash 44$ & 2125 & 2868 & 3673 & 3927 & 4418 & 4704 & 5489 & 5026 & 4469 \\
$45 \vdash 59$ & 409 & 565 & 736 & 837 & 819 & 1006 & 1088 & 1013 & 997 \\
$\geq 60$ & 106 & 123 & 162 & 156 & 161 & 215 & 163 & 166 & 163 \\
\hline
\end{tabular}

Tabela 18 - Distribuição de casos de aids, segundo escolaridade e ano de notificação. São Paulo. 1990-1998.

\begin{tabular}{c|rrrrrrrrr}
\hline escolaridade & 1990 & 1991 & 1992 & 1993 & 1994 & 1995 & 1996 & 1997 & 1998 \\
\hline analfabeto & 63 & 94 & 160 & 233 & 243 & 267 & 349 & 339 & 235 \\
$1^{\prime}-4^{\prime}$ série & 2189 & 2909 & 3969 & 4342 & 4598 & 4960 & 5263 & 5147 & 4814 \\
$5^{\circ}-8^{a}$ série & 604 & 791 & 1012 & 1125 & 1114 & 1217 & 1185 & 1175 & 1017 \\
$2^{\circ}$ grau & 528 & 571 & 700 & 624 & 586 & 582 & 538 & 472 & 441 \\
superior & 147 & 195 & 236 & 245 & 263 & 308 & 300 & 294 & 150 \\
ignorado & 1430 & 1924 & 1990 & 2068 & 2105 & 2268 & 2717 & 1975 & 1485 \\
\hline
\end{tabular}


Tabela 19 - Distribuição da incidência de casos de aids, segundo ano de notificação e categoria de exposição. Pernambuco. 1990-1998.

\begin{tabular}{c|rrrrrrrrr}
\hline grupo & 1990 & 1991 & 1992 & 1993 & 1994 & 1995 & 1996 & 1997 & 1998 \\
\hline udi & 9 & 8 & 9 & 8 & 24 & 11 & 16 & 22 & 13 \\
homo & 100 & 123 & 142 & 168 & 176 & 172 & 184 & 187 & 211 \\
hemo & 12 & 14 & 8 & 10 & 7 & 7 & 8 & 7 & 1 \\
hetero & 16 & 35 & 59 & 78 & 76 & 91 & 188 & 156 & 256 \\
vertical & 2 & 7 & 2 & 7 & 10 & 9 & 13 & 18 & 25 \\
ignorado & 41 & 42 & 32 & 36 & 55 & 93 & 120 & 146 & 138 \\
\hline
\end{tabular}

Tabela 20 - Distribuição de casos, segundo faixa etária c ano de notificação. Pernambuco. 1990-1998.

\begin{tabular}{c|rrrrrrrrr}
\hline $\begin{array}{c}\text { faixa } \\
\text { etária } \\
\text { (anos) }\end{array}$ & 1990 & 1991 & 1992 & 1993 & 1994 & 1995 & 1996 & 1997 & 1998 \\
\hline $0 \vdash 15$ & 9 & 11 & 5 & 10 & 13 & 11 & 14 & 19 & 26 \\
$15 \vdash 29$ & 58 & 75 & 66 & 93 & 107 & 89 & 149 & 144 & 197 \\
$30 \vdash 44$ & 87 & 121 & 146 & 166 & 188 & 223 & 276 & 298 & 334 \\
$45 \vdash 59$ & 21 & 15 & 31 & 36 & 35 & 52 & 78 & 67 & 76 \\
$\geq 60$ & 5 & 7 & 4 & 2 & 5 & 8 & 12 & 8 & 11 \\
\hline
\end{tabular}

Tabela 21 - Distribuição de casos de aids, segundo escolaridade e ano de notificação. Pernambuco. 1990-1998.

\begin{tabular}{c|rrrrrrrrr}
\hline escolaridade & 1990 & 1991 & $\mathbf{1 9 9 2}$ & $\mathbf{1 9 9 3}$ & $\mathbf{1 9 9 4}$ & $\mathbf{1 9 9 5}$ & $\mathbf{1 9 9 6}$ & 1997 & 1998 \\
\hline analfabeto & 4 & 9 & 8 & 9 & 16 & 22 & 48 & 33 & 35 \\
$1^{\circ}-4^{\prime}$ série & 26 & 37 & 59 & 96 & 115 & 112 & 179 & 196 & 304 \\
$5^{\circ}-8^{\text {a }}$ série & 37 & 75 & 80 & 67 & 62 & 70 & 101 & 105 & 121 \\
$2^{\circ}$ grau & 33 & 31 & 46 & 31 & 37 & 44 & 48 & 48 & 59 \\
superior & 4 & 4 & 5 & 7 & 8 & 10 & 13 & 16 & 24 \\
ignorado & 75 & 71 & 51 & 90 & 103 & 121 & 138 & 130 & 97 \\
\hline
\end{tabular}


Tabela 22 - Distribuição da incidência de casos de aids, segundo ano de notificação e categoria de exposição. Santa Catarina. 1990-1998.

\begin{tabular}{c|rrrrrrrrr}
\hline grupo & 1990 & 1991 & 1992 & 1993 & 1994 & 1995 & 1996 & 1997 & 1998 \\
\hline udi & 100 & 160 & 192 & 253 & 289 & 388 & 371 & 330 & 319 \\
homo & 40 & 48 & 63 & 74 & 95 & 96 & 120 & 122 & 163 \\
hemo & 8 & 4 & 6 & 4 & 9 & 11 & 16 & 12 & 2 \\
hetero & 27 & 43 & 84 & 124 & 207 & 287 & 403 & 417 & 577 \\
vertical & 12 & 15 & 20 & 27 & 68 & 71 & 69 & 74 & 55 \\
ignorado & 34 & 55 & 45 & 85 & 53 & 76 & 56 & 58 & 42 \\
\hline
\end{tabular}

Tabela 23 - Distribuição de casos, segundo faixa etária e ano de notificação. Santa Catarina. 1990-1998

\begin{tabular}{c|rrrrrrrrr}
\hline $\begin{array}{c}\text { faixa } \\
\text { etária } \\
\text { (anos) }\end{array}$ & 1990 & 1991 & 1992 & 1993 & 1994 & 1995 & 1996 & 1997 & 1998 \\
\hline $0 \vdash 15$ & 14 & 15 & 24 & 28 & 71 & 74 & 72 & 74 & 60 \\
$15 \vdash 29$ & 113 & 154 & 190 & 240 & 247 & 330 & 332 & 306 & 365 \\
$30 \vdash 44$ & 84 & 143 & 167 & 264 & 341 & 437 & 519 & 524 & 585 \\
$45 \vdash 59$ & 9 & 11 & 26 & 30 & 44 & 73 & 91 & 92 & 126 \\
$\geq 60$ & 1 & 2 & 3 & 5 & 18 & 15 & 21 & 17 & 22 \\
\hline
\end{tabular}

Tabela 24 - Distribuição de casos de aids, segundo escolaridade e ano de notificação. Santa Catarina. 1990-1998.

\begin{tabular}{c|rrrrrrrrr}
\hline escolaridade & 1990 & 1991 & 1992 & 1993 & 1994 & 1995 & 1996 & 1997 & 1998 \\
\hline analfabeto & 2 & 9 & 13 & 27 & 36 & 43 & 47 & 60 & 64 \\
$1^{\circ}-4^{4}$ série & 86 & 153 & 175 & 292 & 351 & 489 & 600 & 649 & 775 \\
$5^{\circ}-8^{\text {a }}$ série & 34 & 38 & 62 & 84 & 109 & 139 & 138 & 121 & 165 \\
$2^{\circ}$ grau & 24 & 30 & 39 & 48 & 35 & 53 & 61 & 43 & 49 \\
superior & 13 & 13 & 21 & 25 & 70 & 79 & 69 & 73 & 56 \\
ignorado & 56 & 74 & 45 & 56 & 88 & 118 & 110 & 51 & 35 \\
\hline
\end{tabular}


ANEXO 3 - Lista dos municípios considerados de alta incidencia de aids pelo índice proposto $(\delta)$, dividido pelo tamanho da população em 1996.

\begin{tabular}{|c|c|c|c|}
\hline meno & pop-96 & $\delta$ & $\mathrm{IDH}$ \\
\hline PB-Cabedelo & 34690 & 0,222 & 0,591 \\
\hline GO-ltaucu & 8485 & 0,227 & 0,581 \\
\hline SC-Sao Joao Batisla & 13637 & 0,227 & 0,743 \\
\hline RN-Sao Francisco do Oeste & 3233 & 0,227 & 0.451 \\
\hline RR-Sao Joao da Baliza & 4058 & 0,232 & 0,682 \\
\hline SP-Paraguacu Paulista & 37561 & 0,236 & 0,736 \\
\hline RN-Pau dos Ferros & 22072 & 0,247 & 0,571 \\
\hline SP-Platina & 2970 & 0,247 & 0,612 \\
\hline SP-Alvinlandia & 2661 & 0,248 & 0,619 \\
\hline RS-Santo Augusto & 15137 & 0,252 & 0,694 \\
\hline SC-Nova Trento & 9369 & 0,261 & 0,750 \\
\hline SP.Pirapora do Bom Jesus & 10499 & 0,276 & 0.657 \\
\hline SE-Campo do Brito & 14913 & 0,277 & 0,444 \\
\hline PB-Arara & 10220 & 0,296 & 0,374 \\
\hline PB-Serra Redonda & 7721 & 0,336 & 0,364 \\
\hline SC-Camboriu & 34054 & 0,397 & 0,718 \\
\hline SE-Cumbe & 3500 & 0.441 & 0.409 \\
\hline CE-Frecheirinha & 10880 & 0,491 & 0,367 \\
\hline tre 50 e 200 mil habitantes & pop-96 & $\delta$ & $\mathrm{IDH}$ \\
\hline BA-Valenca & 74661 & 0,210 & 0,488 \\
\hline SP-Suzano & 180740 & 0,212 & 0,758 \\
\hline SP-Sertaozinho & 88545 & 0,214 & 0,790 \\
\hline SP-Sao Carlos & 175517 & 0,216 & 0,797 \\
\hline RJ-Cabo Frio & 101401 & 0,217 & 0,730 \\
\hline PE-Sao Lourenco da Mata & 89754 & 0,218 & 0,515 \\
\hline RS-Viamao & 196685 & 0,220 & 0,737 \\
\hline MS-Dourados & 153191 & 0.222 & 0,760 \\
\hline SP-Ubaluba & 55033 & 0,223 & 0,769 \\
\hline BA-Jequie & 165345 & 0,224 & 0,509 \\
\hline PE-Igarassu & 72930 & 0,224 & 0,474 \\
\hline CE-Maracanau & 160065 & 0.226 & 0,537 \\
\hline PA-Tucurui & 58679 & 0.226 & 0,544 \\
\hline SE-Estancia & 56749 & 0,227 & 0,487 \\
\hline SP-Cruzeiro & 72155 & 0,230 & 0,771 \\
\hline RS-Alvorada & 162005 & 0,231 & 0,697 \\
\hline BA-Teixeira de Freitas & 96512 & 0,238 & 0,551 \\
\hline SP-Aracatuba & 162577 & 0.243 & 0,797 \\
\hline SP-Rio Claro & 153389 & 0,245 & 0,815 \\
\hline SP-Lorena & 73296 & 0,251 & 0,794 \\
\hline SE-Itabaiana & 72052 & 0,252 & 0,507 \\
\hline SP-Moji-Mirim & 75337 & 0,253 & 0,784 \\
\hline SP-Andradina & .53600 & 0,254 & 0,768 \\
\hline SP-Assis & 83133 & 0,255 & 0.792 \\
\hline SP-Itanhaem & 58017 & 0,259 & 0,748 \\
\hline PA-Redencao & 58029 & 0,263 & 0.559 \\
\hline RS-Passo Fundo & 156333 & 0,264 & 0,790 \\
\hline PR-Paranagua & 115406 & 0,265 & 0,769 \\
\hline BA-Itabuna & 183403 & 0,267 & 0,634 \\
\hline SP-Ilu & 122528 & 0,269 & 0,774 \\
\hline RS-Rio Grande & 178256 & 0,270 & 0,772 \\
\hline SP-Jaboticabal & 62774 & 0,275 & 0,772 \\
\hline SP-Itapira & 60791 & 0,280 & 0,778 \\
\hline SP-Franco da Rocha & 98310 & 0,280 & 0,744 \\
\hline SP-Itapevi & 133523 & 0,282 & 0,680 \\
\hline RO-Ji-Parana & 95356 & 0,282 & 0.657 \\
\hline PA-Parauapebas & 63563 & 0,287 & 0,601 \\
\hline SC-Criciuma & 159101 & 0,287 & 0,790 \\
\hline
\end{tabular}

\begin{tabular}{|c|c|c|c|}
\hline PB-Bayeux & 84169 & 0,288 & 0,501 \\
\hline SP-Lins & 60788 & 0,299 & 0,787 \\
\hline SP-Presidente Prudente & 177367 & 0,299 & 0,795 \\
\hline MT-Sinop & 54306 & 0,311 & 0,752 \\
\hline SP-Votuporanga & 69863 & 0,314 & 0,788 \\
\hline PE Abreu e Lima & 80828 & 0,317 & 0,569 \\
\hline SP-Jacarei & 167751 & 0,319 & 0,782 \\
\hline SC-Sao Jose & 147559 & 0,321 & 0,819 \\
\hline SP-Caraguatatuba & 67398 & 0,322 & 0,761 \\
\hline PE-Camaragibe & 111119 & 0,329 & 0,585 \\
\hline SP-Atibaia & 95342 & 0,343 & 0,777 \\
\hline SP-Marilia & 177632 & 0,348 & 0,784 \\
\hline Go-Planallina & 58576 & 0,349 & 0,570 \\
\hline SP-Taquaritinga & 50330 & 0,354 & 0,762 \\
\hline TO-Palmas & 86116 & 0,356 & 0,754 \\
\hline MA-Timon & 118428 & 0,360 & 0,481 \\
\hline MG-Pocos de Caldas & 121831 & 0,374 & 0,790 \\
\hline BA-Lauro de Freitas & 97219 & 0,374 & 0,738 \\
\hline MT-Rondonopolis & 142524 & 0,379 & 0,753 \\
\hline PE-Vitoria de Santo Antao & 110888 & 0,381 & 0,497 \\
\hline TO-Gurupi & 64725 & 0,423 & 0,759 \\
\hline BA-Porto Seguro & 64957 & 0,426 & 0,534 \\
\hline SP-Sao Caetano do Sul & 139825 & 0,431 & 0,820 \\
\hline GOLuziania & 106695 & 0,435 & 0,716 \\
\hline MS-Ponta Pora & 58505 & 0,440 & 0,760 \\
\hline SP-Taboao da Serra & 182506 & 0,443 & 0,789 \\
\hline SP-Bebedouro & 72633 & 0,446 & 0,794 \\
\hline BA-Juazeiro & 172065 & 0,449 & 0,522 \\
\hline MT-Varzea Grande & 193401 & 0,450 & 0,678 \\
\hline SP-Cacapava & 68117 & 0,461 & 0,796 \\
\hline SP-Barretos & 100646 & 0,474 & 0,779 \\
\hline SP-Araraquara & 168468 & 0,483 & 0,799 \\
\hline SP-Praia Grande & 150388 & 0,497 & 0,767 \\
\hline GO-Rio Verde & 100586 & 0,503 & 0,726 \\
\hline SP-Cubatao & 97257 & 0,549 & 0,756 \\
\hline CE-Sobral & 138565 & 0,552 & 0,481 \\
\hline PE-Cabo de Santo Agostinho & 140764 & 0,575 & 0,541 \\
\hline MS-Tres Lagoas & 74797 & 0,580 & 0,719 \\
\hline MS-Corumba & 89083 & 0,586 & 0,702 \\
\hline SP-Catandiva & 100942 & 0,645 & 0,804 \\
\hline RR-Boa Vista & 153936 & 0,646 & 0,752 \\
\hline SC-Balneario Camboriu & 58188 & 0,752 & 0,810 \\
\hline SC-Itajai & 134942 & 0,901 & 0,792 \\
\hline le 200-500 mil habitants & pop-96 & $\delta$ & $\mathrm{IDH}$ \\
\hline RJ-Petropolis & 269669 & 0,215 & 0,783 \\
\hline BA-theus & 242445 & 0,216 & 0,534 \\
\hline PE-Caruaru & 231989 & 0,230 & 0,607 \\
\hline BA-Vitoria da Conquisla & 242155 & 0,230 & 0,574 \\
\hline ES-Vitoria & 265874 & 0,230 & 0,813 \\
\hline SP-Piracicaba & 302886 & 0,240 & 0,803 \\
\hline RS-Gravalai & 206023 & 0,256 & 0,784 \\
\hline MG-Juiz de Fora & 424479 & 0,268 & 0,801 \\
\hline SC-Joinville & 397951 & 0,269 & 0,808 \\
\hline BA-Feira de Santana & 450487 & 0,272 & 0,644 \\
\hline MG-Uberaba & 232413 & 0,285 & 0,792 \\
\hline SP-Sao Jose dos Campos & 486167 & 0,286 & 0,815 \\
\hline SP-Bauru & 292566 & 0,305 & 0,802 \\
\hline RJ-Niteroi & 450364 & 0,307 & 0,821 \\
\hline
\end{tabular}




$\begin{array}{llll}\text { RS-Canoas } & 284059 & 0,308 & 0,793 \\ \text { * PB-Campina Grande } & 340316 & 0,312 & 0,618 \\ \text { * PR-Londrina } & 412553 & 0,312 & 0,792 \\ \text { SP-Taubate } & 220230 & 0,367 & 0,815 \\ \text { SP-Sorocaba } & 431561 & 0,382 & 0,799 \\ \text { SC-Blumenau } & 231401 & 0,402 & 0,822 \\ \text { MA-Imperatriz } & 225892 & 0,438 & 0,555 \\ \text { SP-Guaruja } & 226365 & 0,450 & 0,753 \\ \text { AP-Macapa } & 220962 & 0,470 & 0,750 \\ \text { PA-Ananindeua } & 341257 & 0,584 & 0,657 \\ \text { SP-Sao Vicente } & 279528 & 0,600 & 0,786 \\ \text { * SP-Sao Jose do Rio Prelo } & 323627 & 0,611 & 0,802 \\ \text { * SE-Aracaju } & 428194 & 0,626 & 0,770 \\ \text { RO-Porto Velho } & 294220 & 0,634 & 0,754 \\ \text { PE-Otinda } & 349380 & 0,655 & 0,765 \\ \text { * SP-Ribeirao Preto } & 456252 & 0,693 & 0,825 \\ \text { PE-Paulista } & 233634 & 0,757 & 0,731 \\ \text { * SP-Santos } & 412243 & 0,895 & 0,830 \\ \text { * SC-Florianopolis } & 271281 & 0,958 & 0,833 \\ \text { * MT-Cuiaba } & 433355 & 1,000 & 0,784\end{array}$

\begin{tabular}{llll} 
mais de 500 mil habilanles & pop-96 & $\delta$ & IDH \\
\hline RN-Natal & 656037 & 0,215 & 0,776 \\
* MG-Belo Horizonte & 2091371 & 0,241 & 0,796 \\
* SP-Guarulhos & 972197 & 0,254 & 0,773 \\
AL-Maceio & 723142 & 0,320 & 0,744 \\
* PE-Jaboalao dos Guararapes & 529966 & 0,326 & 0,690 \\
* SP-Osasco & 622912 & 0,333 & 0,784 \\
RJ-Nova Iguacu & 826188 & 0,339 & 0,648 \\
* MA-Sao Luis & 780833 & 0,384 & 0,733 \\
* SP-Campinas & 908906 & 0,506 & 0,816 \\
* CE-Fortaleza & 1965513 & 0,533 & 0,762 \\
* GO-Goiania & 1001756 & 0,542 & 0,797 \\
* SP-Santo Andre & 624820 & 0,583 & 0,813 \\
* MS-Campo Grande & 600069 & 0,680 & 0,792 \\
* BA-Salvador & 2211539 & 0,688 & 0,793 \\
* RJ-Rio de Janeiro & 5551538 & 0,720 & 0,808 \\
* PA-Belem & 1144312 & 0,833 & 0,796 \\
* PE-Recife & 1346045 & 0,838 & 0,790 \\
* SP-Sao Paulo & 9839066 & 0,842 & 0,804 \\
* RS-Porto Alegre & 1288879 & 1,000 & 0,825 \\
\hline
\end{tabular}

* Lista de municipios que tiveram projetos aprovados pelo Ministério da Saúde, obtendo financiamento para executar ações contra a aids de 1993 a 1997, através de Organizações Não-Governamentais.

\begin{tabular}{|c|c|c|c|}
\hline UF - Município & projetos & UF - Município & projetos \\
\hline GO - Alto Paraíso & 1 & RJ - Niterói & 10 \\
SE - Aracajú & 8 & SP - Osasco & 7 \\
RJ - Arraial do Cabo & 1 & PR - Paranaguá & 2 \\
MG - Belo Horizonte & 15 & SP - Pirajuí & 9 \\
PA - Belém & 6 & SP - Pirassununga & 1 \\
DF - Brasília & 12 & RS - Porto Alegre & 13 \\
SP - Campinas & 13 & PE - Recife & 24 \\
PB - Campina Grande & 1 & SP - Ribeirão Preto & 1 \\
MS - Campo Grande & 4 & RJ - Rio de Janeiro & 79 \\
GO - Ceres & 4 & MT - Rondonópolis & 1 \\
PR - Colombo & 1 & BA - Salvador & 22 \\
PI - Colônia & 1 & SP - Santo André & 1 \\
MT - Cuiabá & 1 & SP - Santos & 8 \\
PR - Curitiba & 15 & RJ - São Gonçalo & 4 \\
SC - Florianópolis & 4 & SP - São José dos Campos & 8 \\
CE - Fortaleza & 14 & SP - São José do Rio Preto & 7 \\
GO - Goiânia & 4 & RS -São Leopoldo & 1 \\
RJ - Goitacazes & 1 & MA -São Luis & 6 \\
SP - Guarulhos & 1 & SP - São Paulo & 91 \\
MA - lmperatriz & 5 & SP - Taboão da Serra & 4 \\
PE - Jaboatão dos Guararapes & 1 & PI - Teresina & 3 \\
MG - Janaúba & 1 & MS - Três Lagoas & 3 \\
PB - João Pessoa & 2 & MG - Uberaba & 2 \\
MG - Juiz de Fora & 1 & ES - Vila Velha & 1 \\
PR - Londrina & 7 & ES - Vitória & 5 \\
AM - Manaus & 2 & SP - Votuporanga & 1 \\
RN - Mossoró & 1 & & \\
\hline
\end{tabular}

Fonte - http://www.aids.gov.br/ 